Supporting Information ---------NMR Spectra of Compounds

\title{
Diversity in Platinum-Catalyzed Hydrative Cyclization of Trialkyne Substrates to Form Tetracyclic Ketones
}

\author{
Hsu-Kai Chang, Yen-Chen Liao and Rai-Shung Liu
}

Contents

(1) ${ }^{1} \mathrm{H}$ and ${ }^{13} \mathrm{C}$ NMR Spectra of Compounds 3-30----------------------S2 S57

(2) ${ }^{1} \mathrm{H}$ NOE Spectra of Compound 4, 23, 27 and 30-----------------------------S58 S87 


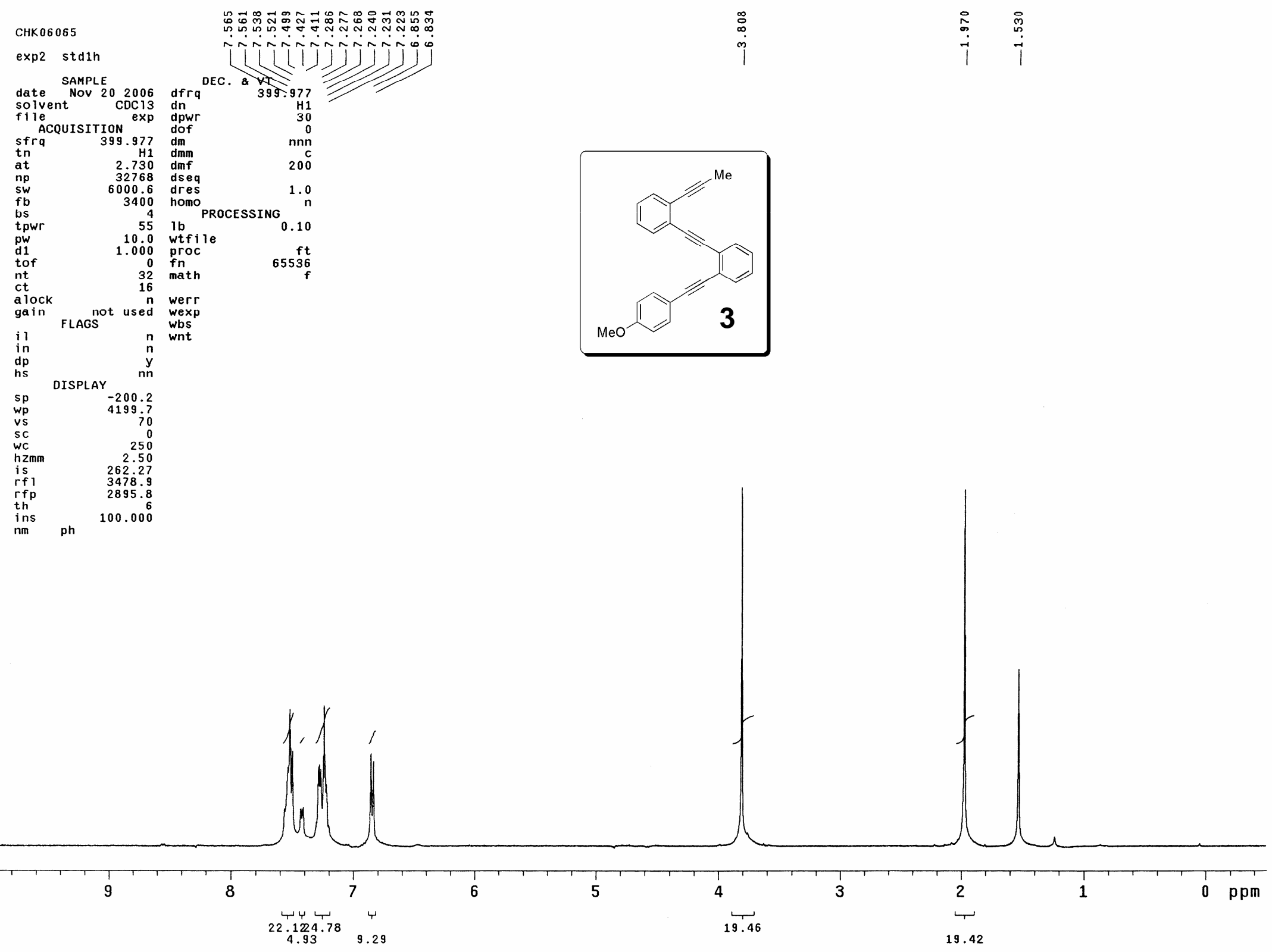



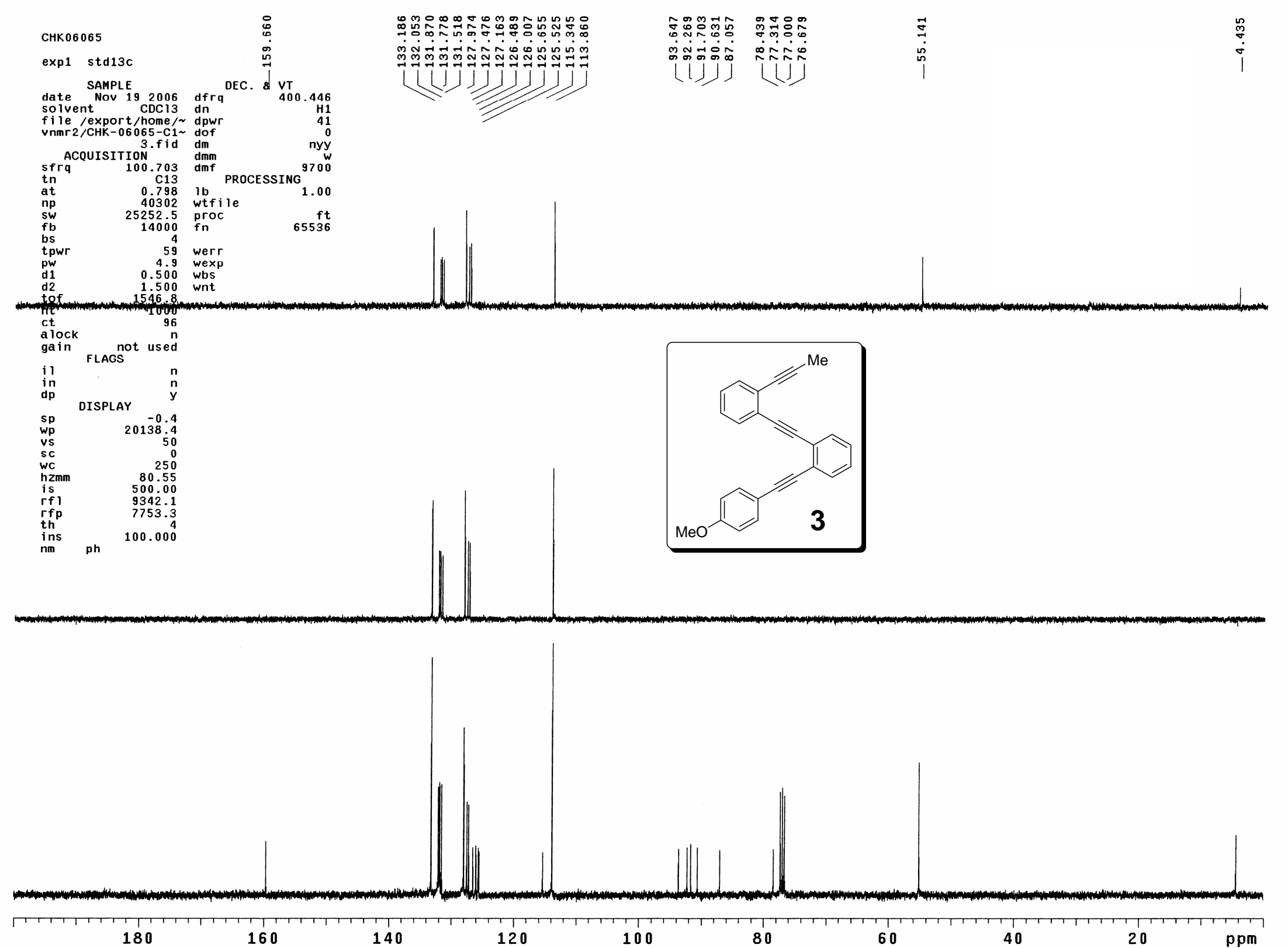


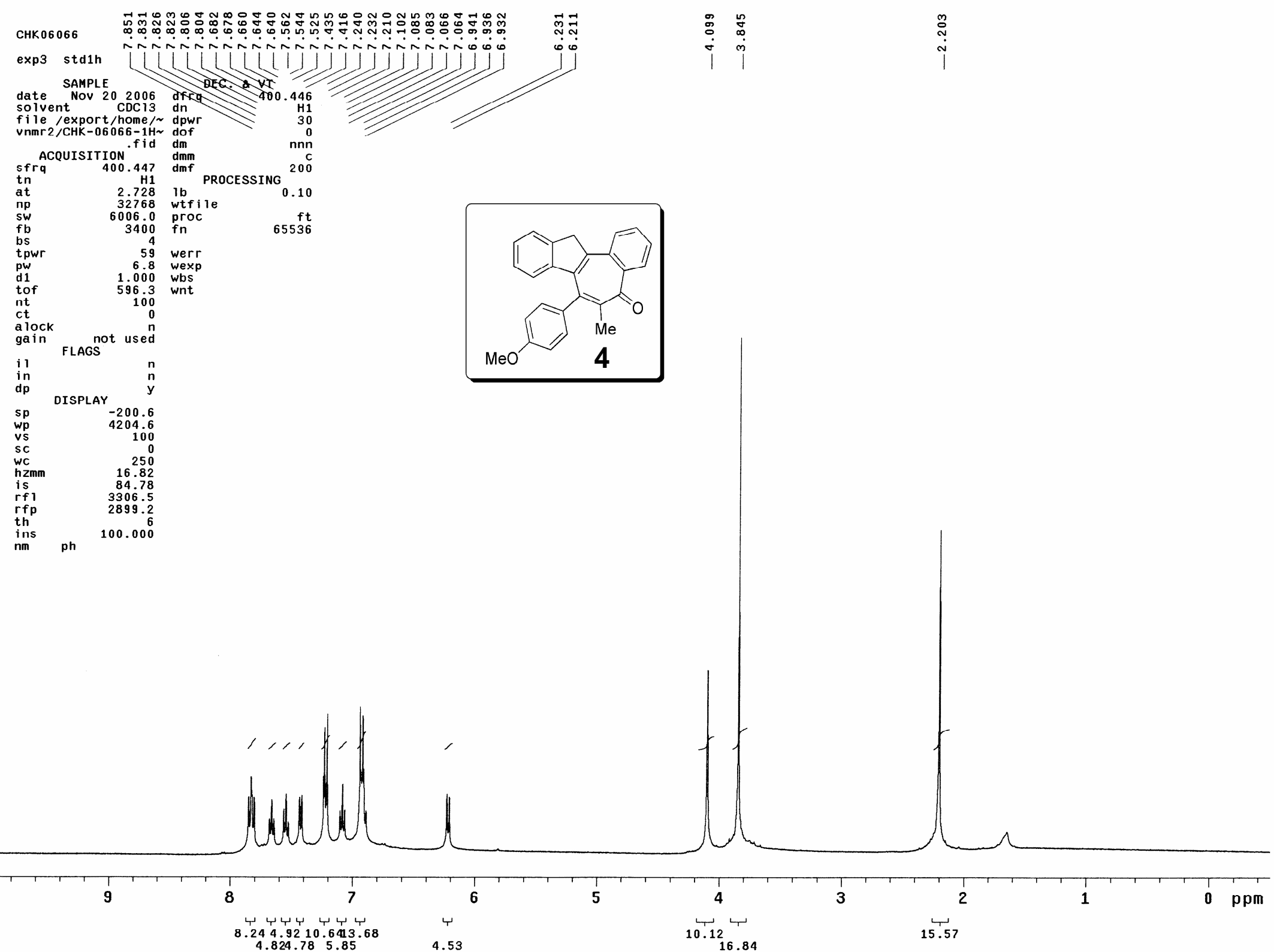




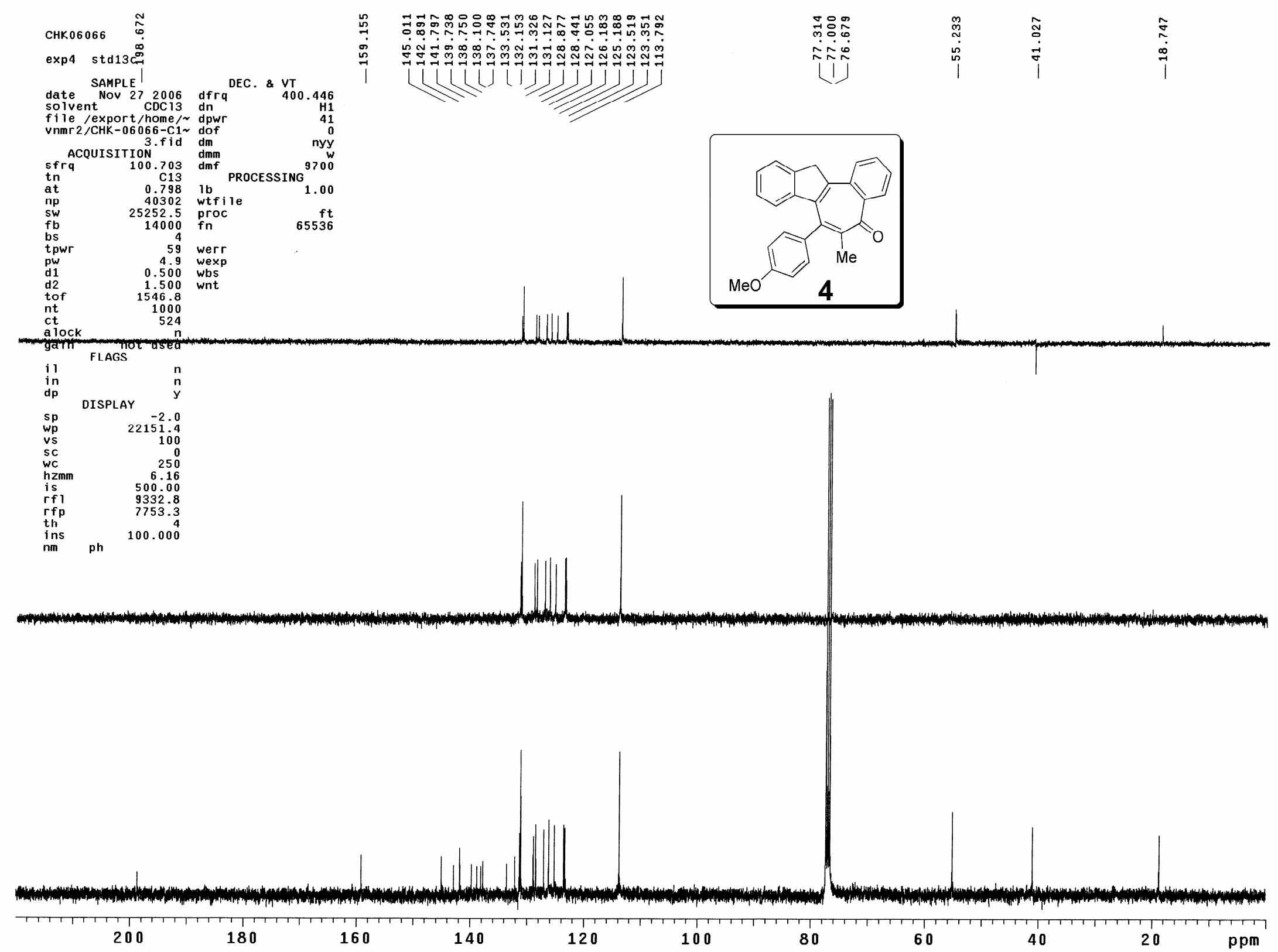


Current Data Parameters

NAME

$\mathrm{CHK} 07003$

PROCNO

F2 - Acquisition Parameters

Time-

PROBHD

PULPROG

20070115
22.49

TD

SOLVENT

DS

SWH

FIDRES

$A Q$
$R G$

DW

DE

TDO

spect

$\mathrm{zg} 30$

32768
$\mathrm{CDC} 13$

$6410.256 \mathrm{~Hz}$

$2.5559540 \mathrm{sec}$

$$
28.5
$$

78.000 usec

6.00 usec

$2.00000000 \mathrm{sec}$

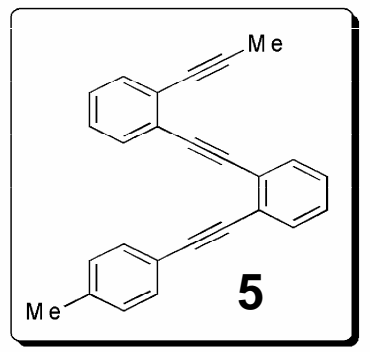

$=======$ CHANNEL $\mathrm{f} 1$

$\begin{array}{lr}\text { NUC1 } & 1 \mathrm{H} \\ \mathrm{P} 1 & 10.00 \text { usec }\end{array}$

$\begin{array}{ll}\text { PL1 } & -2.40 \mathrm{~dB} \\ \text { SFO1 } & 400.1528010 \mathrm{MHz}\end{array}$

F2 - Processing parameters

F2 - Processing parameters

SI $\quad 400.1500168 \mathrm{MHz}$

WDW

$\begin{array}{lc}\mathrm{SSB} & 0 \\ \mathrm{LB} & 0.00 \mathrm{~Hz}\end{array}$

$\begin{array}{ll}\mathrm{GB} & 0.00 \\ \mathrm{PC} & 1.00\end{array}$

1111

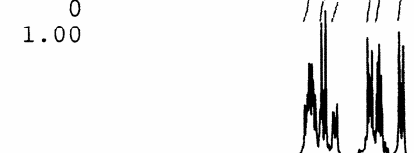

10

9

8

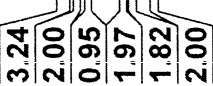

5

4

2

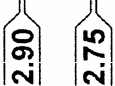




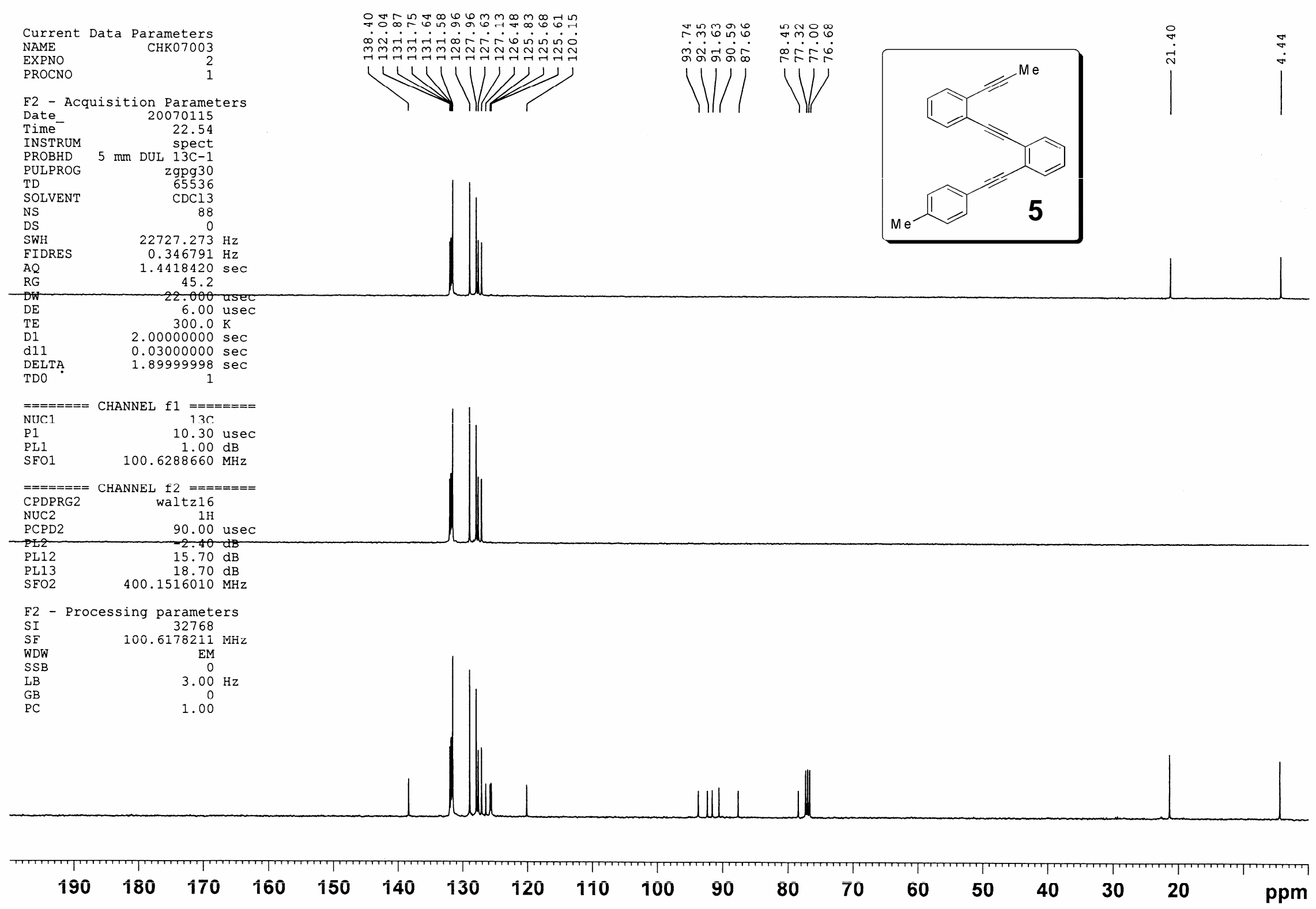




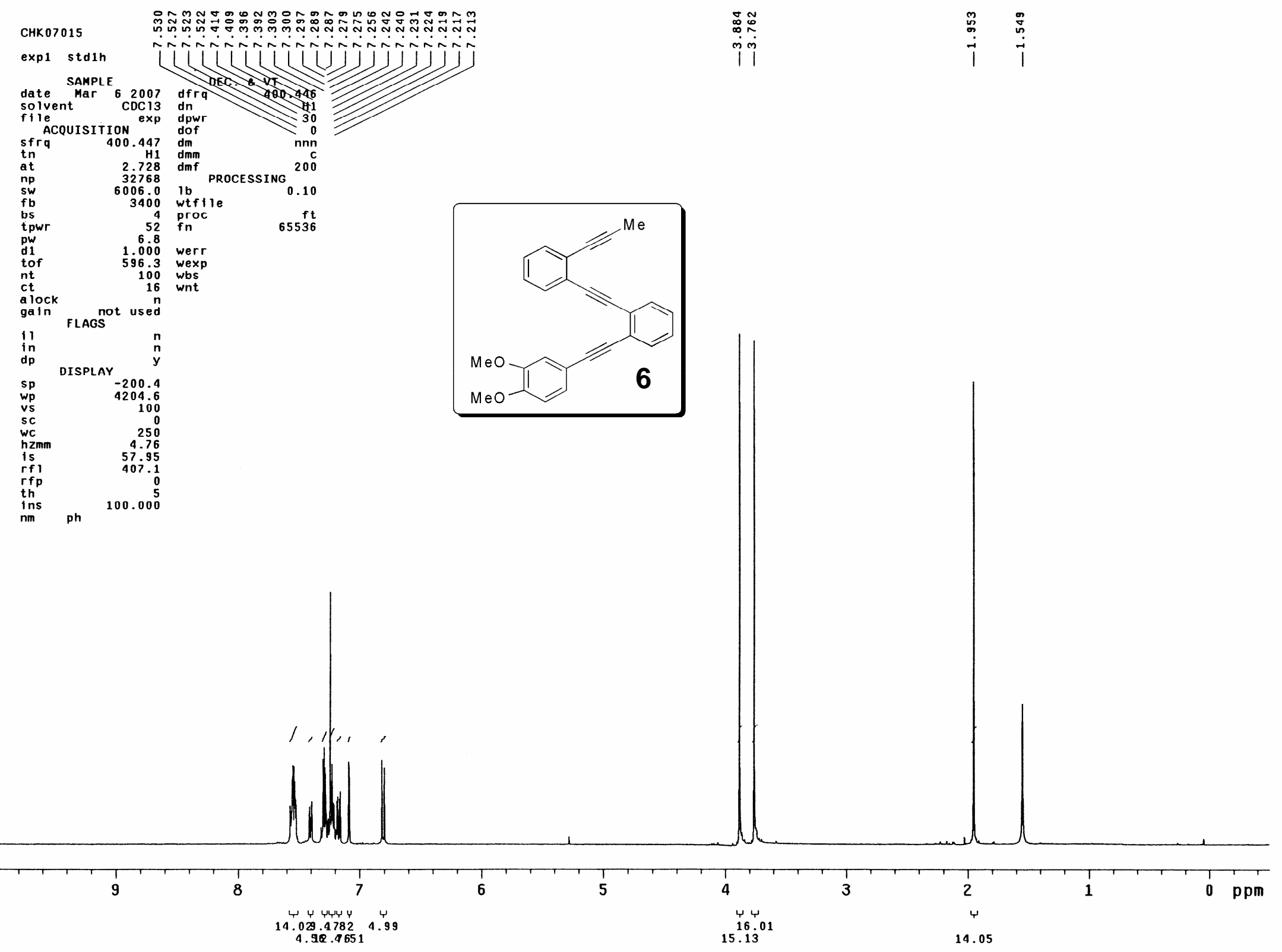



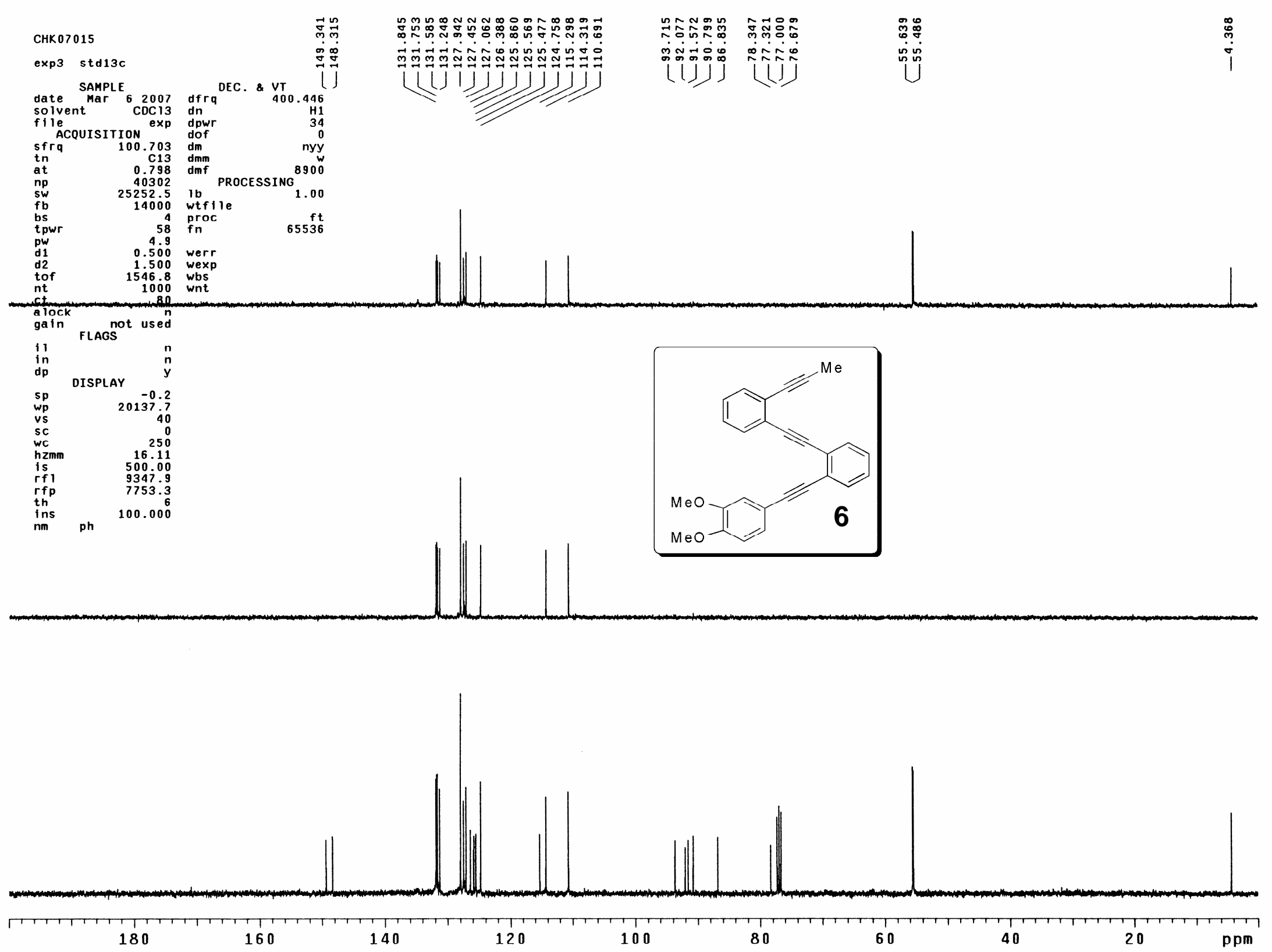


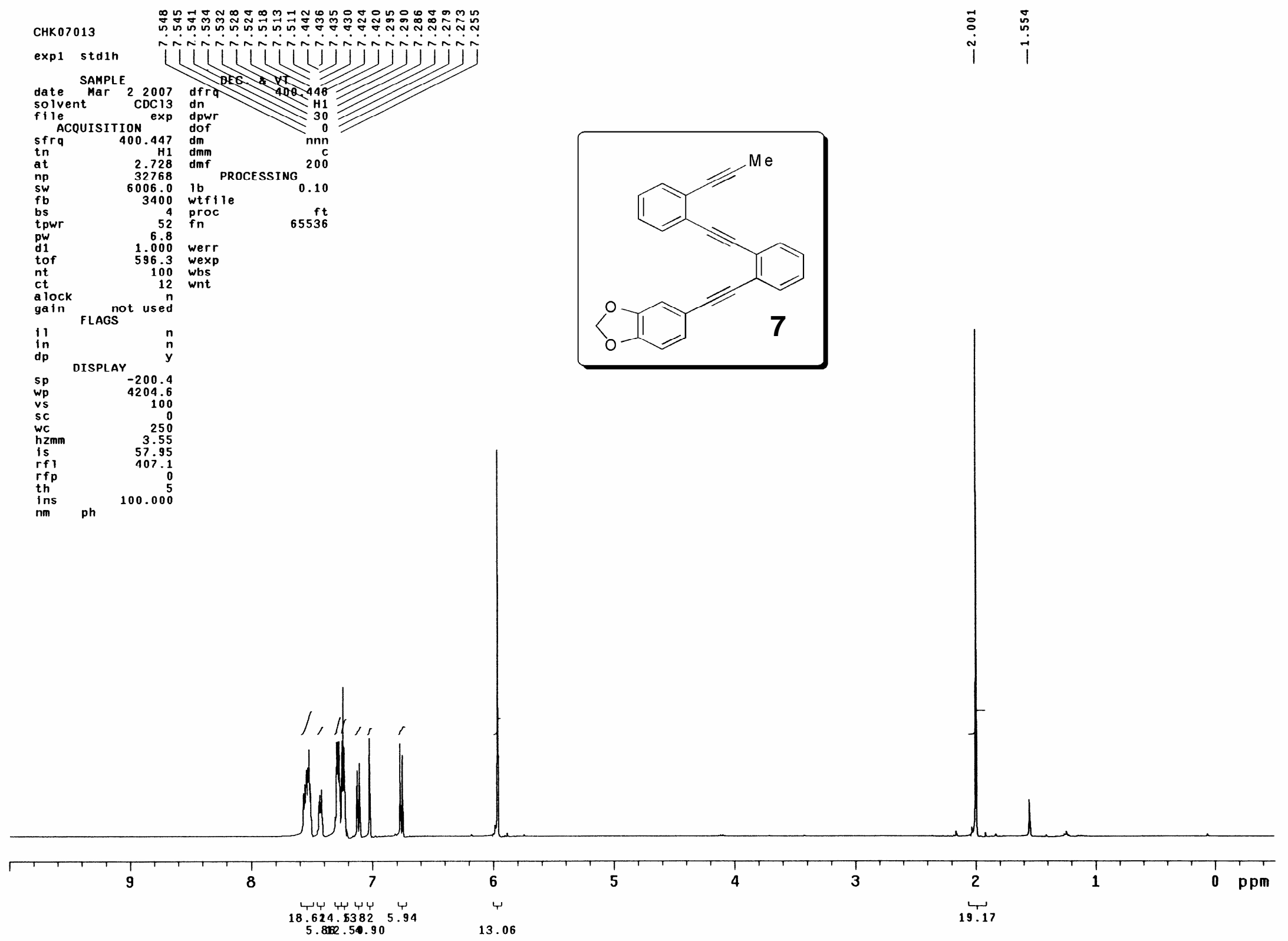



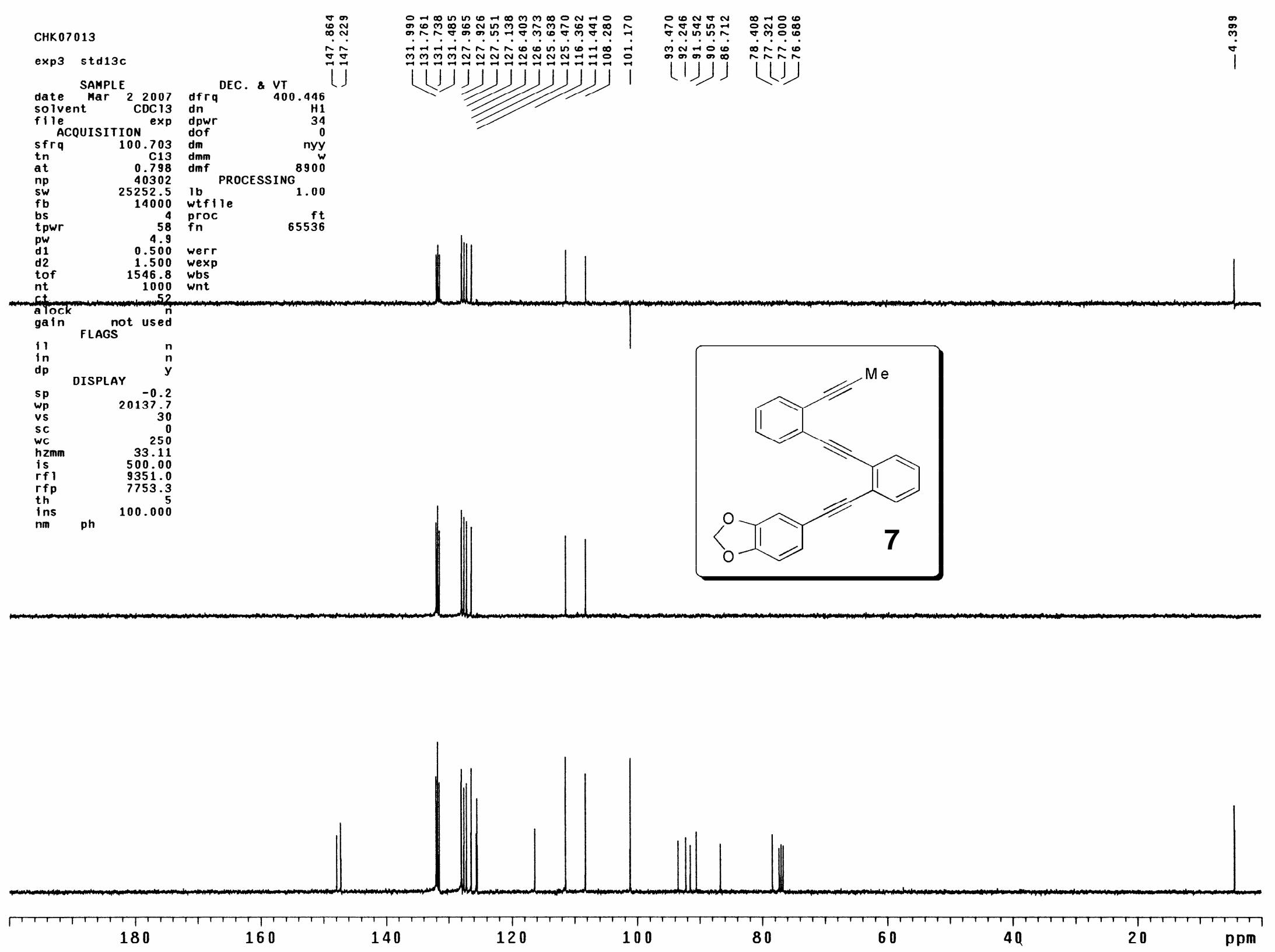


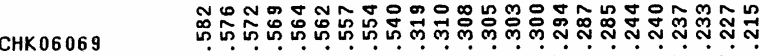

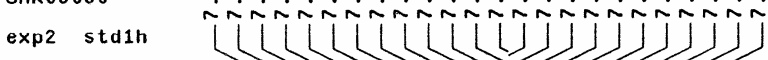

SAMPLE ${ }_{\text {DeC }} 2006$ dft

date $\operatorname{DeC} \quad 62006$
solvent $\quad \mathrm{CDCl}_{3}$

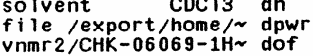

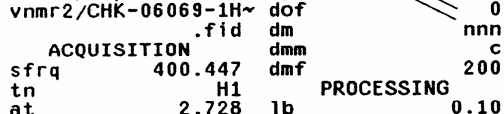

$\begin{array}{lrll}\text { tn } & \text { H1 } & \text { PROCESING } \\ \text { at } & 2.728 & \text { wb } \\ \text { np } & 32768 & \text { wtfile } & 0.10 \\ \text { sw } & 6006.0 & \text { oroc } & f t\end{array}$

bs $\quad 3400$ fn

$\begin{array}{lrl}\text { bs } & 4 & \text { werr } \\ \text { tipwi } & 53 & \text { werr } \\ \text { pw } & 6.8 & \text { wexp } \\ \text { dit } & 1.00 & \text { whs }\end{array}$

$\begin{array}{lrl}\text { d1 } & 1.000 & \text { wbs } \\ \text { tof } & 596.3 & \text { wnt } \\ \text { nt } & 100 & \end{array}$

a lock

gain not used

$\begin{array}{lll}i 1 & & n \\ i n & n \\ d p & & n\end{array}$

$\begin{array}{lr}\text { sp } & \text { DISPLAY } \\ \text { wp } & -200.6 \\ \text { vs } & 4204.6 \\ \text { sc } & 100\end{array}$

$\begin{array}{lr}\text { SC } & 100 \\ \text { WC } & 0 \\ \text { h7 } & 150\end{array}$

$\begin{array}{lr}h>m m & 1.27 \\ \text { is } & 84.78 \\ \text { if } & 3307.4 \\ \text { if } & 2830.2 \\ \text { th } & \end{array}$

ph

65536

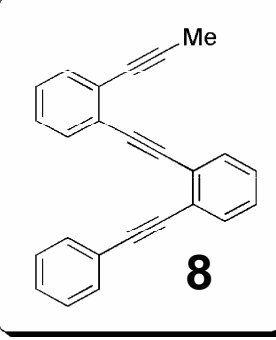

品

i نj

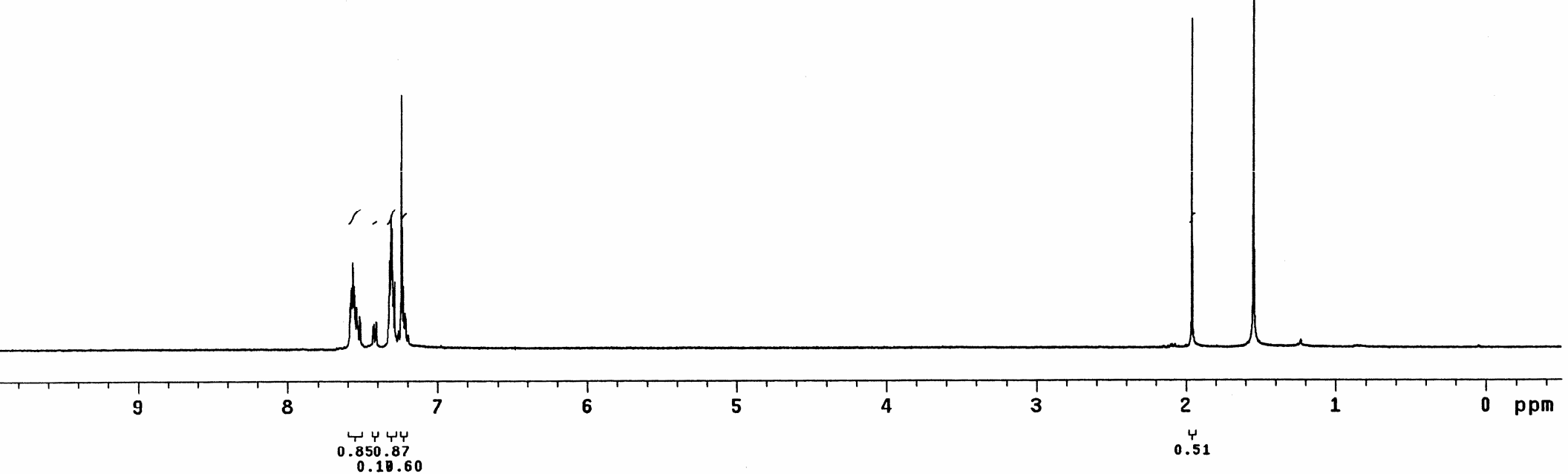



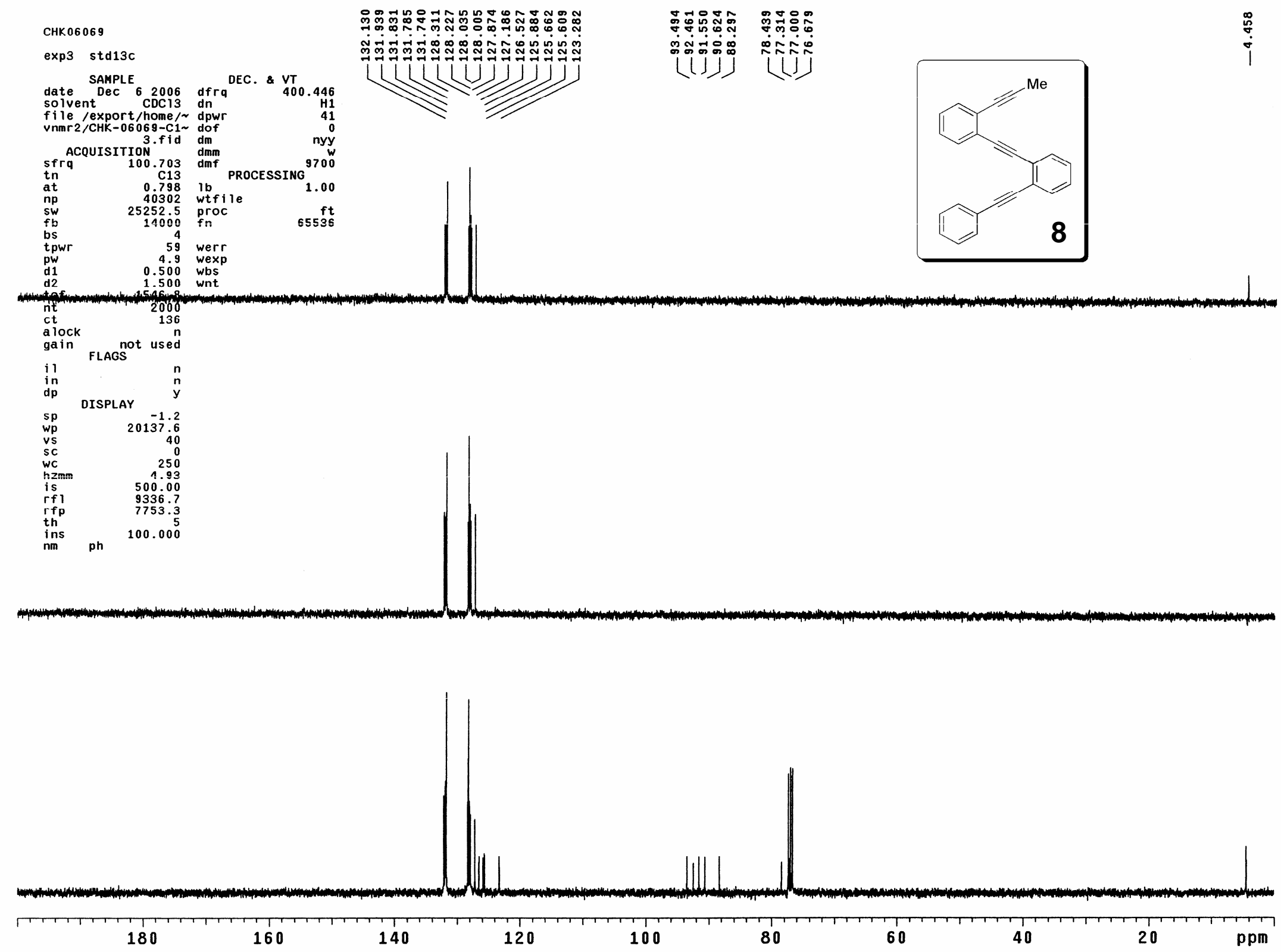


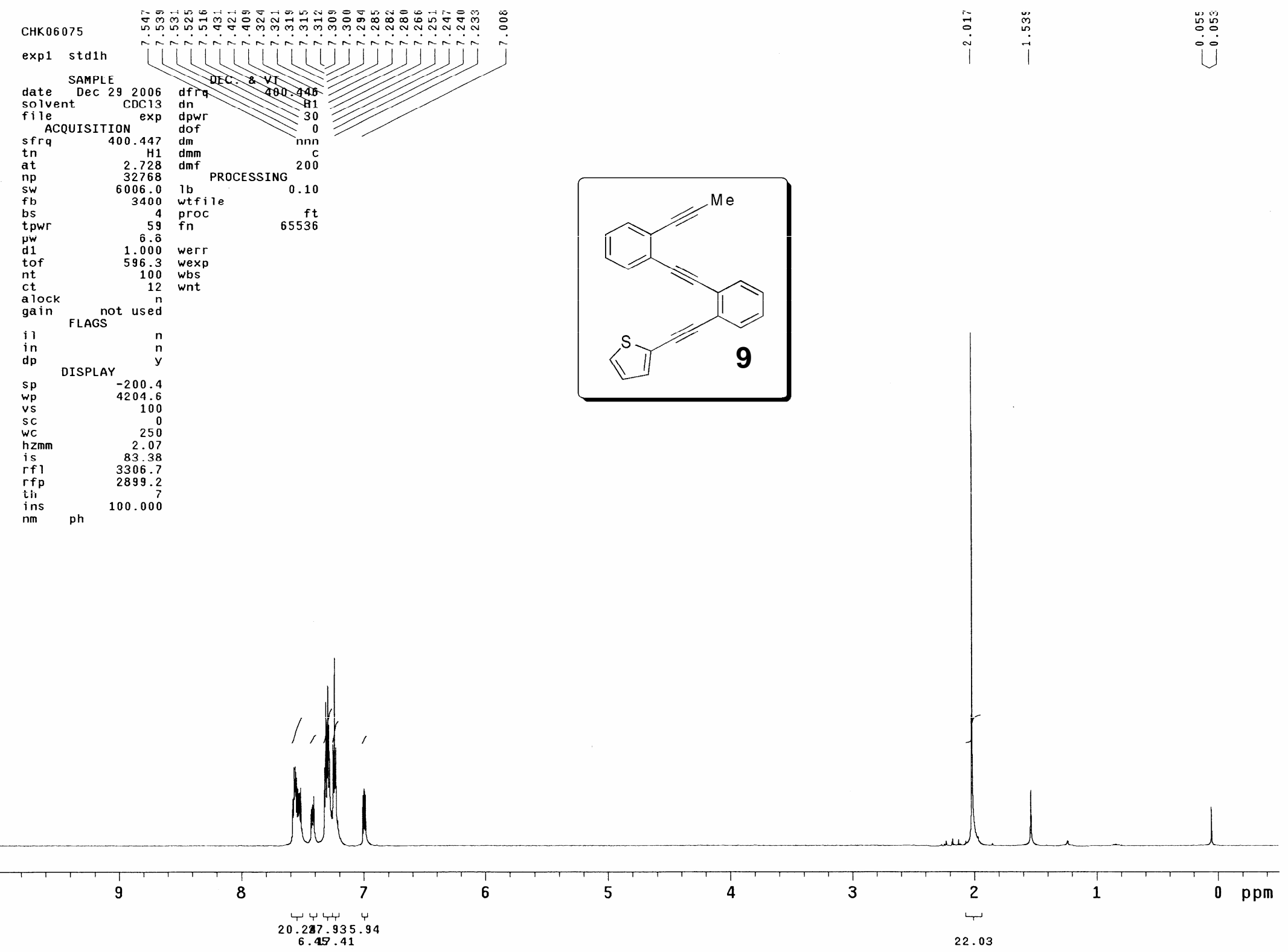




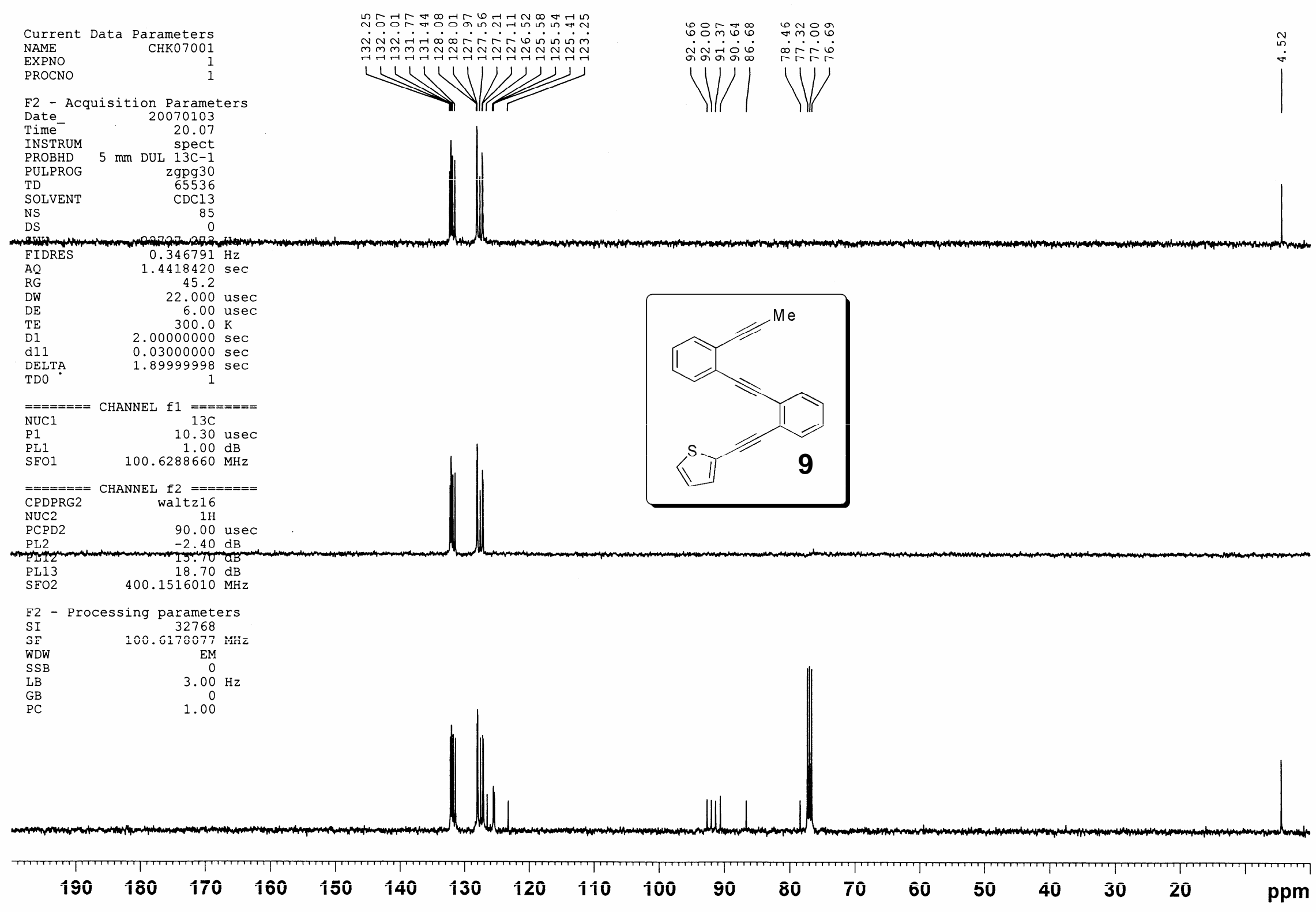




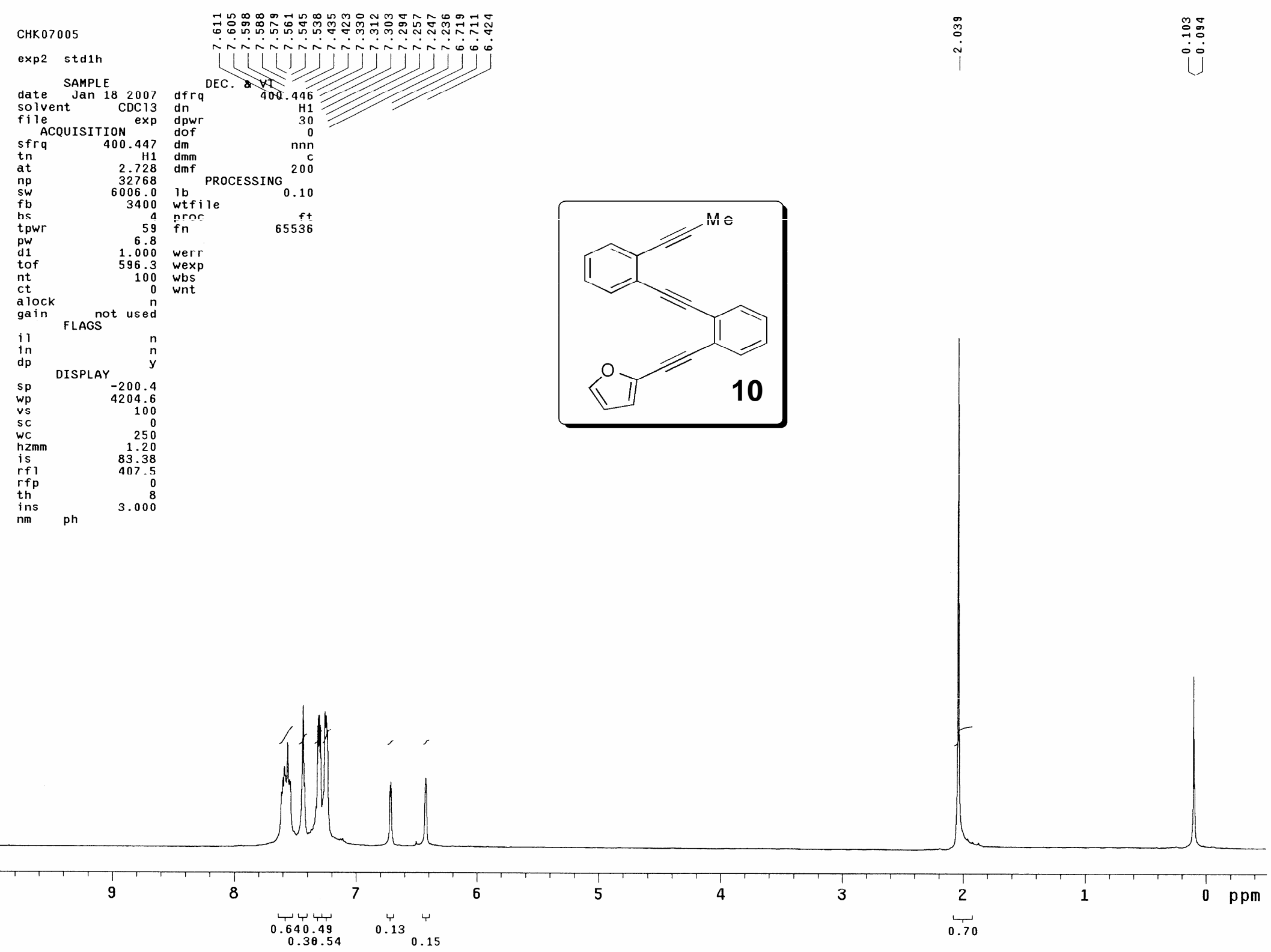



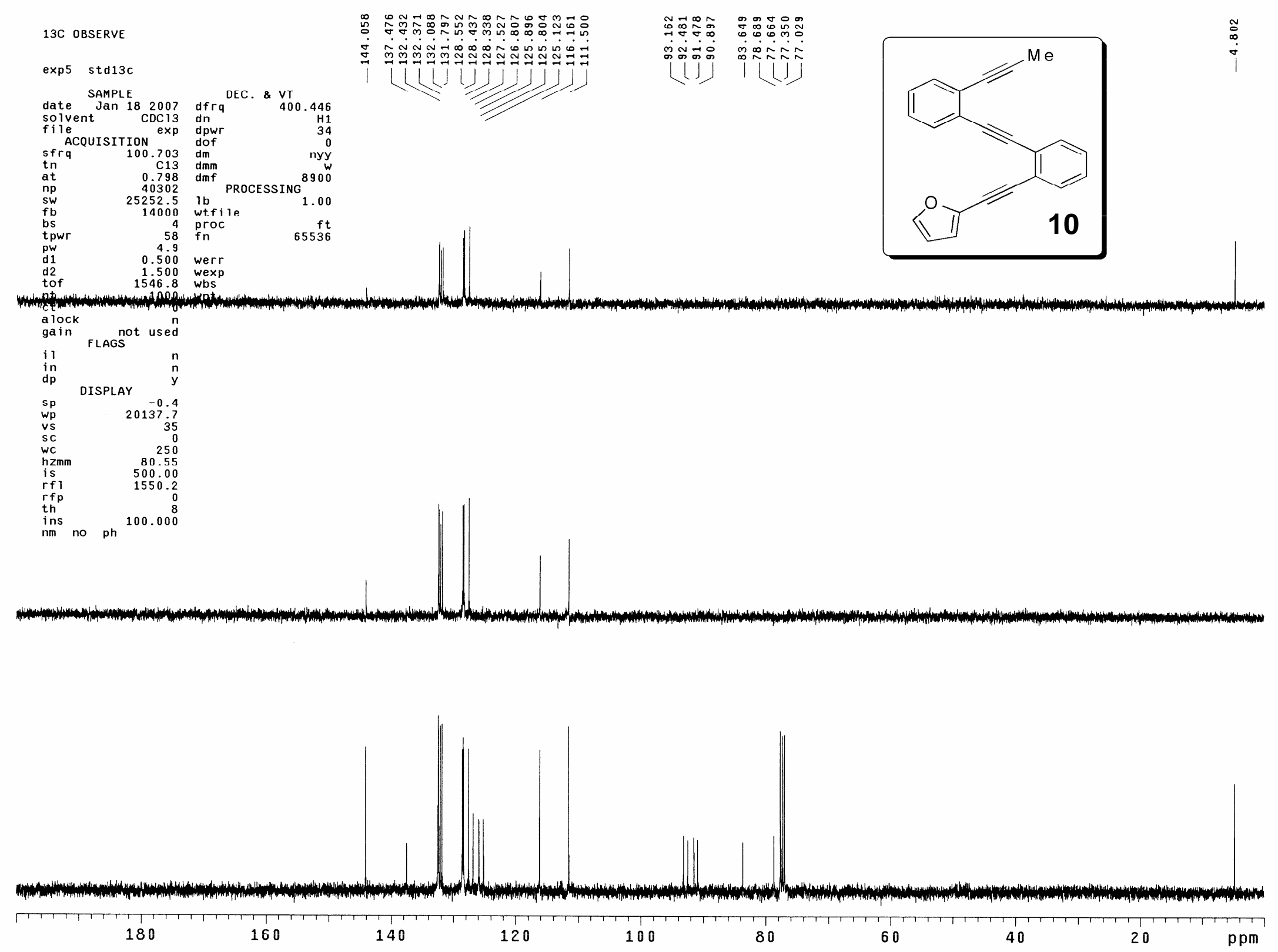


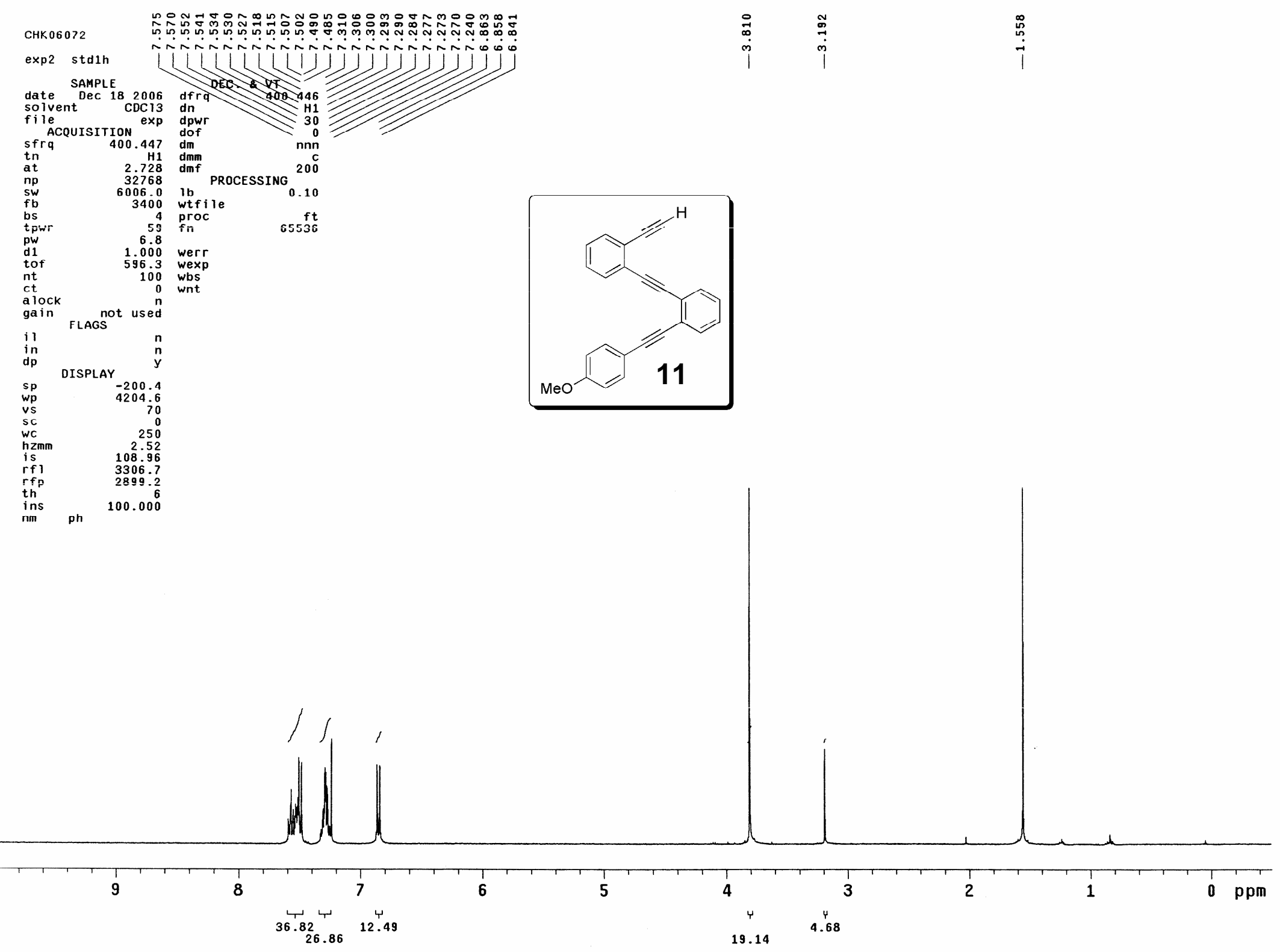




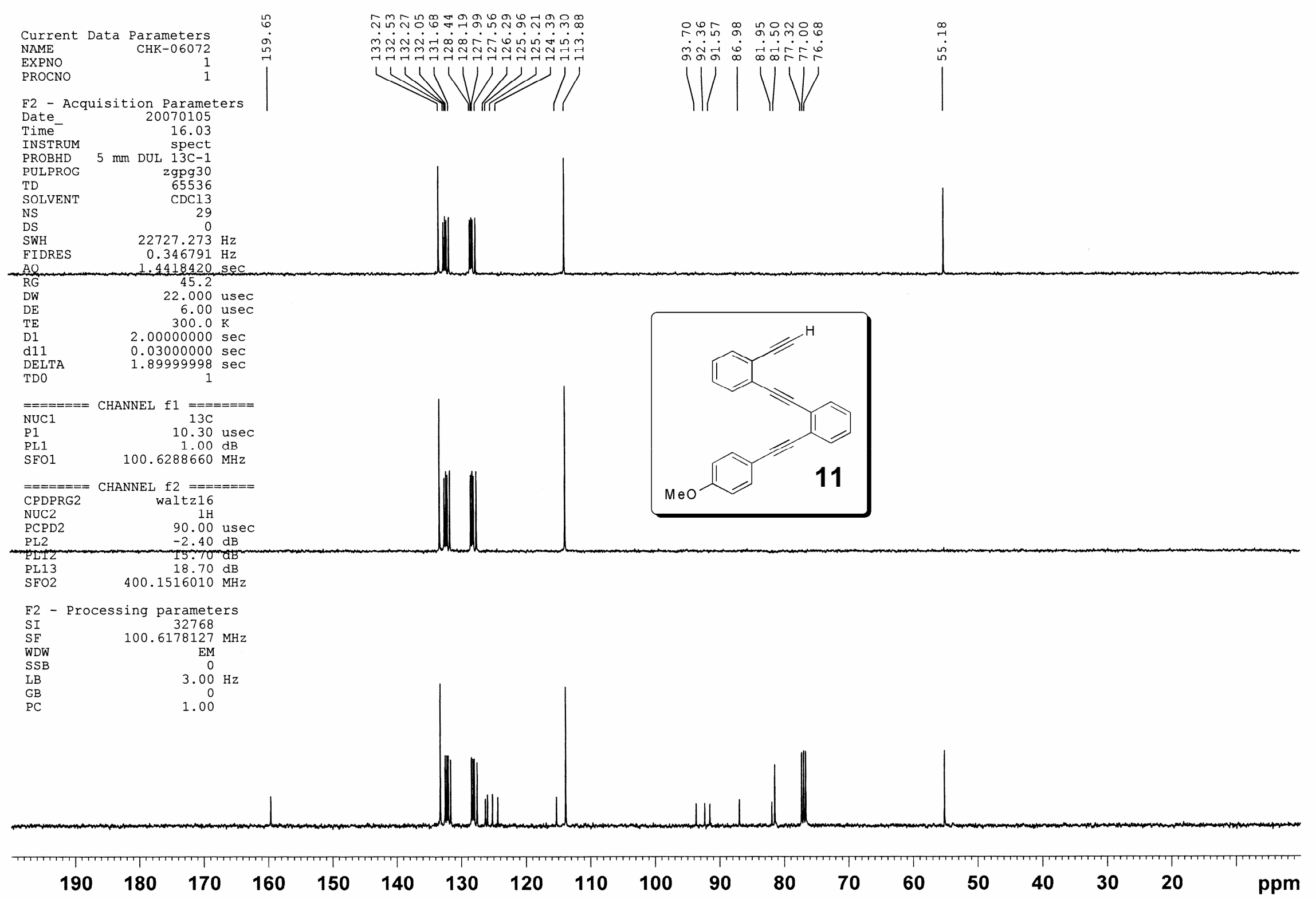




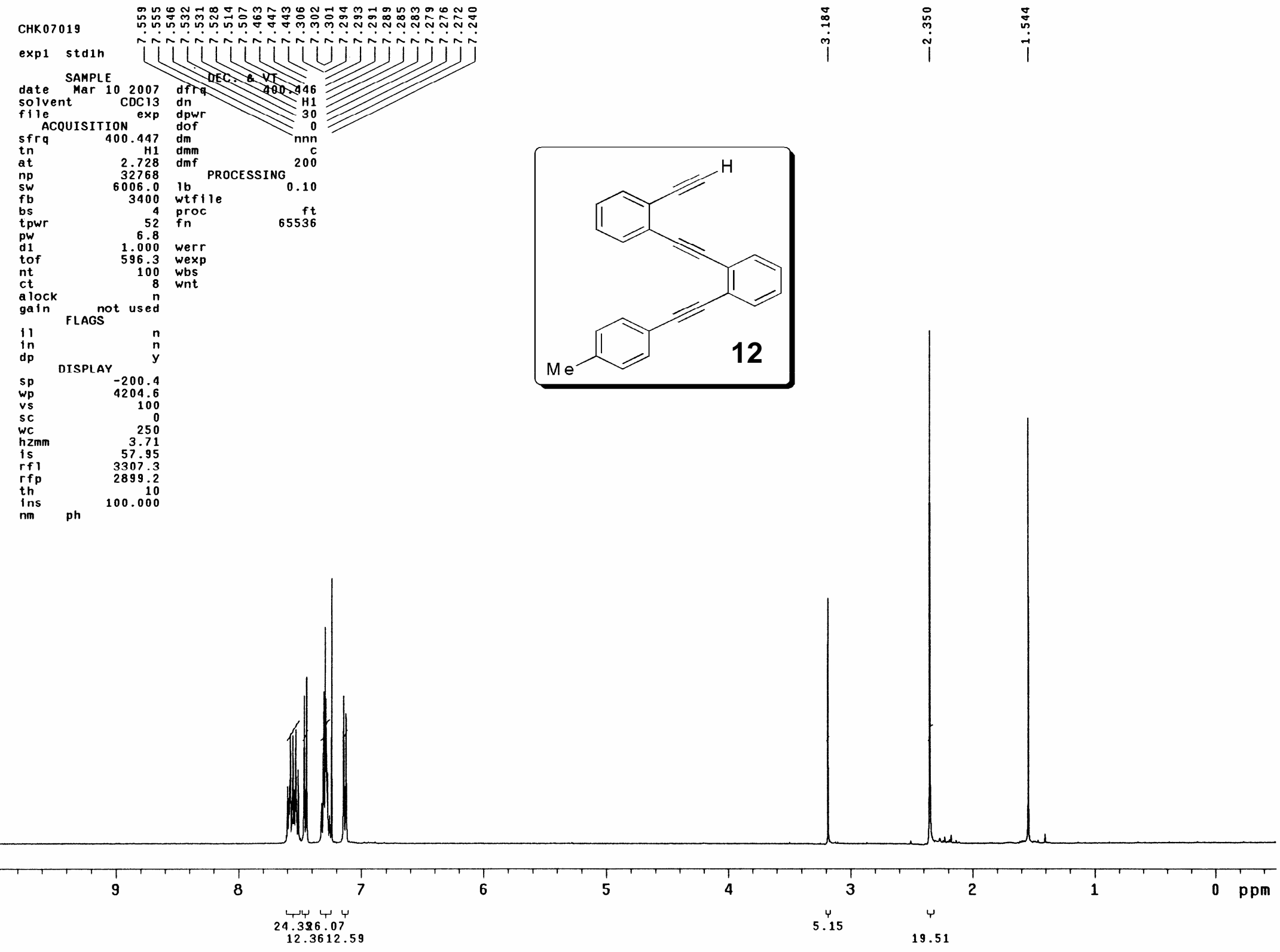



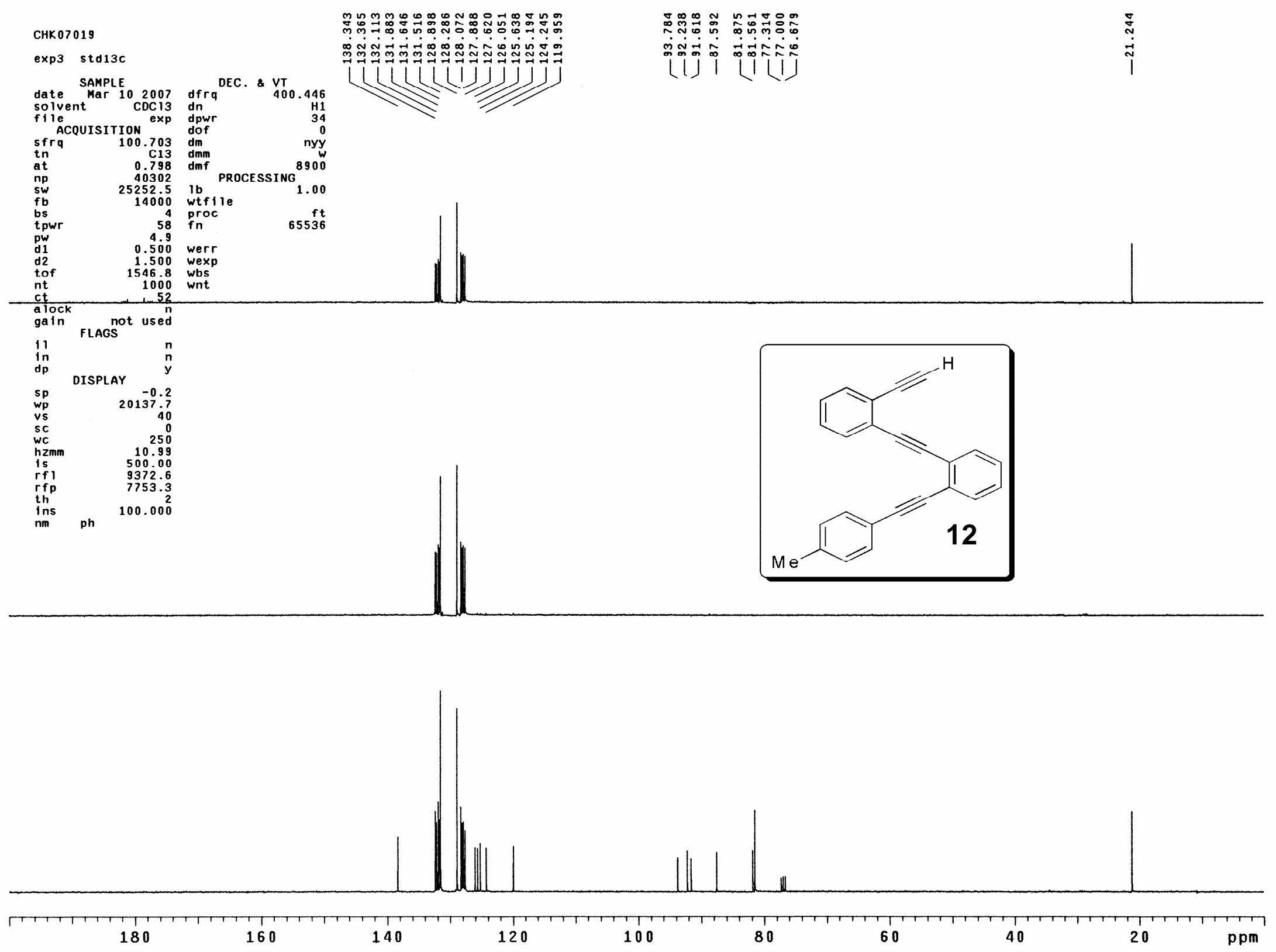


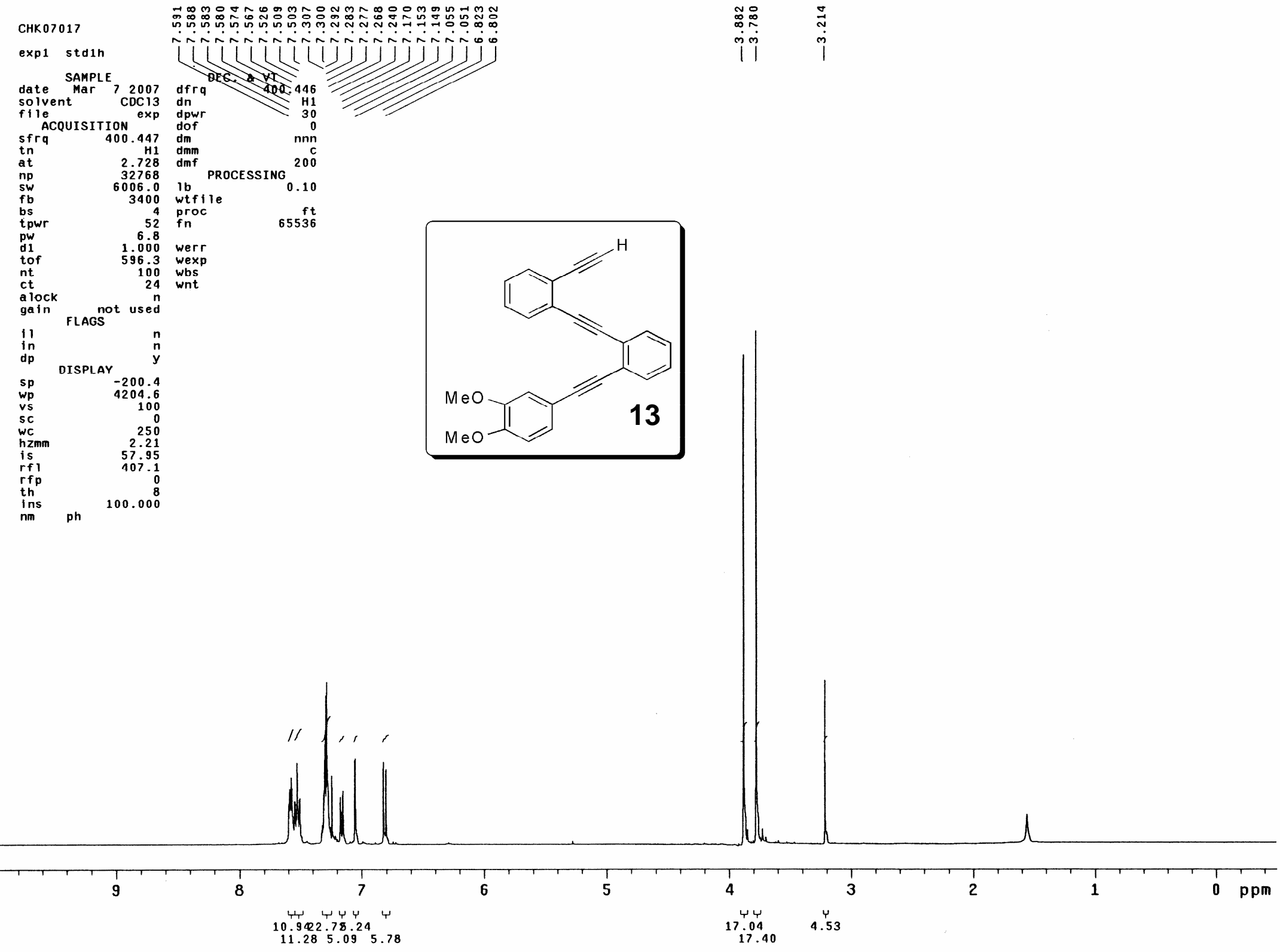



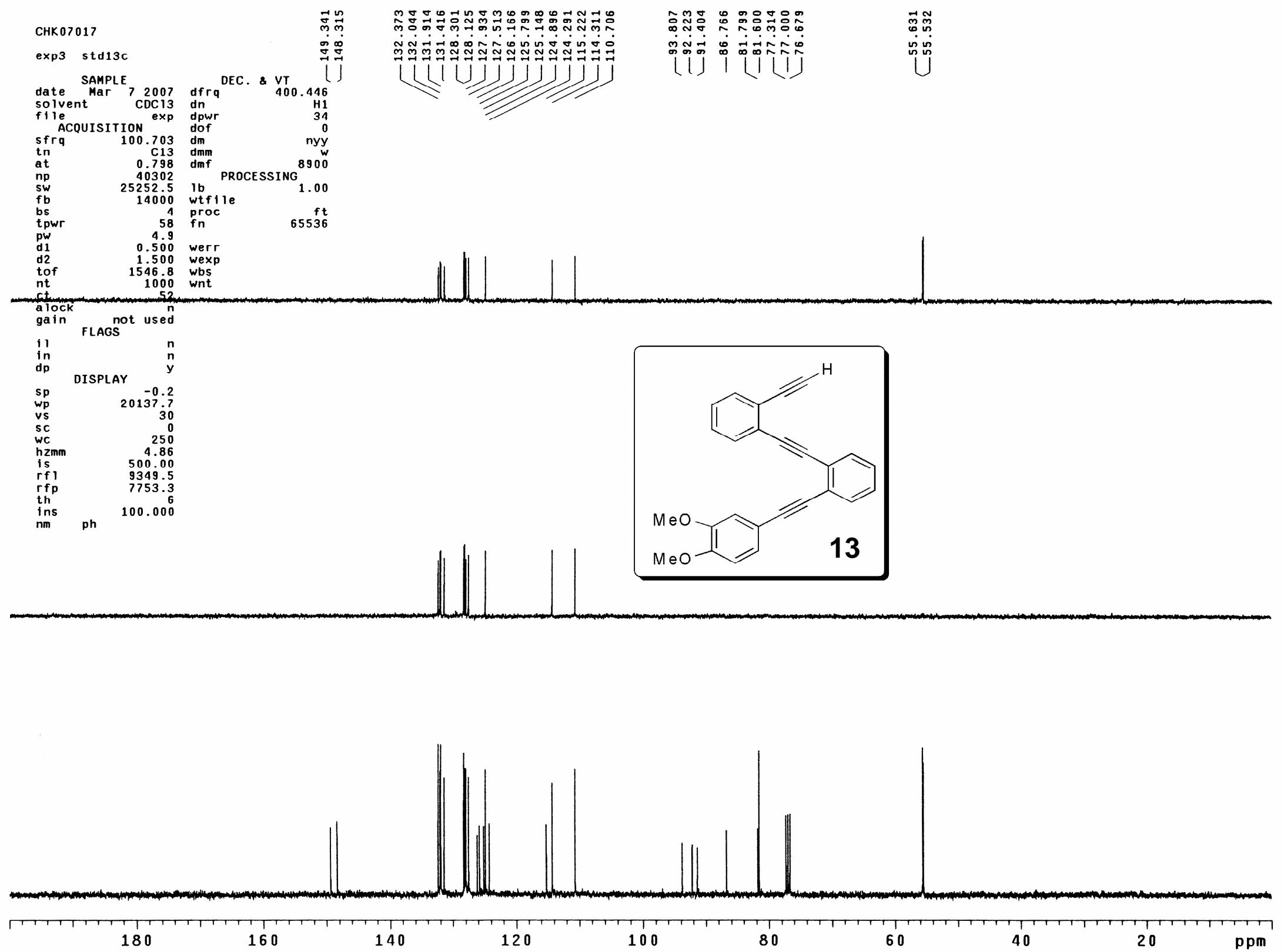


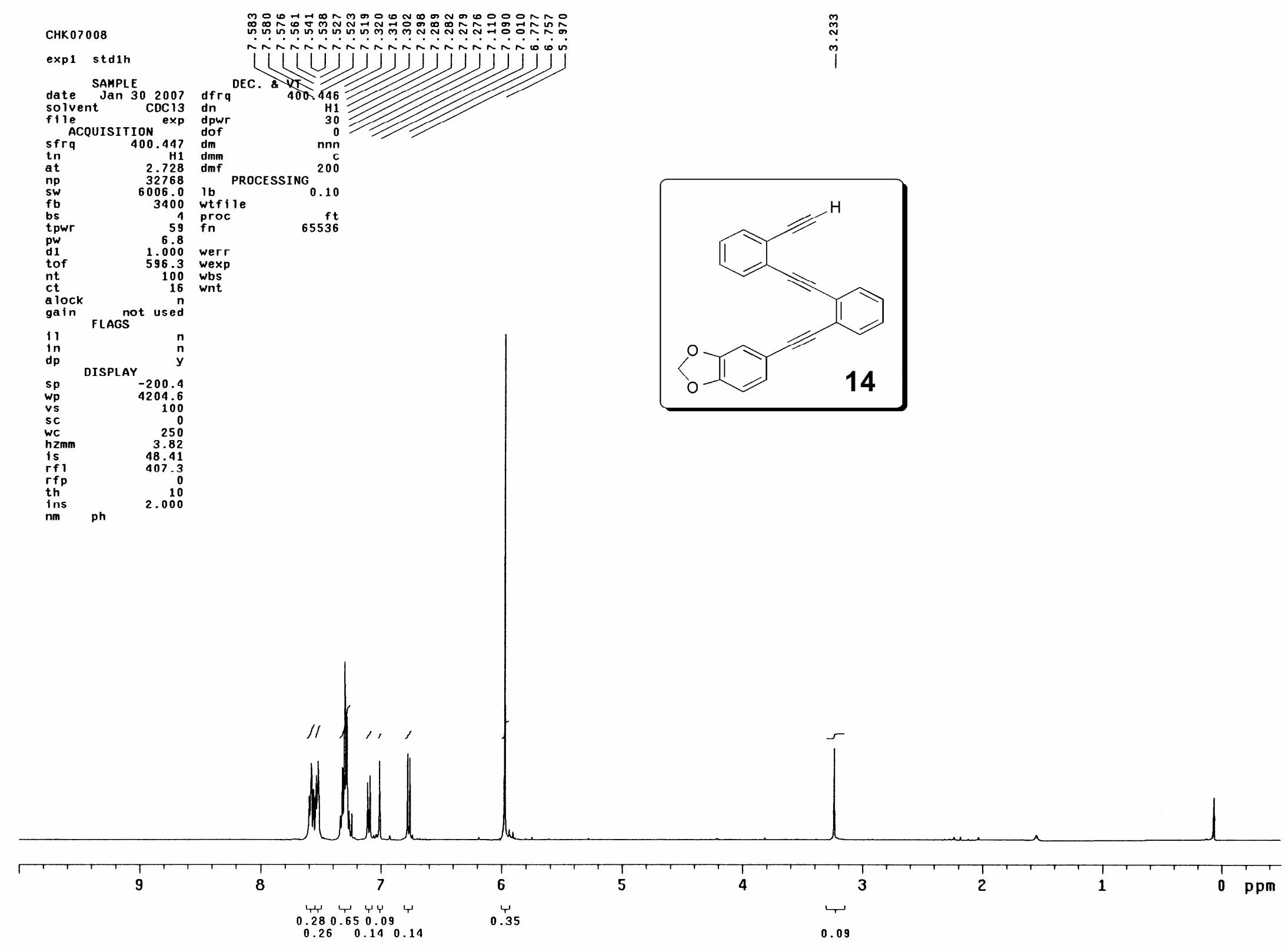



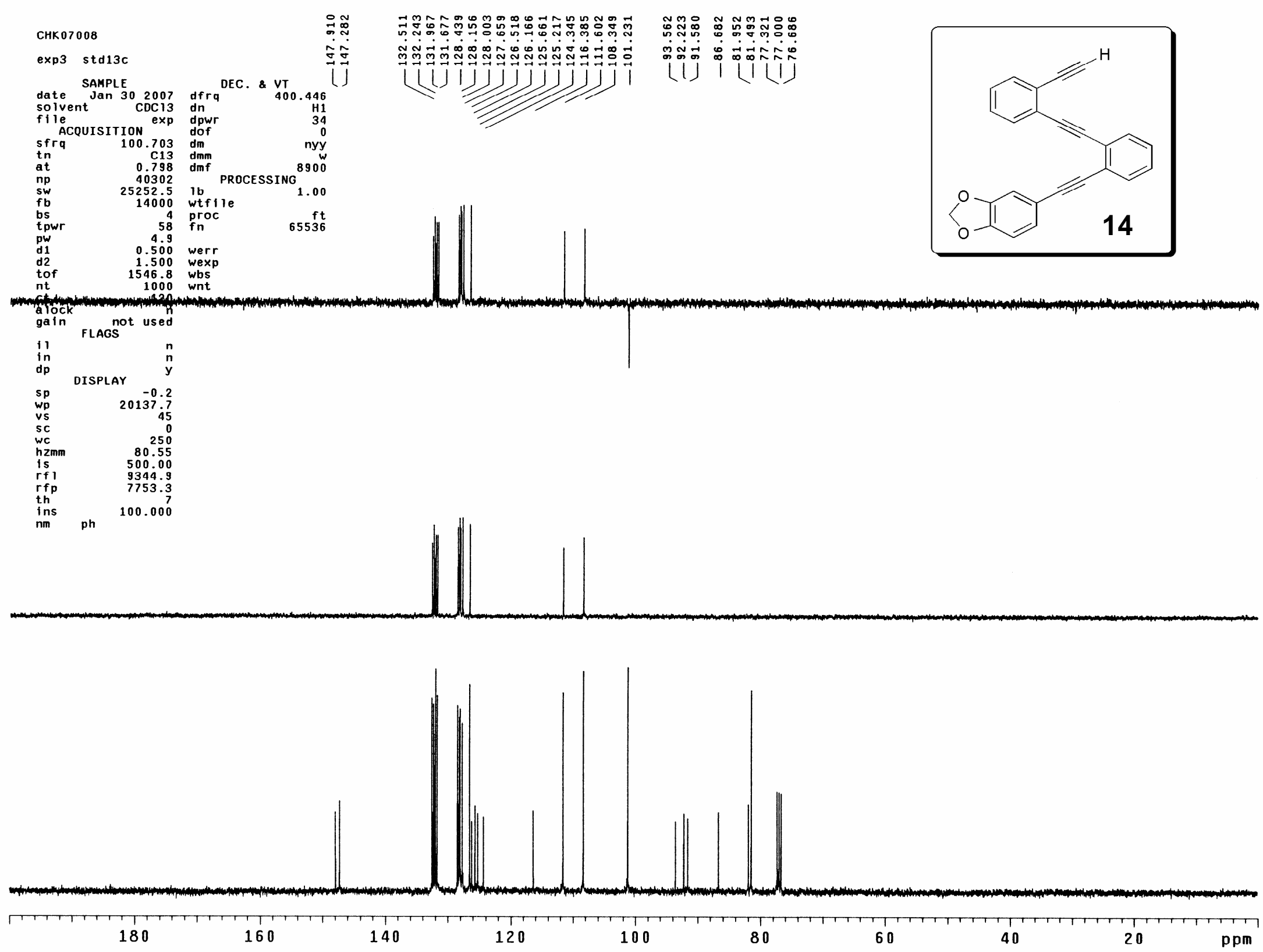


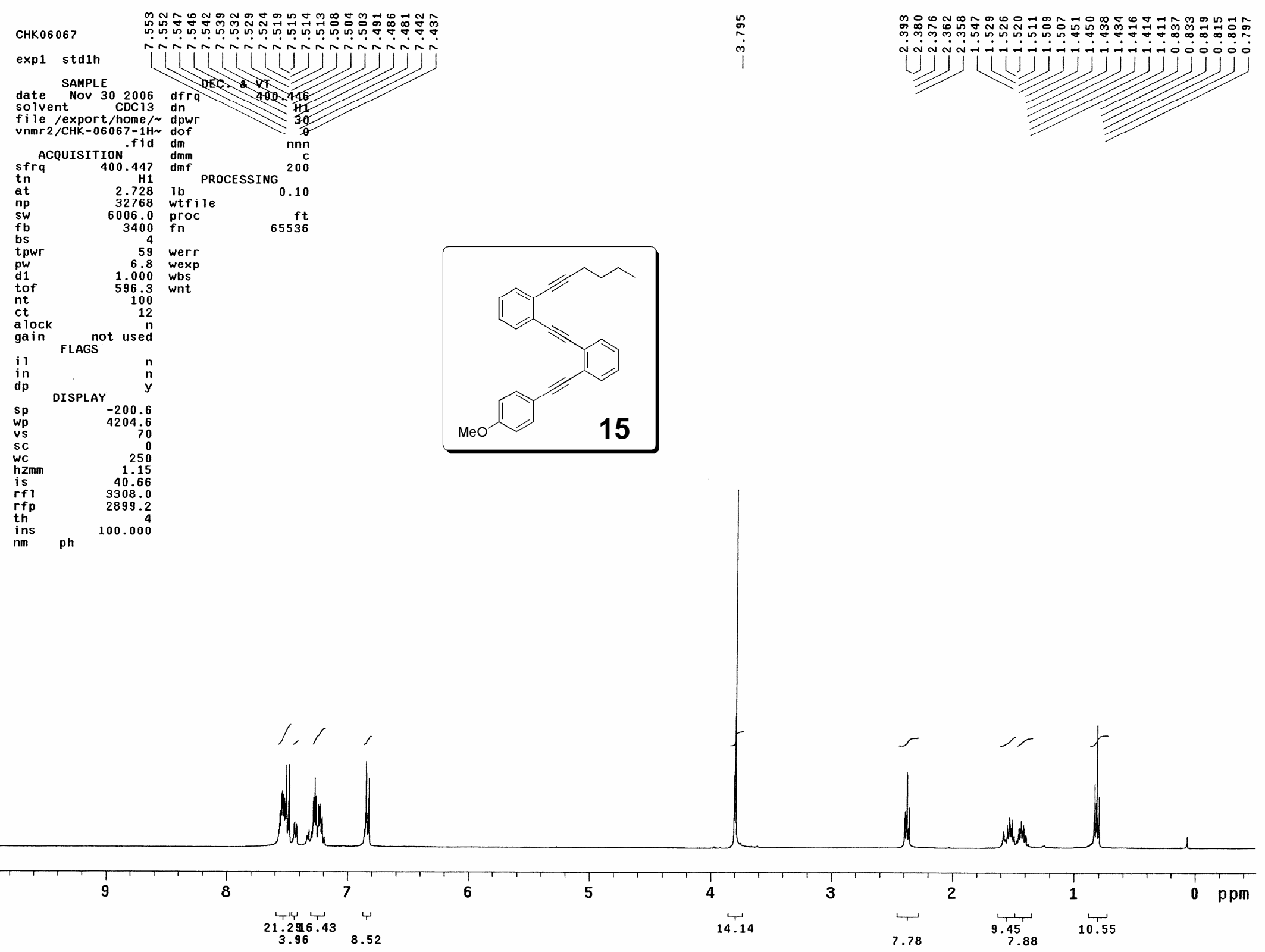



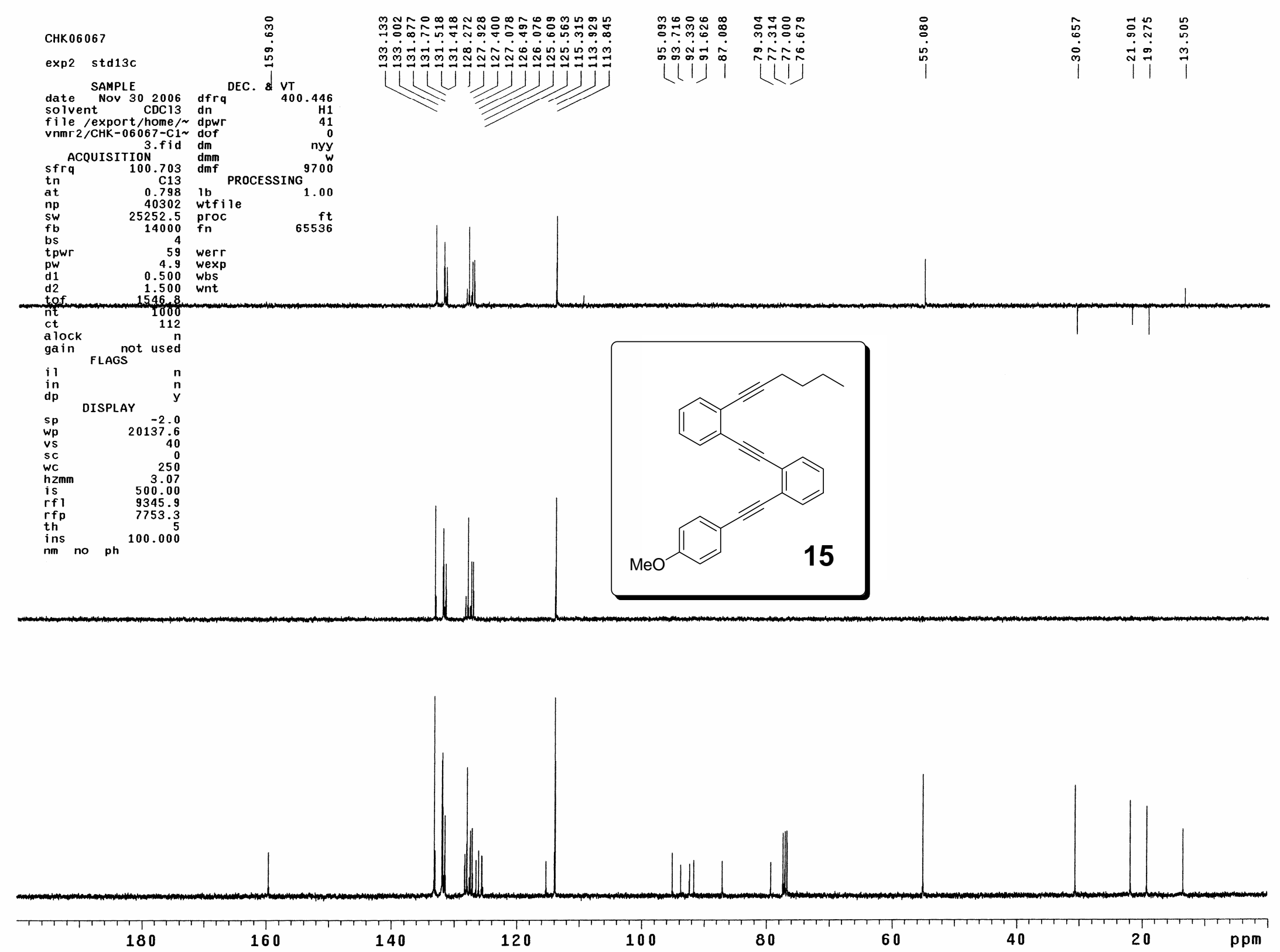


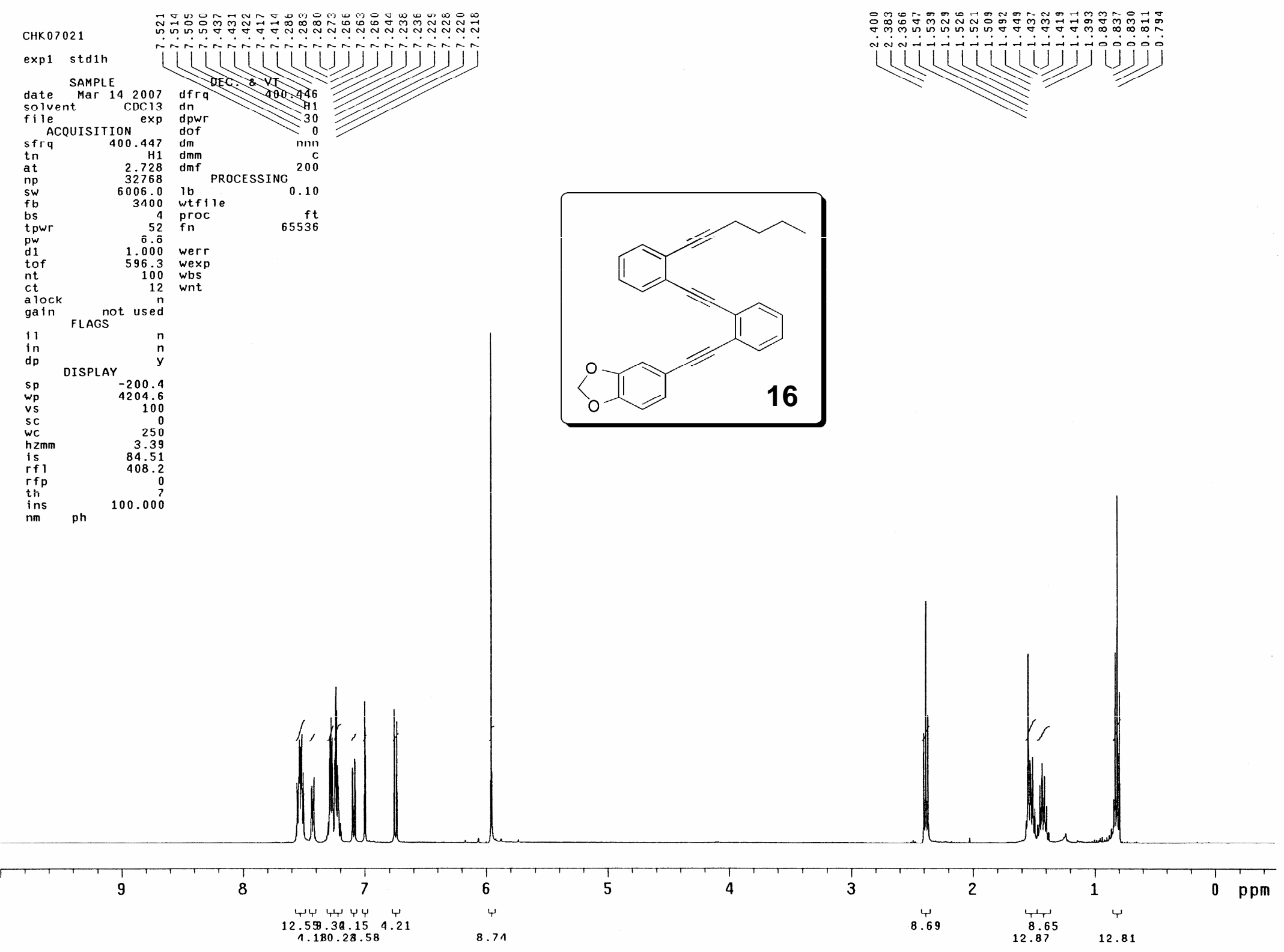



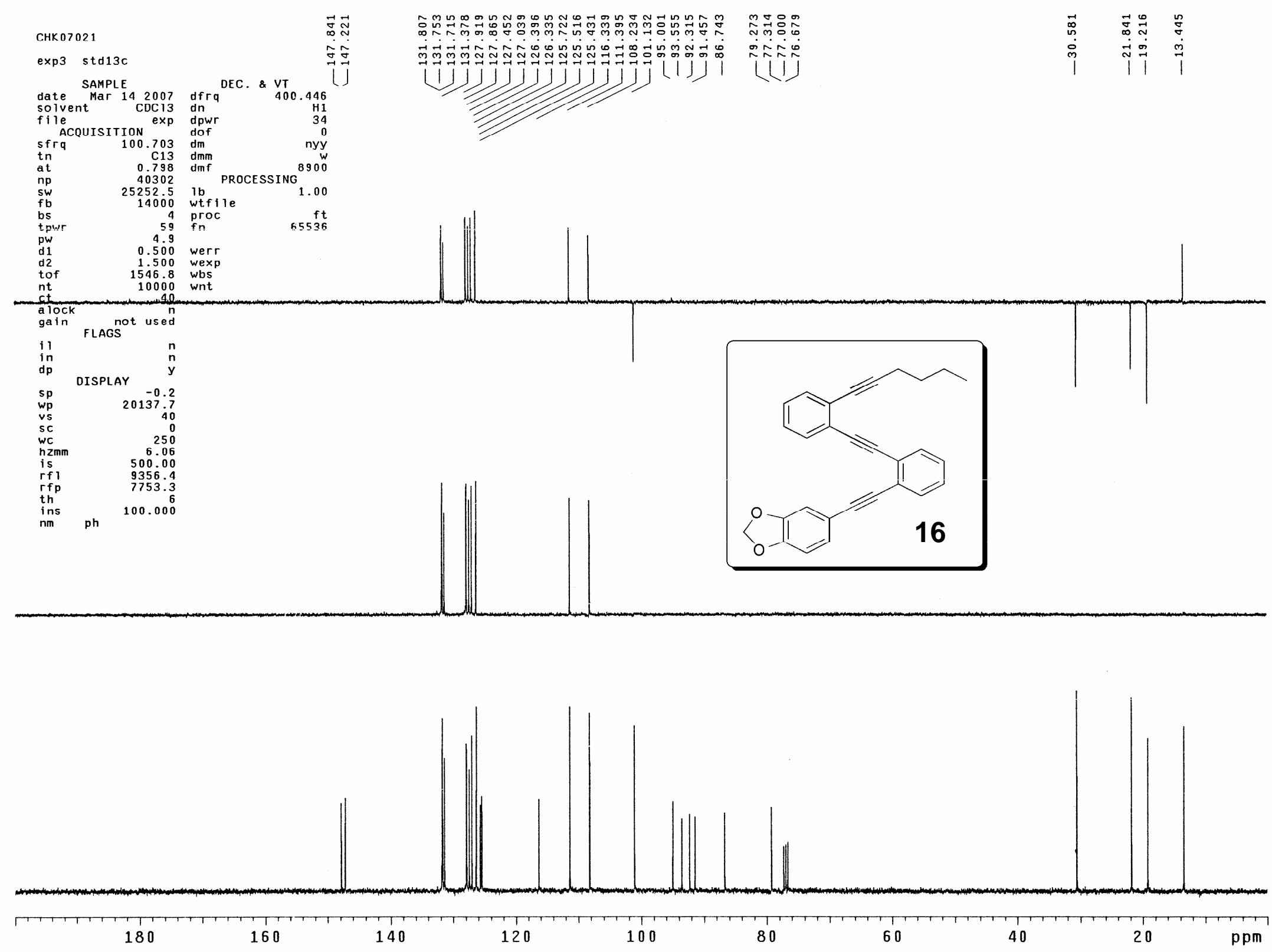


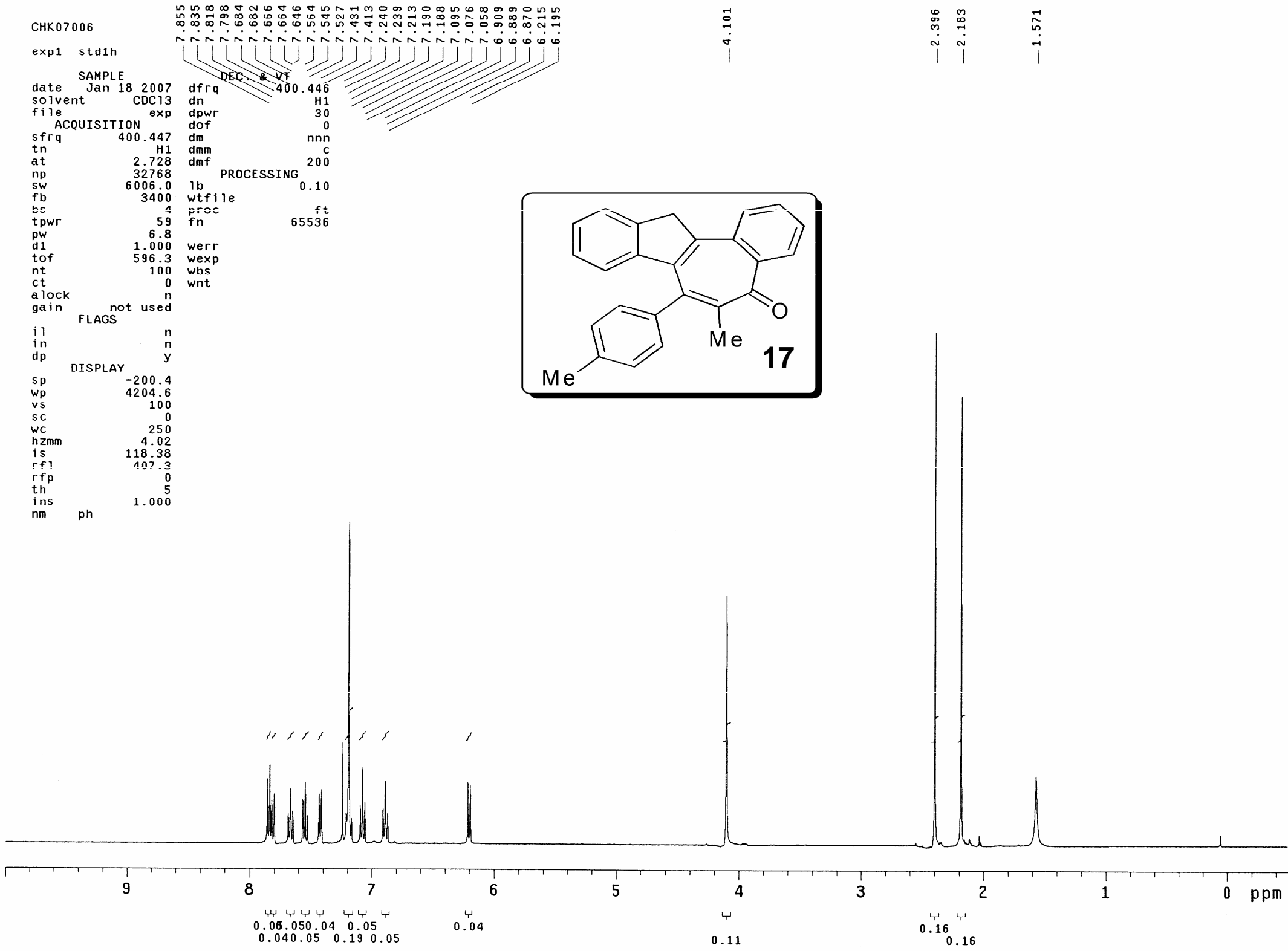




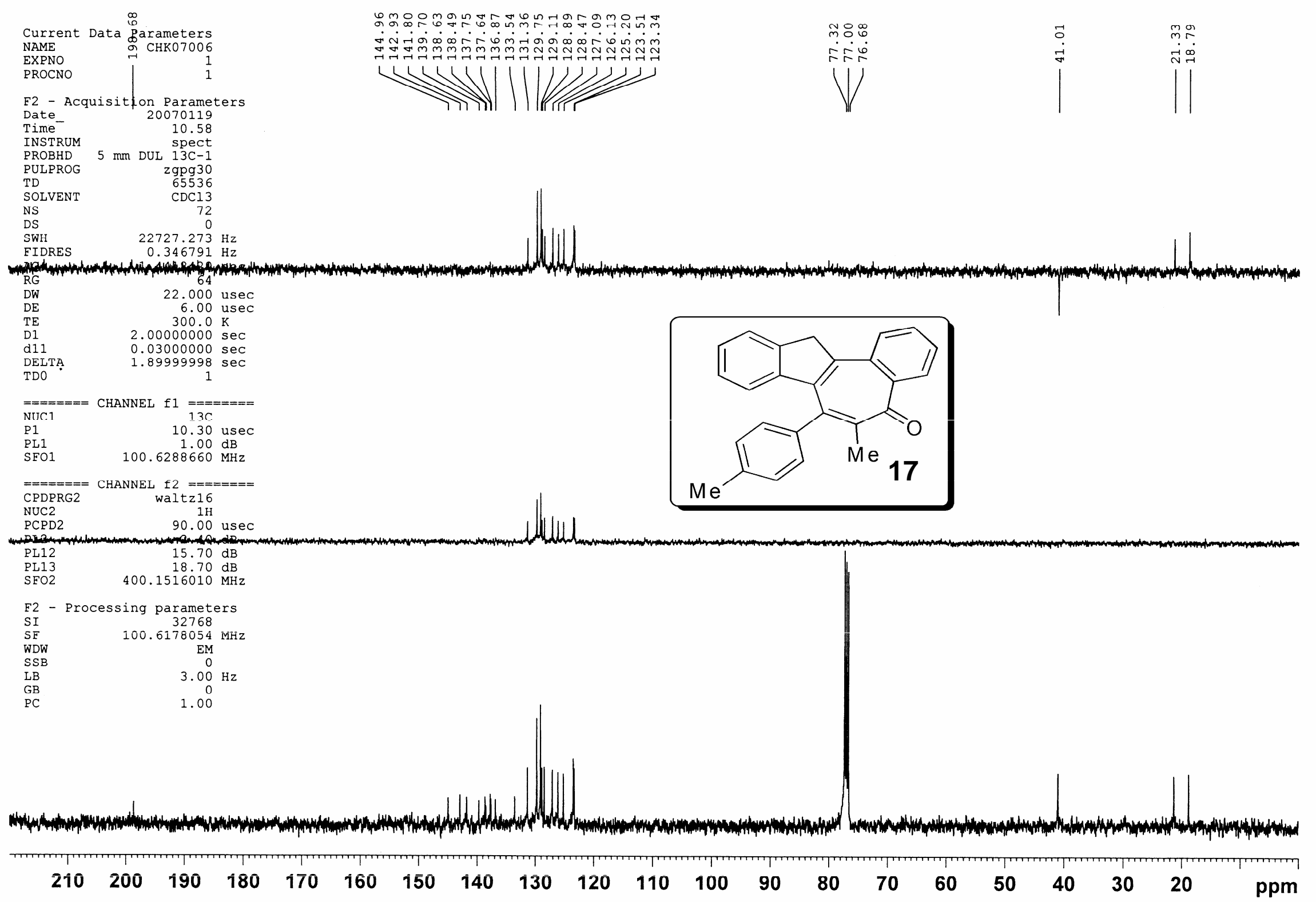



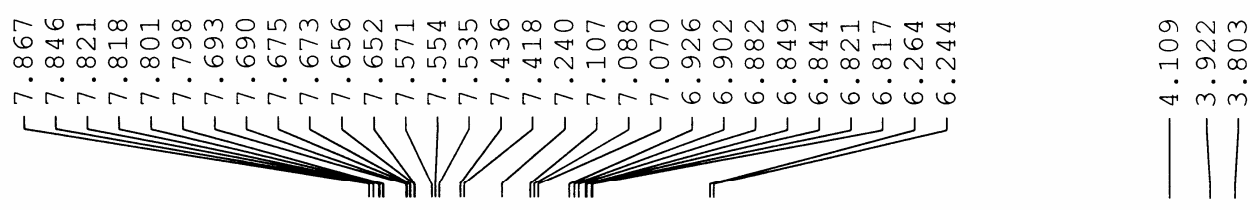

Current Data Parameters

EXPNO
PROCNO

F2 - Acquisition Parameters

Date Acquisition 20070307

Date
Time
Insom

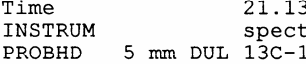

PULPROG

SOLVENT

NS

$\begin{array}{lr}\text { DS } & 0 \\ \text { SWH } & 6410.256 \mathrm{~Hz} \\ \text { FIDRES } & 0.195625 \mathrm{~Hz}\end{array}$

$\begin{array}{lr}\text { AQ } & 2.5559540 \mathrm{sec} \\ \text { RG } & 1030 \\ \text { DW } & 78.000 \mathrm{usec}\end{array}$

$\begin{array}{lr}78.000 \text { usec } \\ \mathrm{DE} & 6.00 \text { usec } \\ \mathrm{TE} & 300.0 \mathrm{~K}\end{array}$

D1 $2.00000000 \mathrm{sec}$

TDO

$\begin{array}{ll}=======\text { CHANNEL } \mathrm{f} 1======== \\ \text { NÜCI } & 1 \mathrm{H} \\ \text { P1 } & 10.00 \mathrm{usec} \\ \text { PL1 } & -2.40 \mathrm{~dB}\end{array}$

SFO1 $\quad 400.1528010 \mathrm{MHz}$

F2 - Processing parameters

$\begin{array}{ll}\text { SI } & 16384 \\ \text { SF } & 400.15001680 \mathrm{MHi}\end{array}$

$\begin{array}{lr}\text { SF } & 400.1500168 \\ \text { WDW } & \text { EM } \\ \text { SSB } & 0\end{array}$

$\begin{array}{lc}\text { SSB } & 0 \\ \text { LB } & 0.00 \mathrm{~Hz} \\ \text { GB } & 0\end{array}$

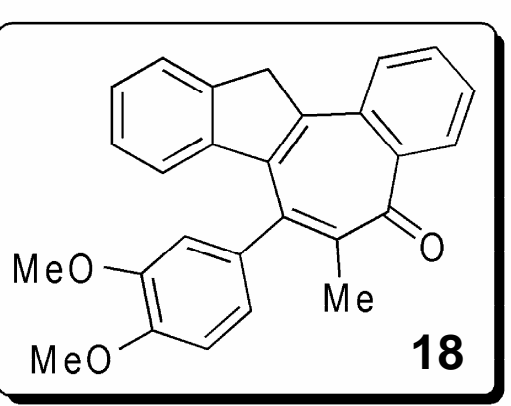

ษ ri:

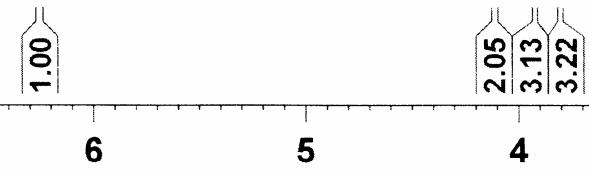

Nָ

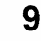

8 

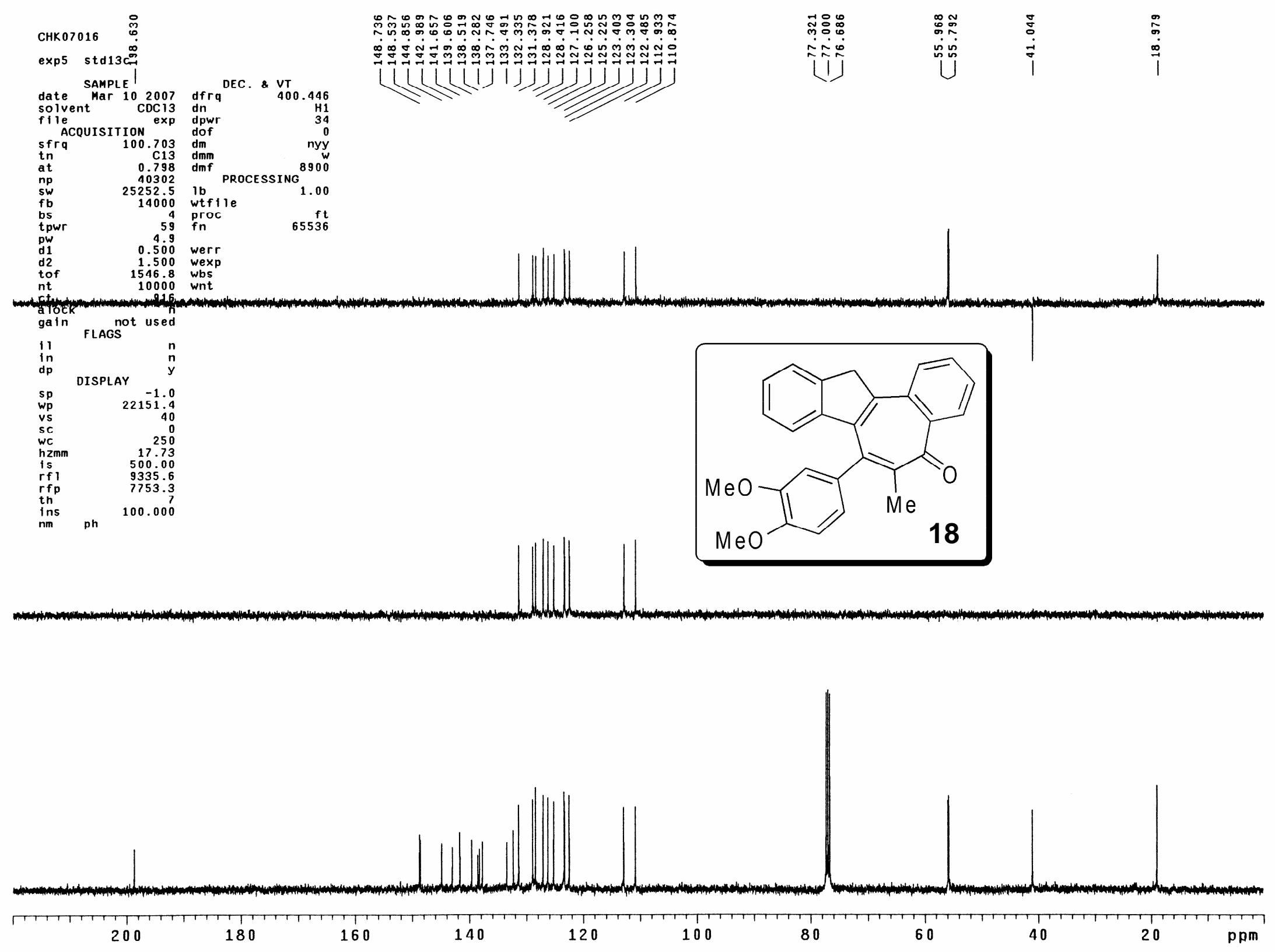


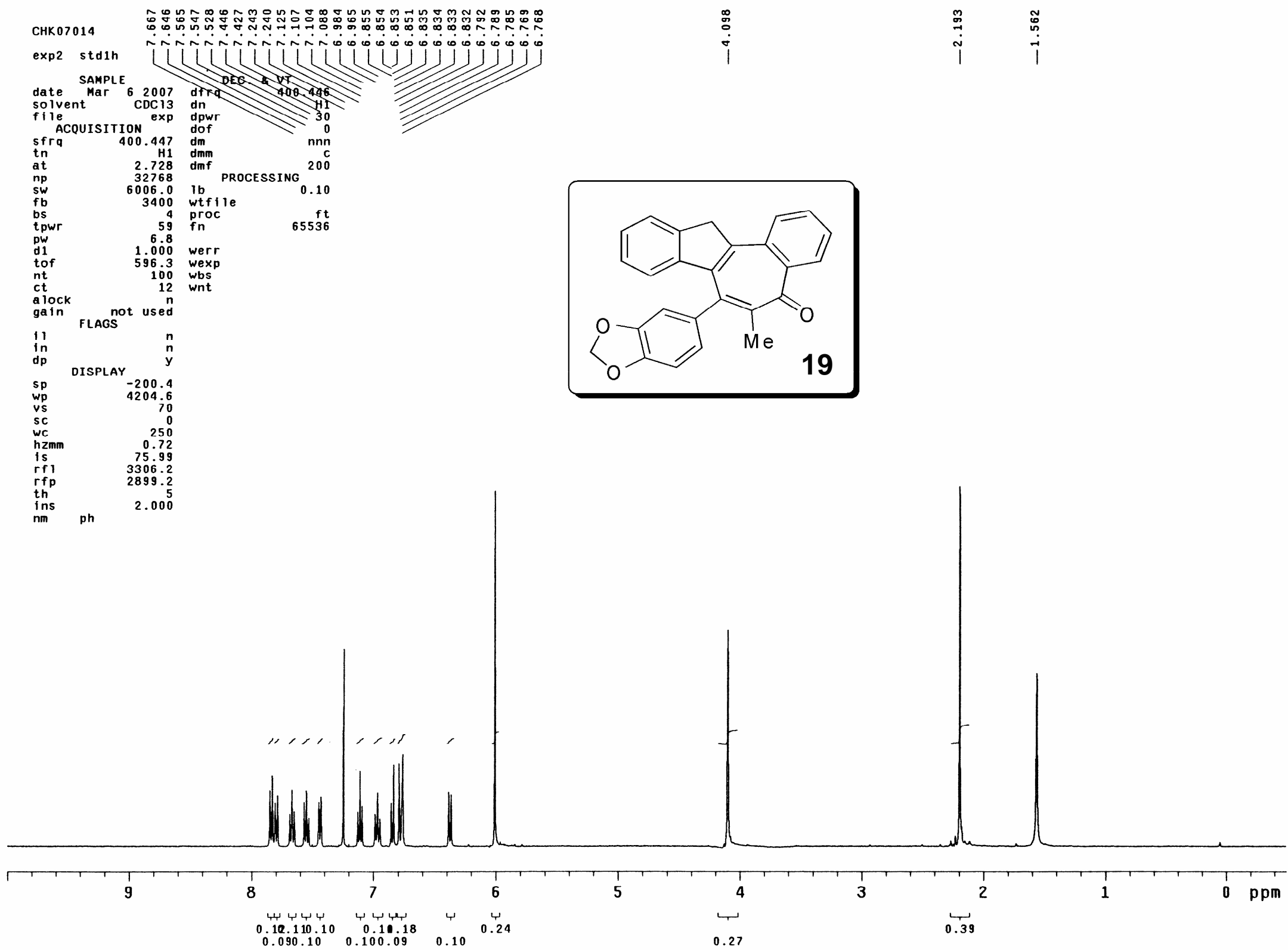



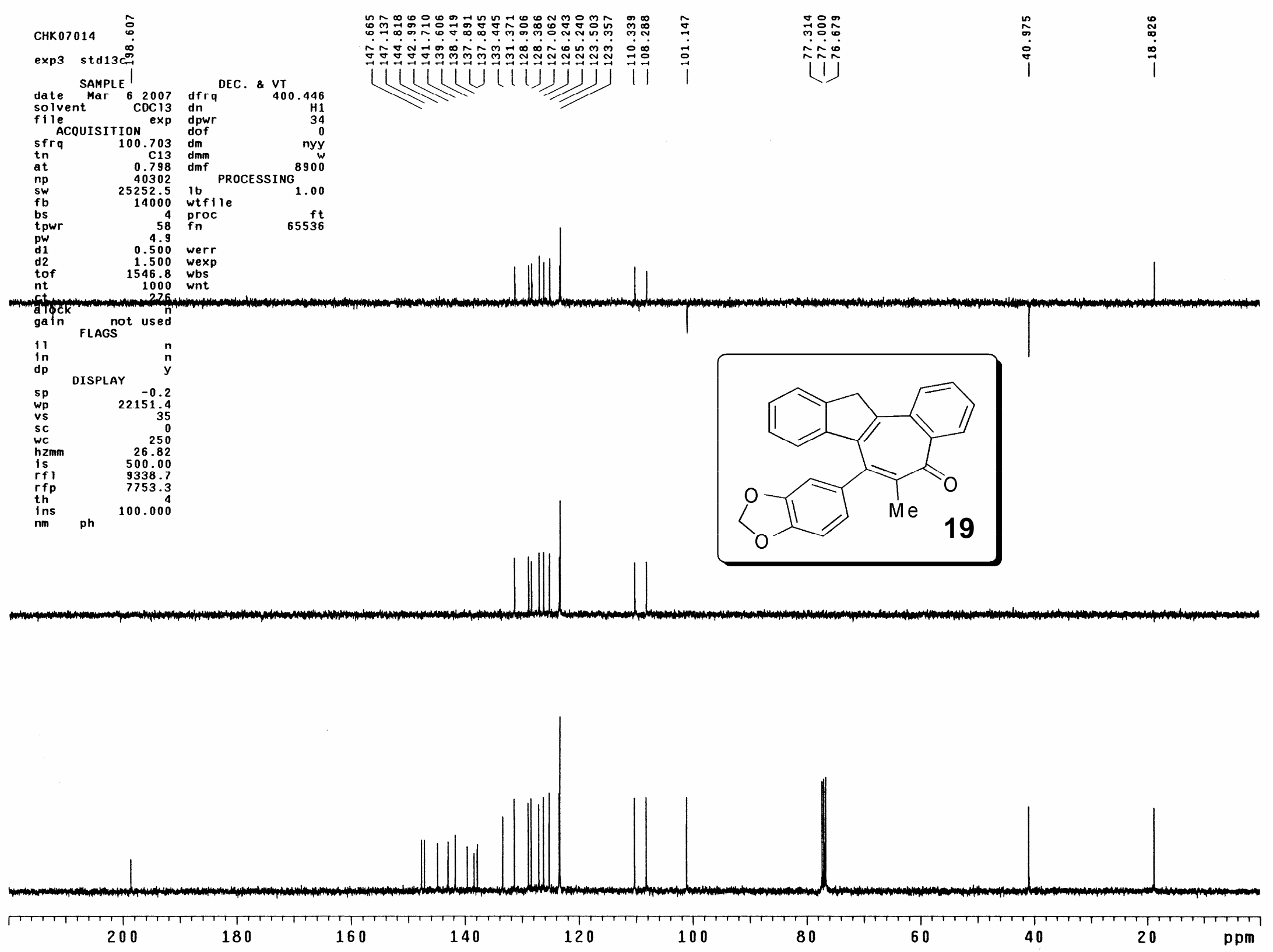
CHK06071

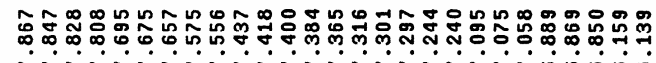

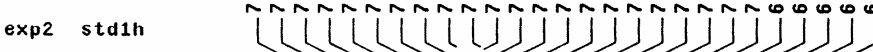

SAMPLE 2006 dfrq -400.446

date $\operatorname{Dec} 122006$ df
solvent $12 \mathrm{CDCl}_{3} \mathrm{dn}$
file $/$ export

flie /export/home/ $\sim$ dpwr
vnmr2/CHK-06071-1H dof

ACQuisition fid $\mathrm{dm}_{\mathrm{dmm}}$

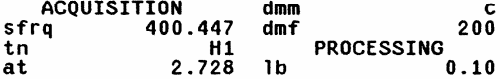

$\begin{array}{llll}\text { tn } & \text { H1 } & \text { lo PROCESSING } \\ \text { at } & 32728 & \text { lo } \\ \text { np } & 32768 & \text { wtfile } & 0.10\end{array}$

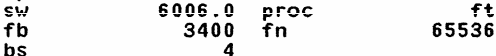

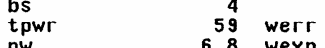

$\begin{array}{lrl}\text { pw } & 6.8 & \text { wexp } \\ \text { d1 } & 1.000 & \text { whs } \\ \text { tof } & 596.3 & \text { wnt } \\ \text { nt } & 100 & \end{array}$

$\begin{array}{lr}\text { ct } & 0 \\ \text { a lock not used } & n\end{array}$

gain fLAGS used

$\begin{array}{ll}\text { in } & n \\ \text { in } & n \\ \text { dp } & n\end{array}$

$\begin{array}{lr}\text { sp } & \text { DISPLAY } \\ \text { wp } & -200.6 \\ \text { vs } & 4204.6 \\ \text { s } & 100\end{array}$

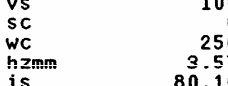

$\begin{array}{lr}\text { is } & 80.10 \\ \text { rf } & 3305.6 \\ \text { rfp } & 2635.2 \\ \text { th } & \\ \text { ins } & \end{array}$

ph

$\stackrel{\cong}{\exists}$

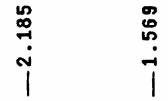
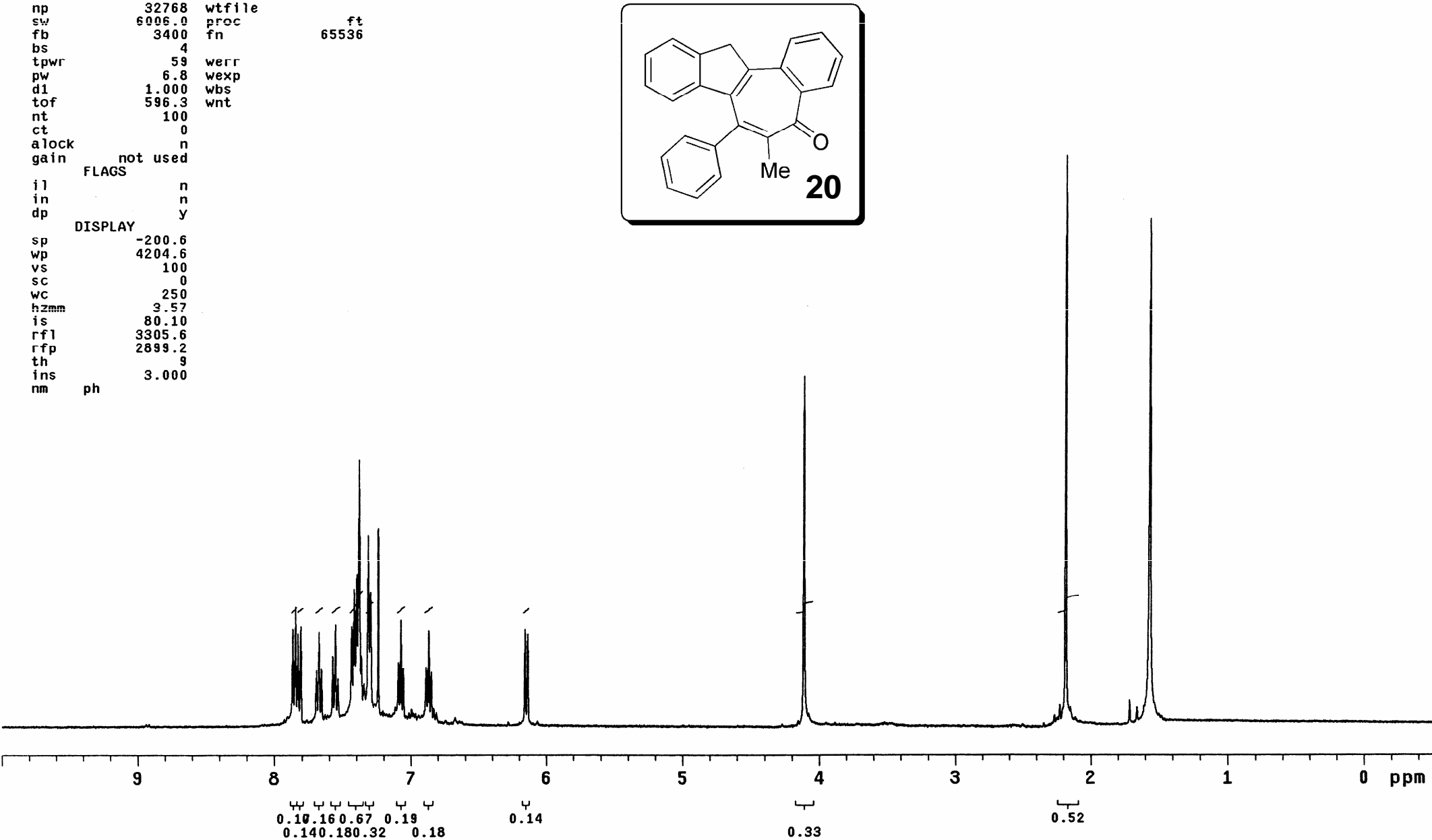

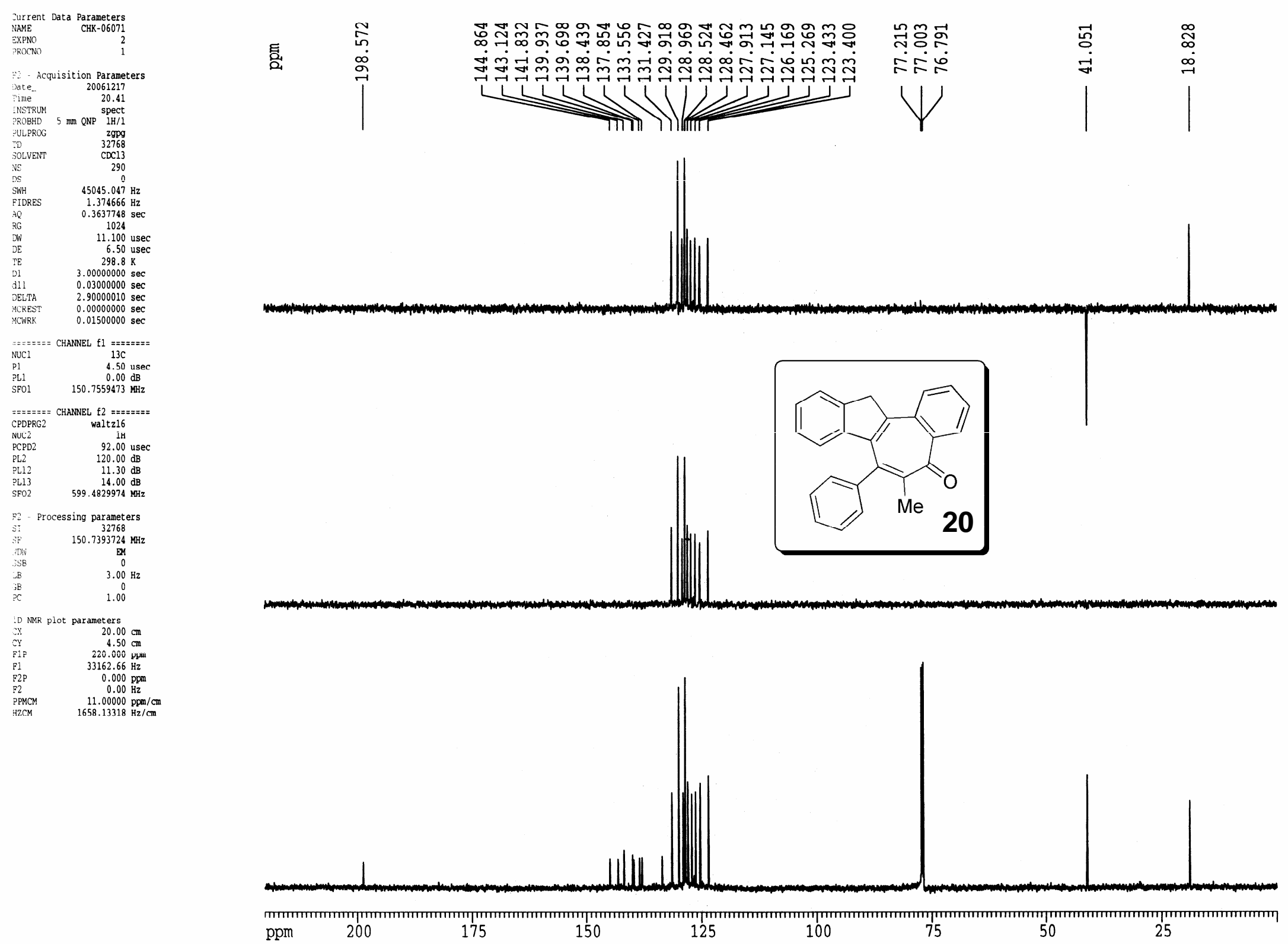


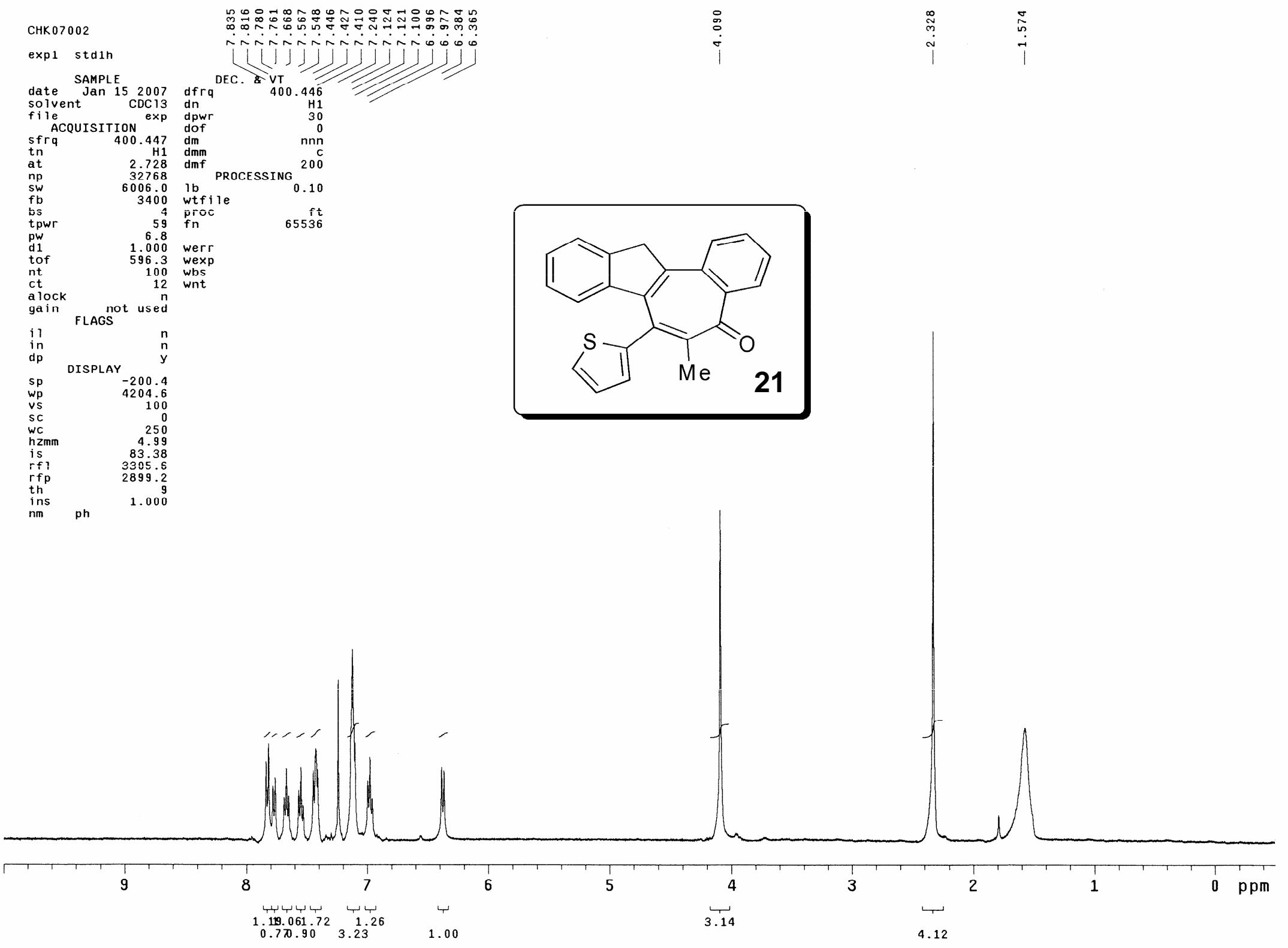




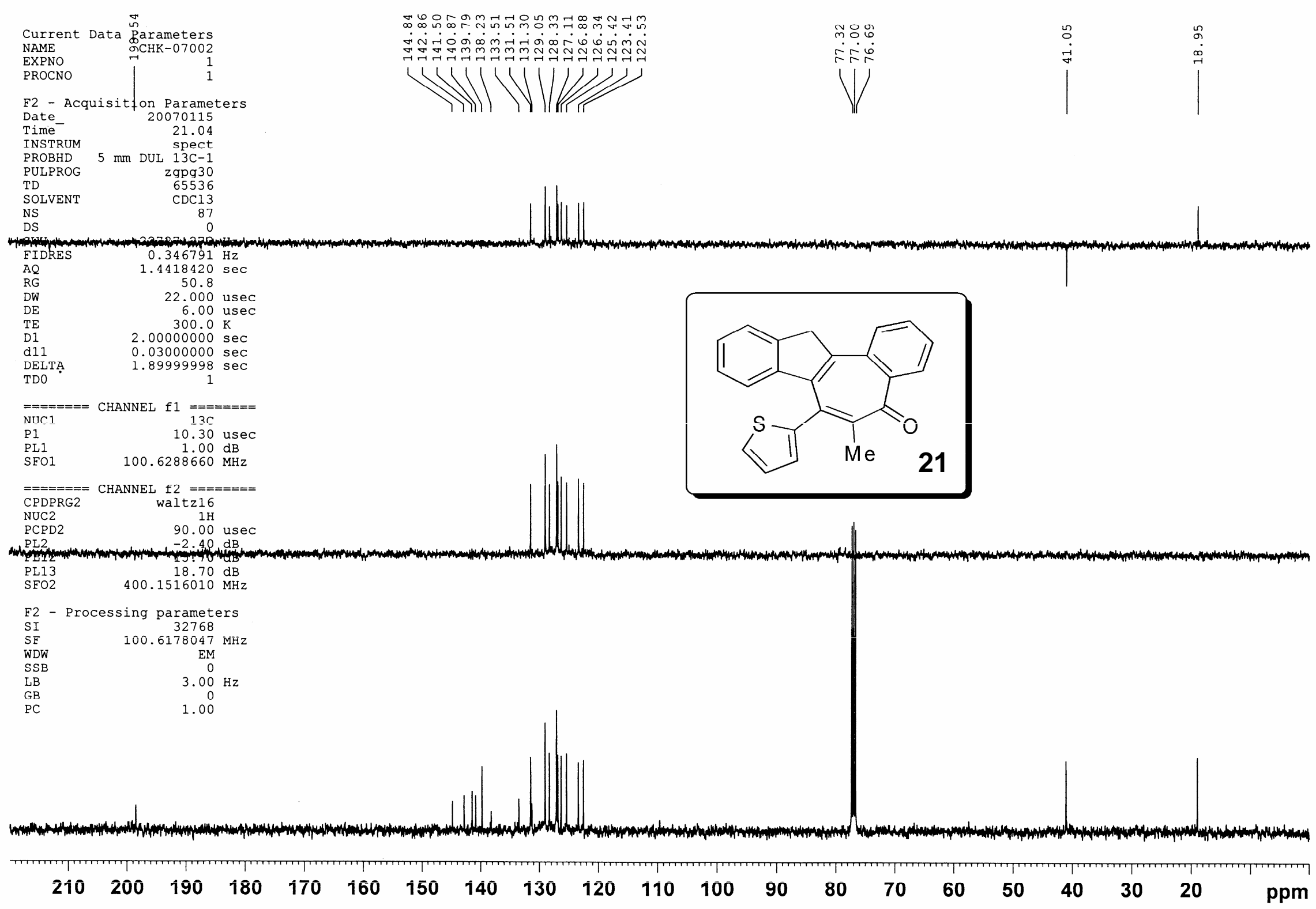




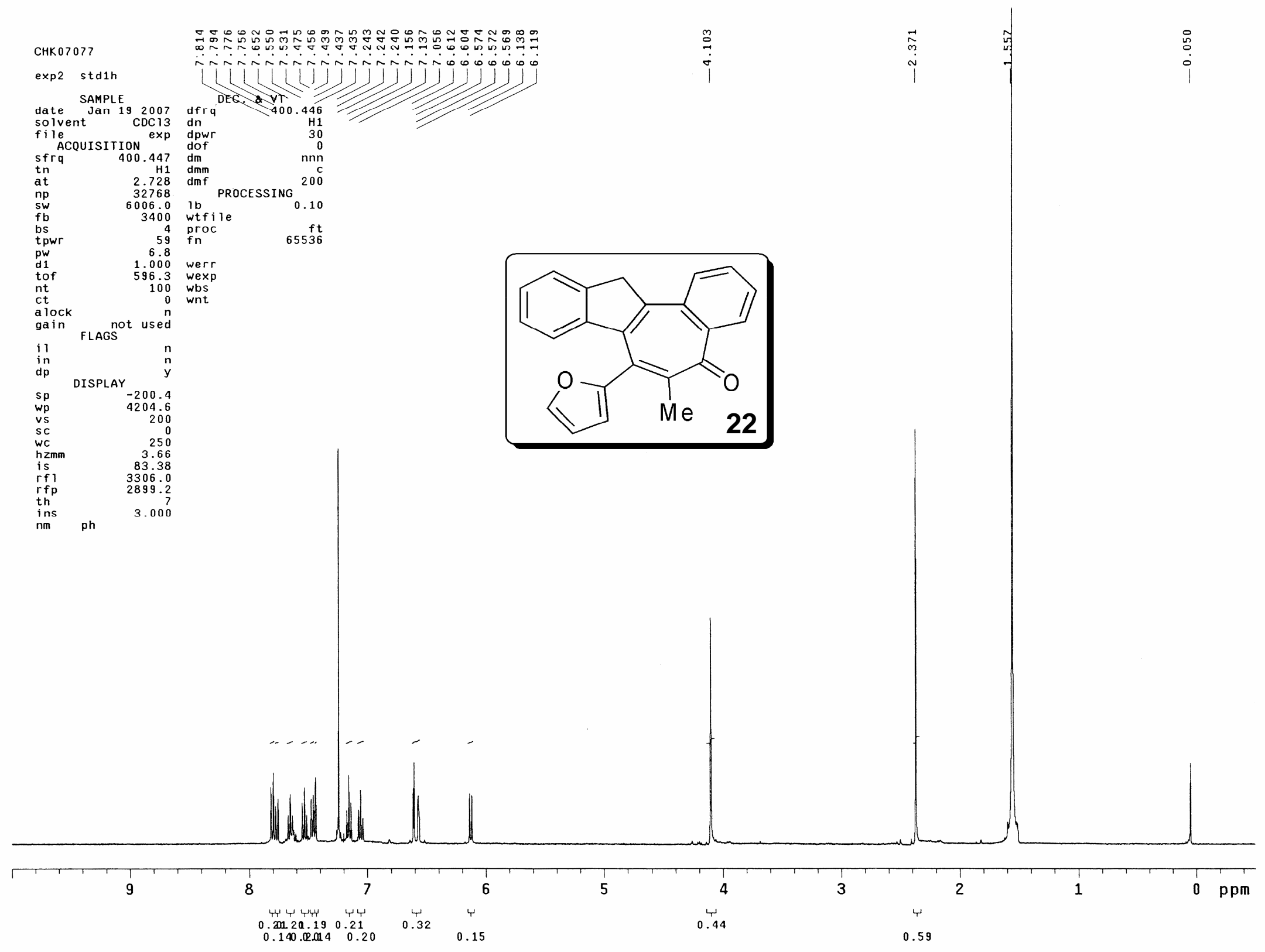




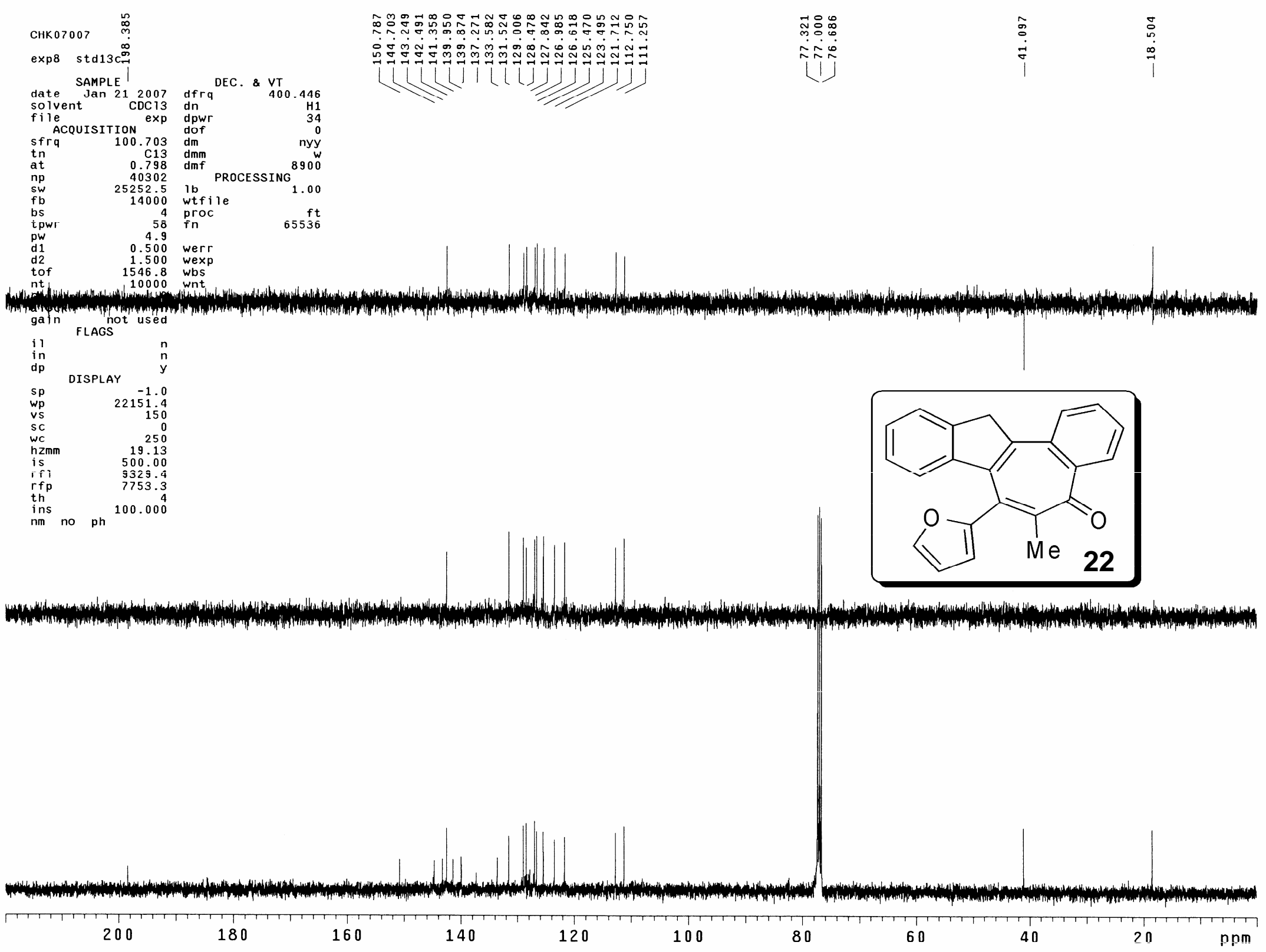




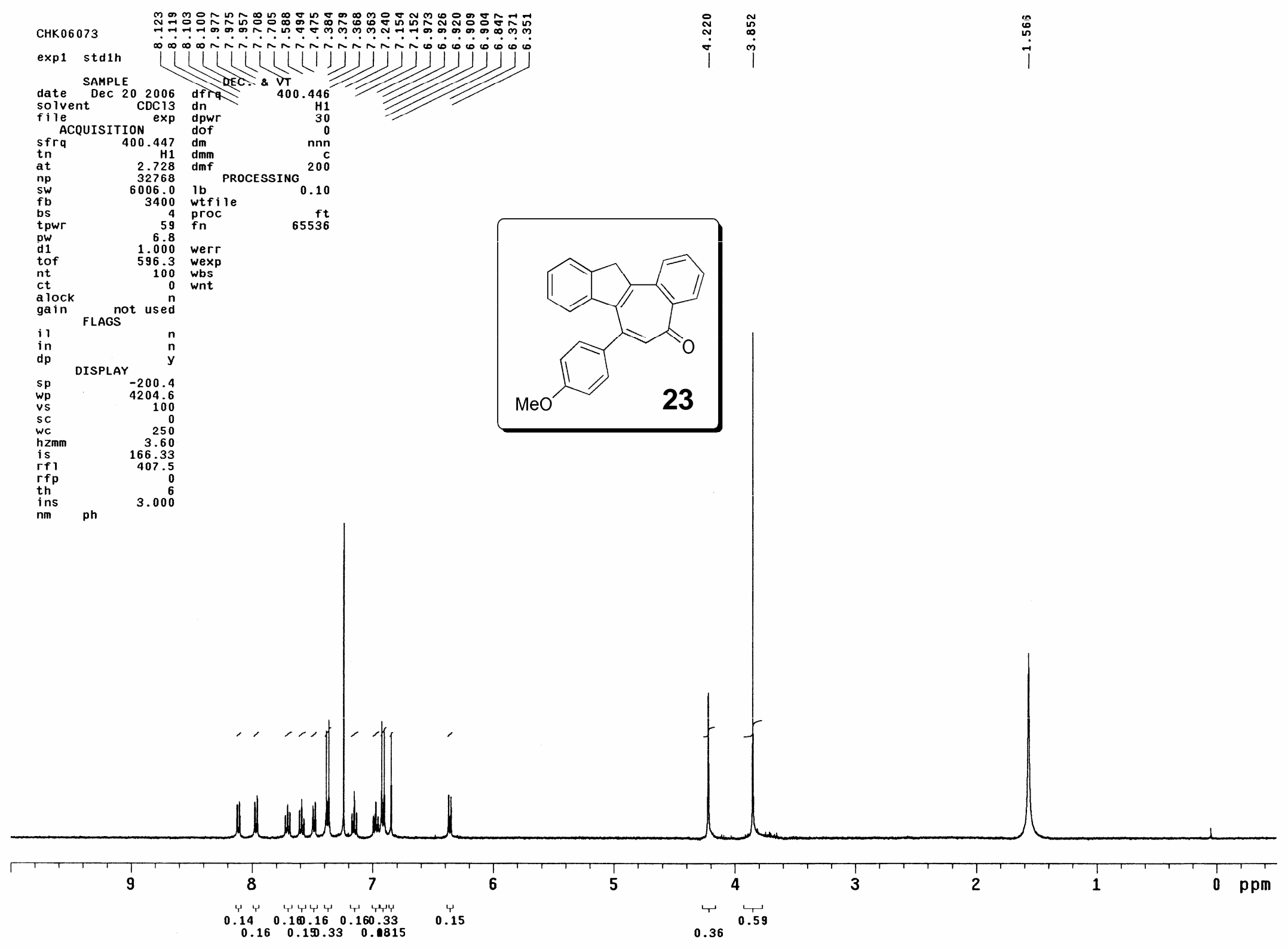



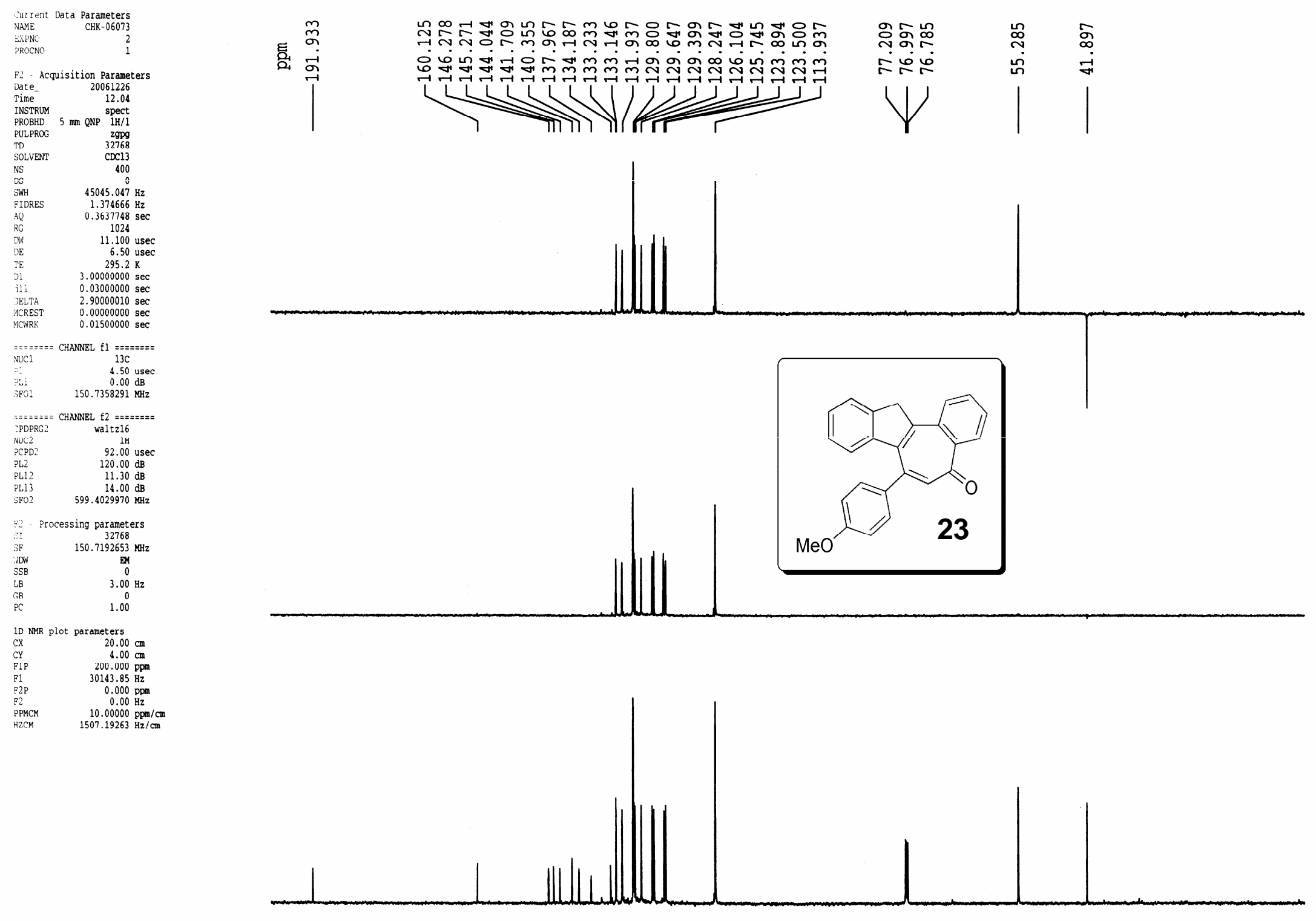

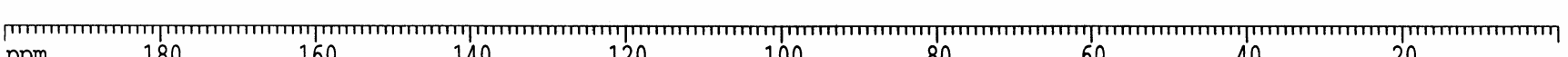
npm 


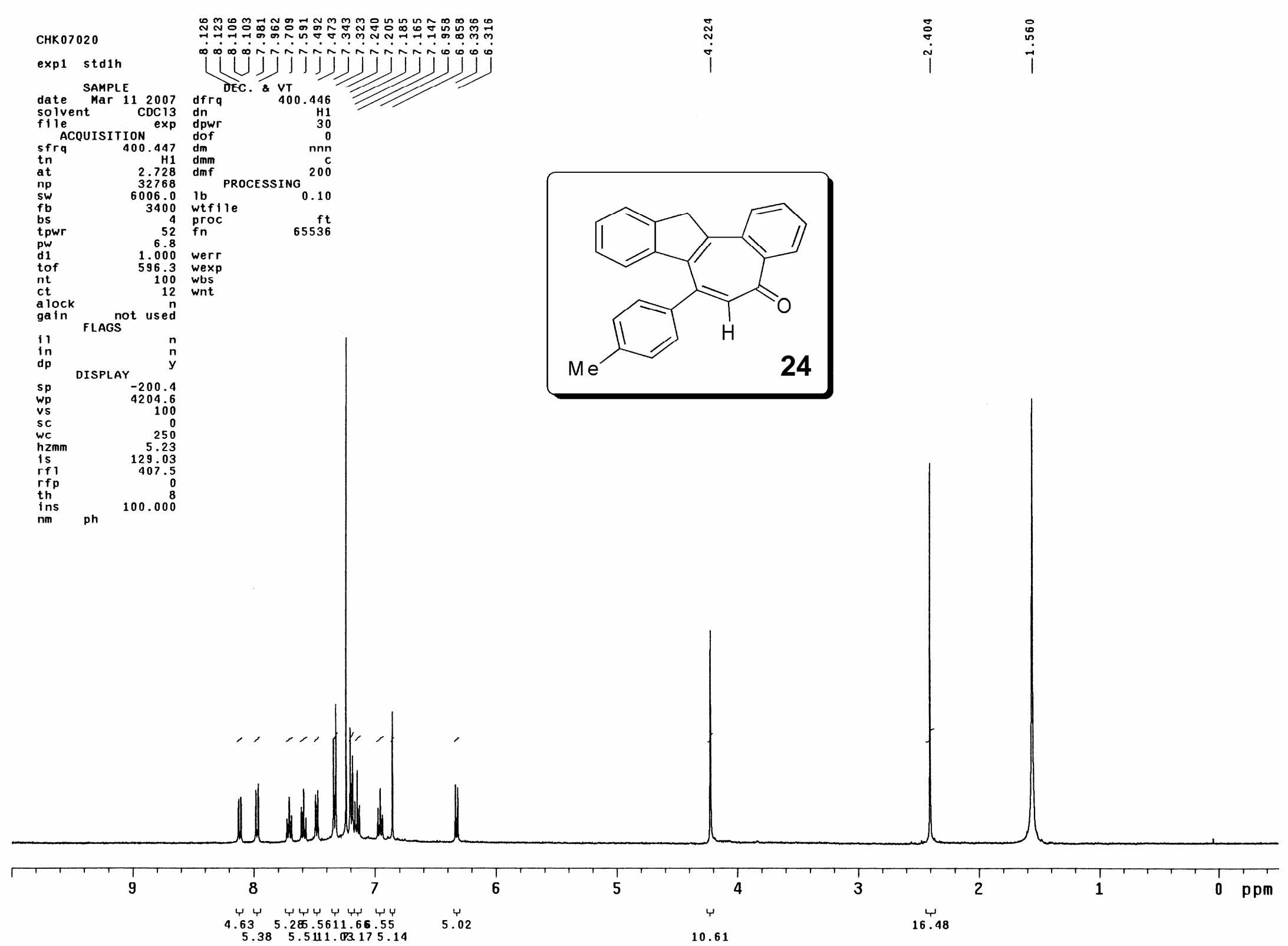



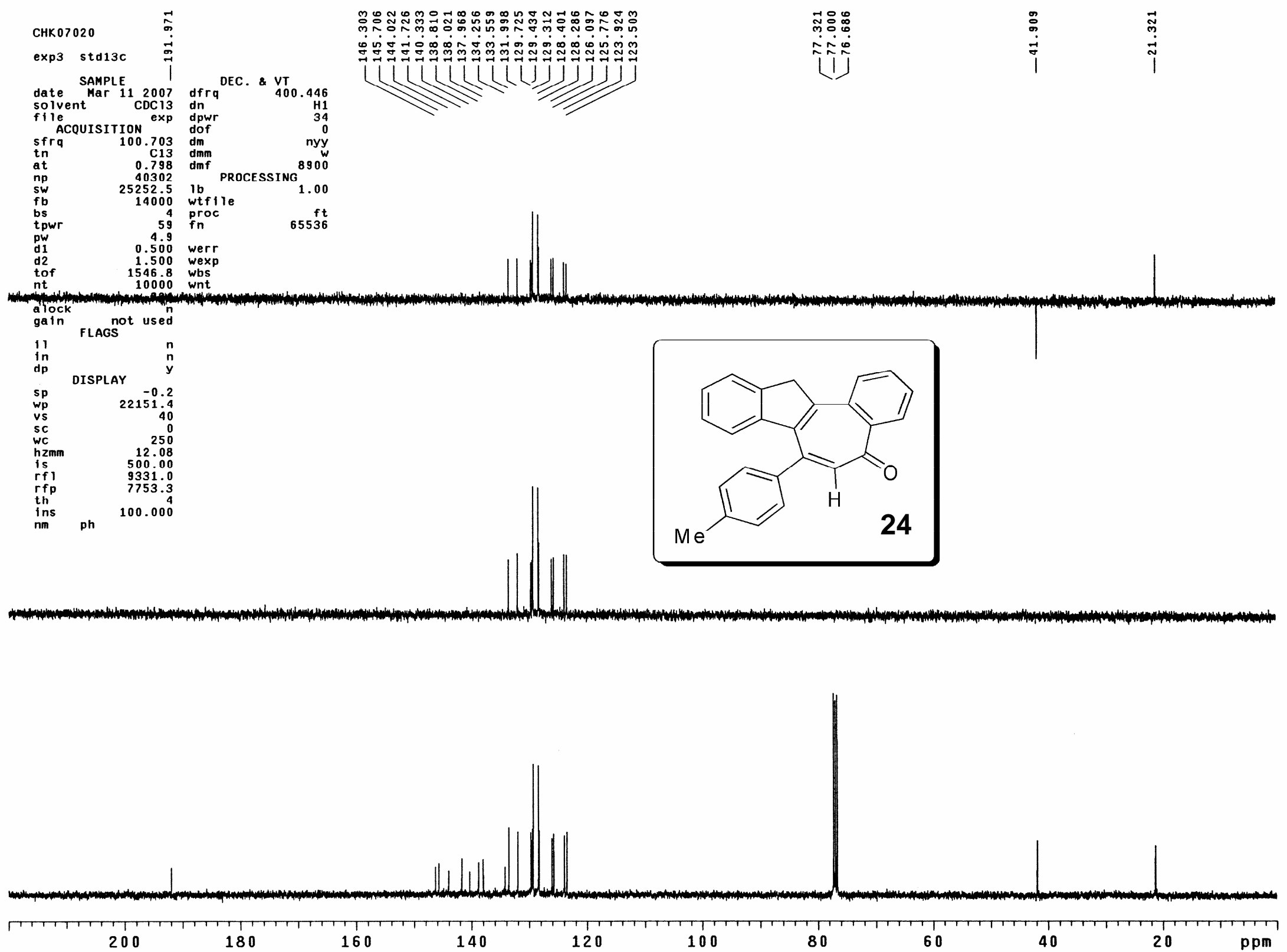


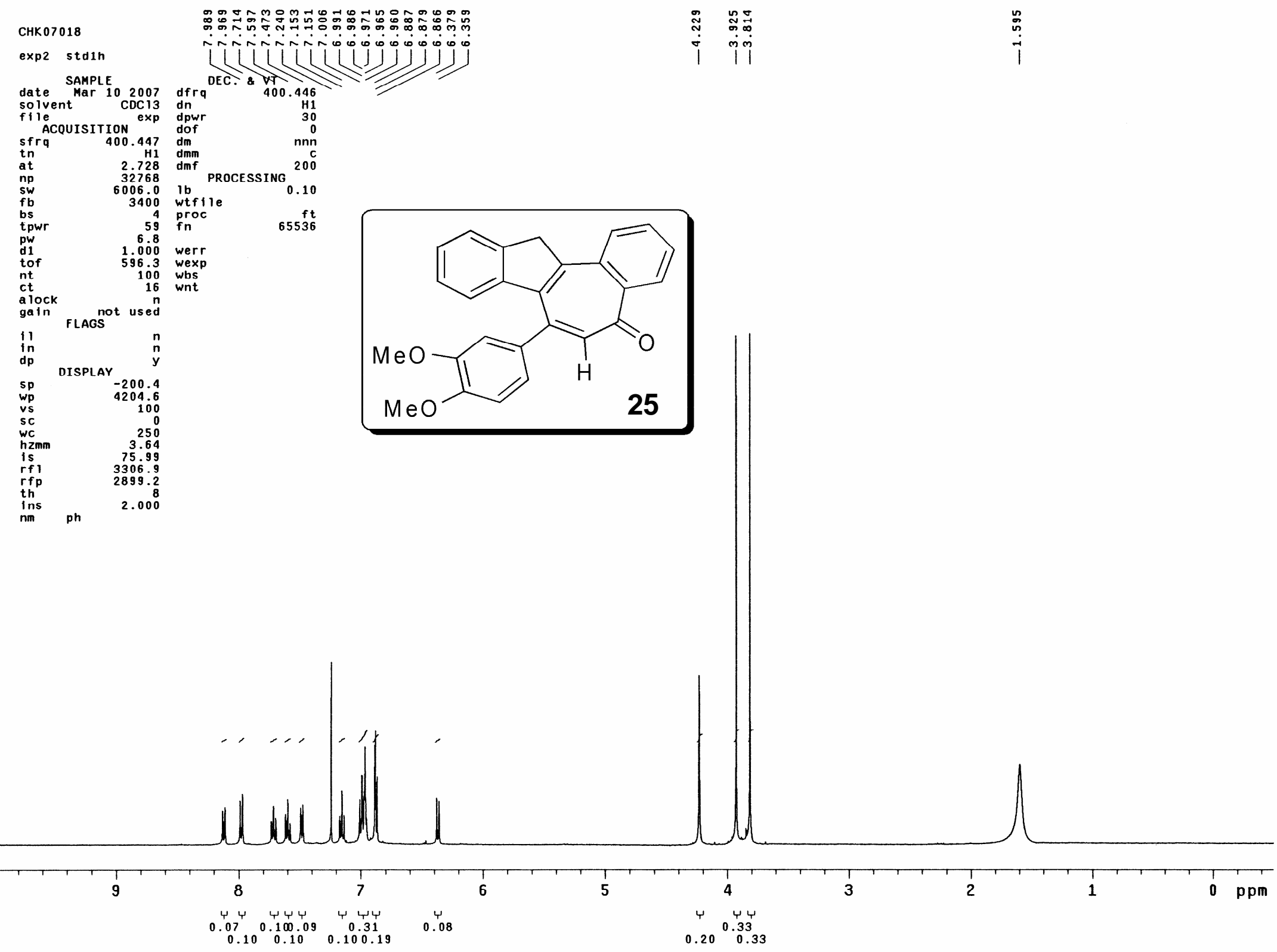




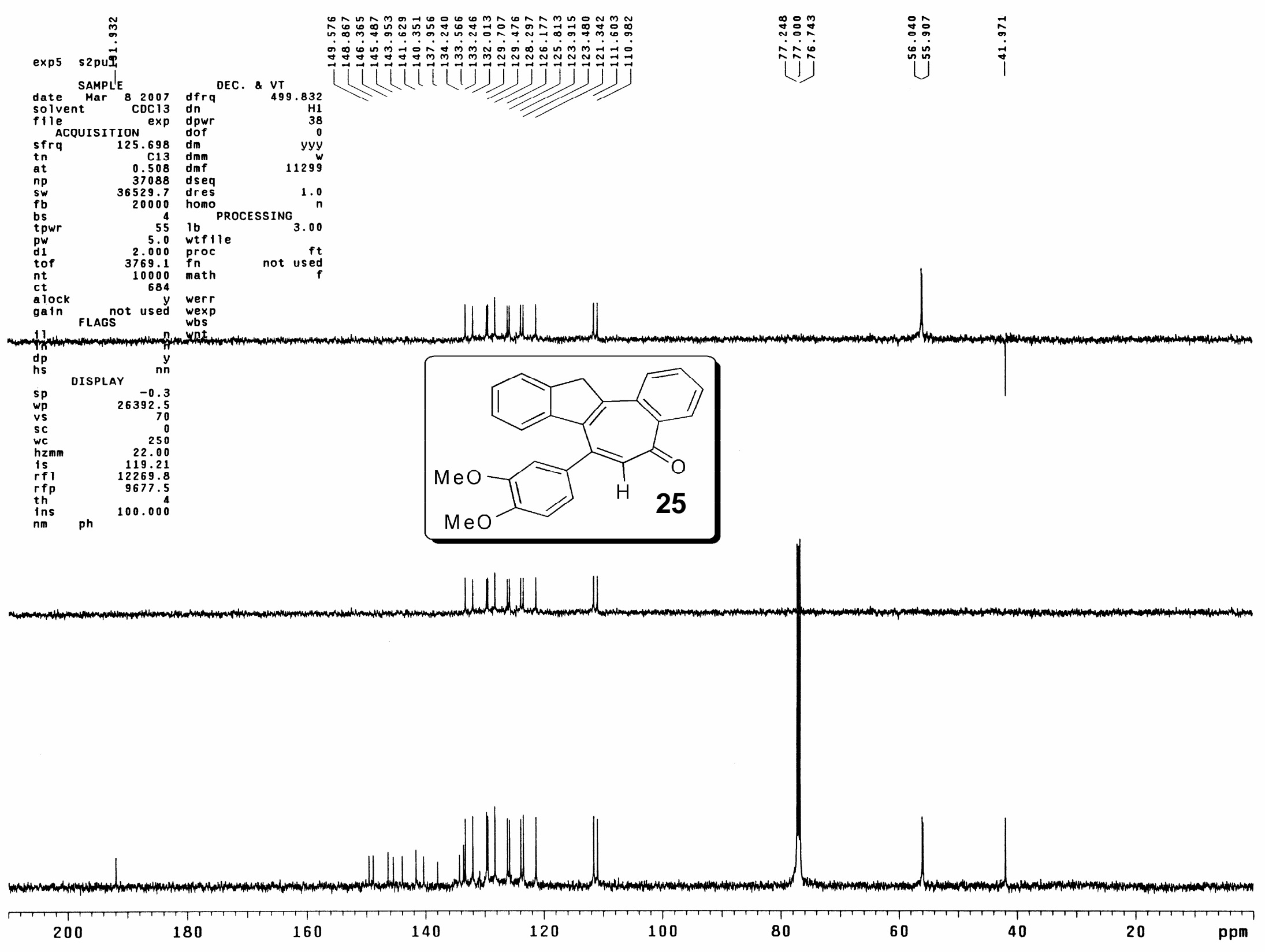




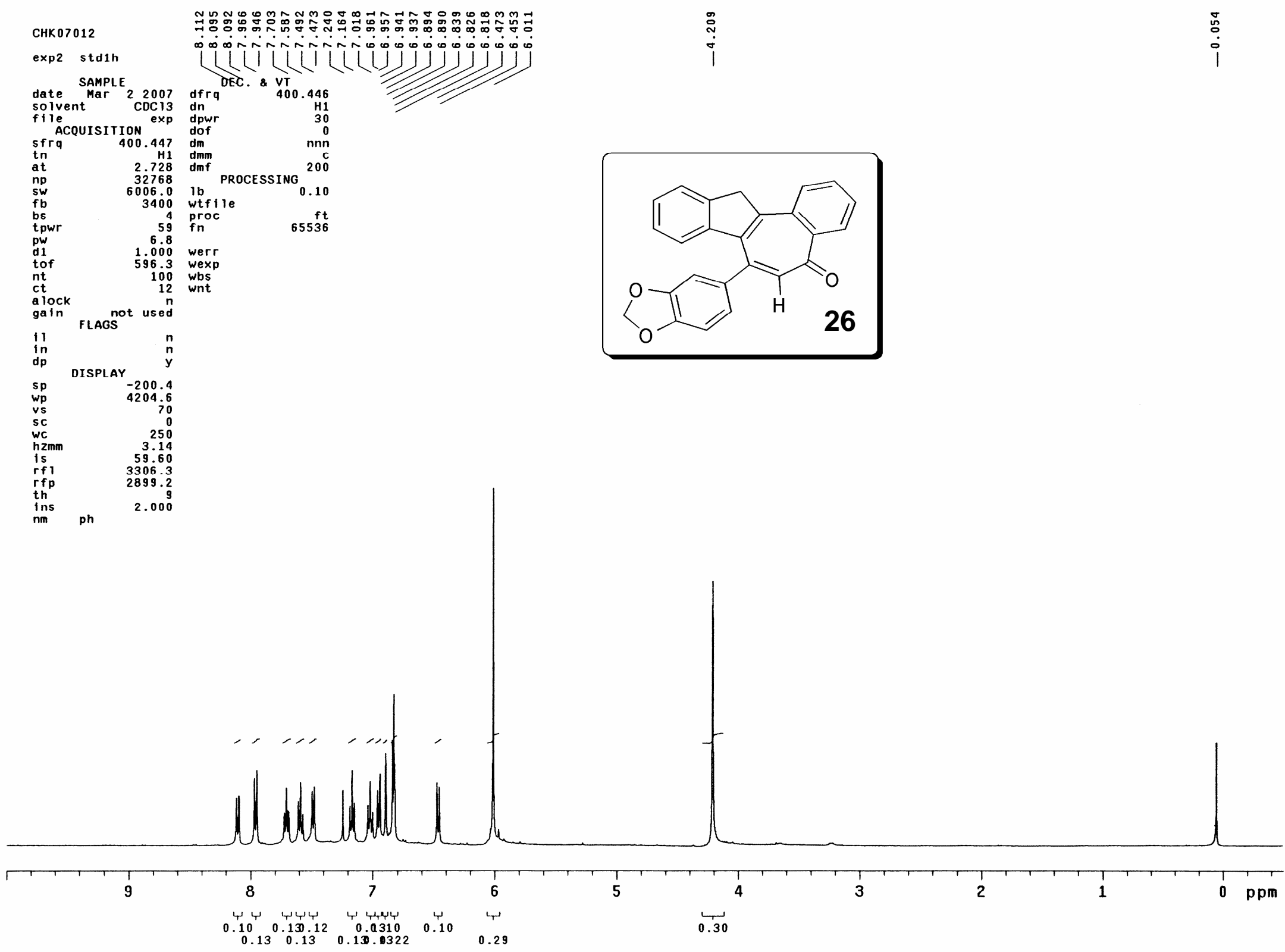




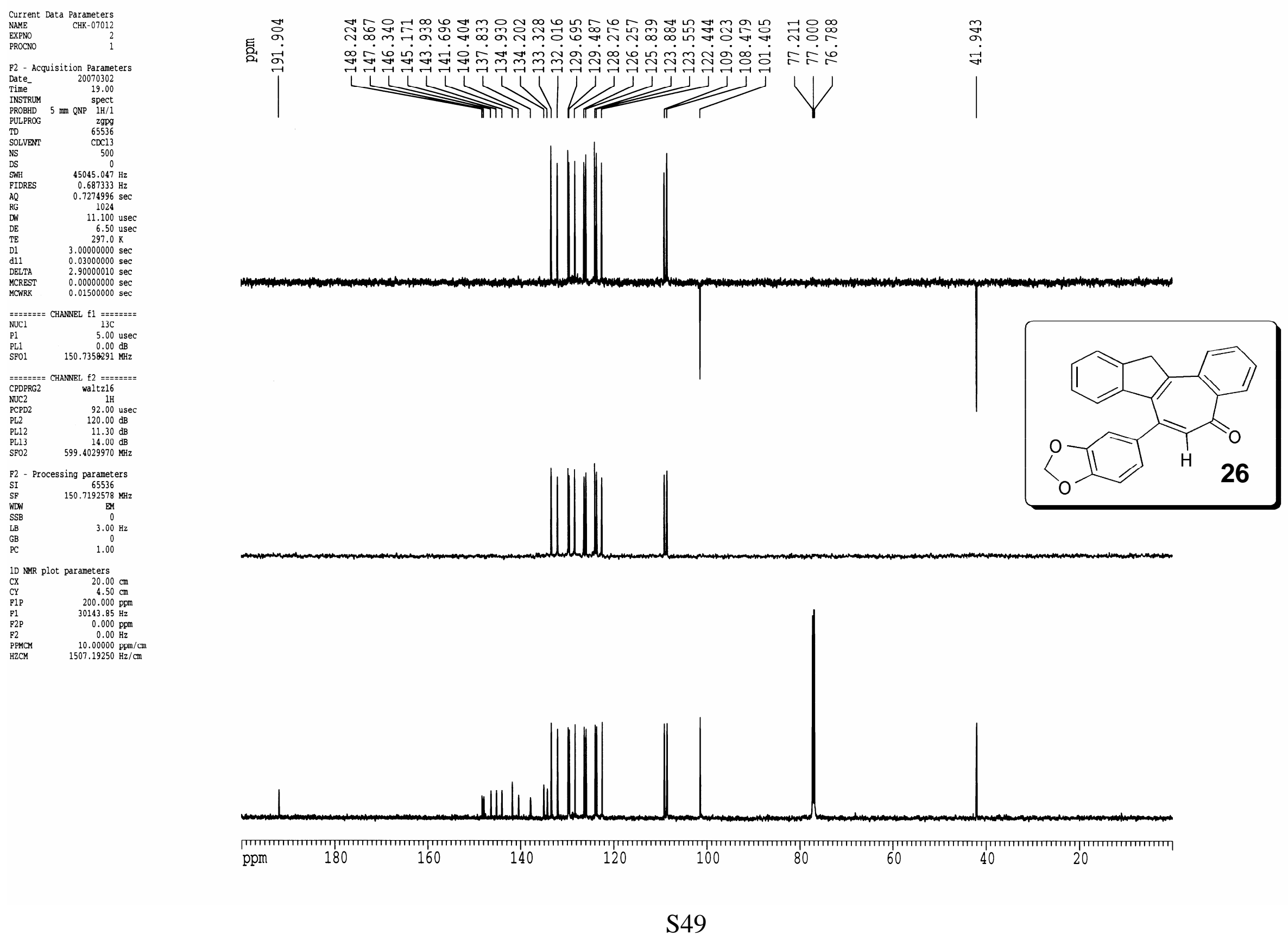




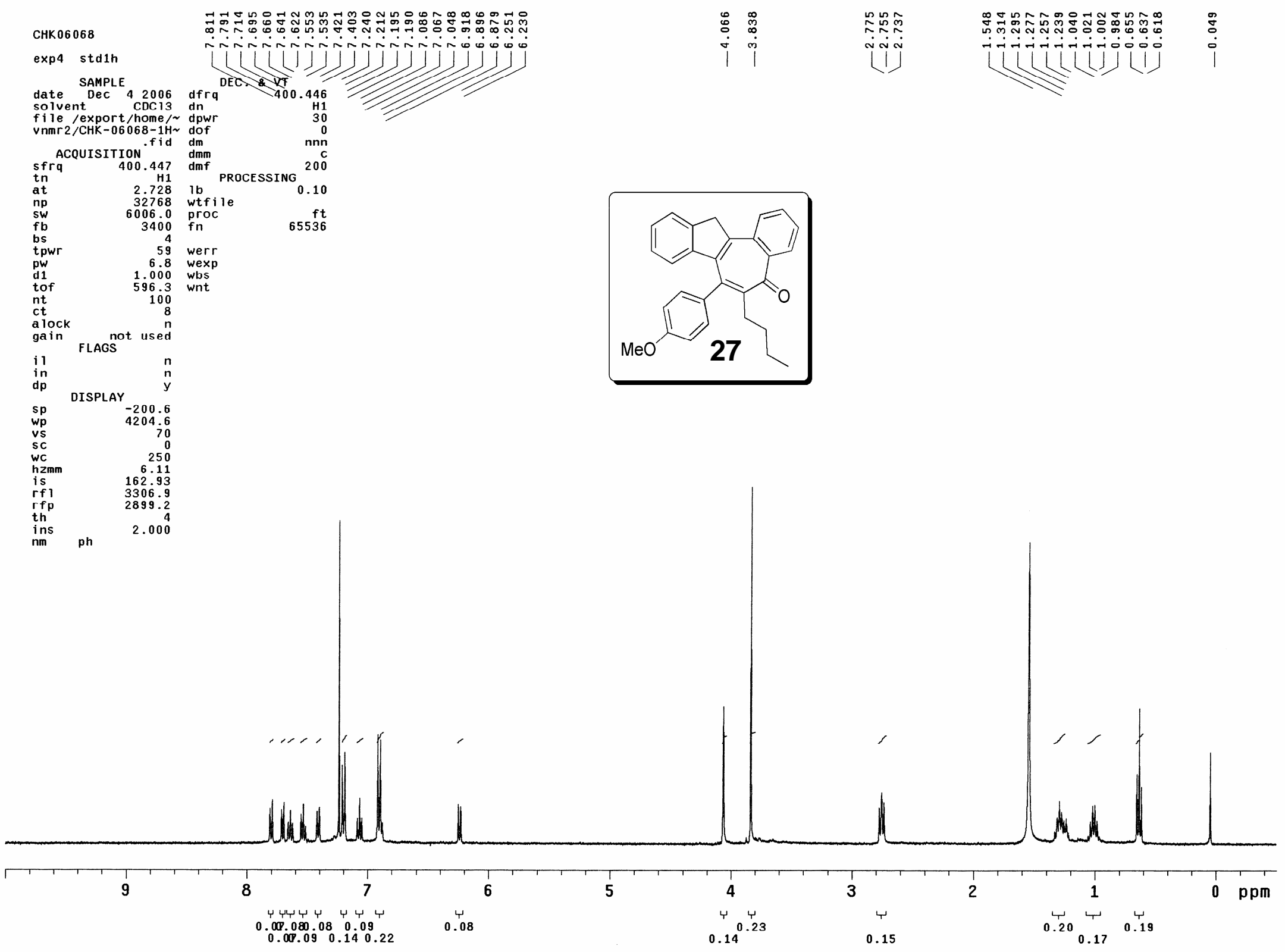




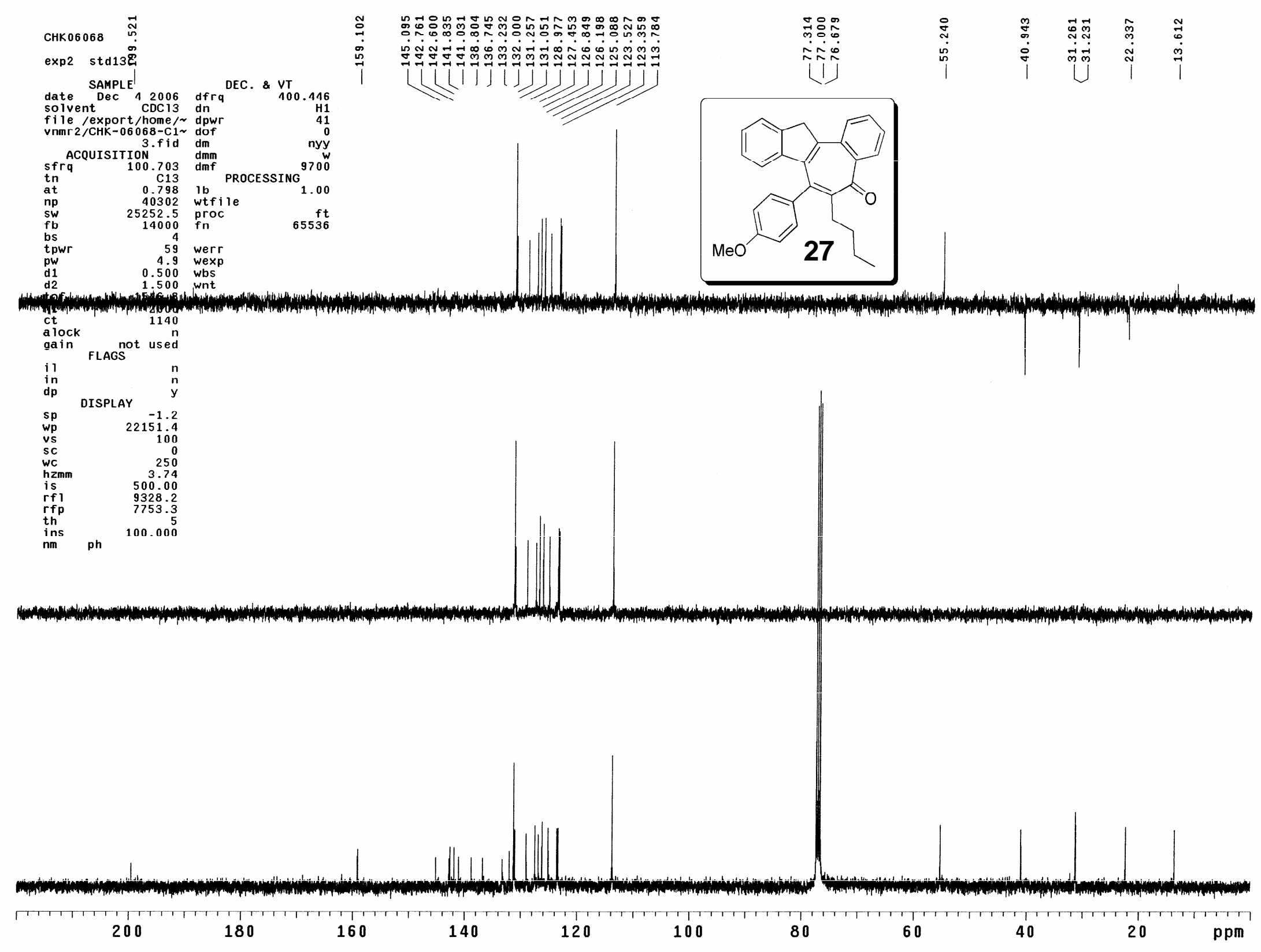




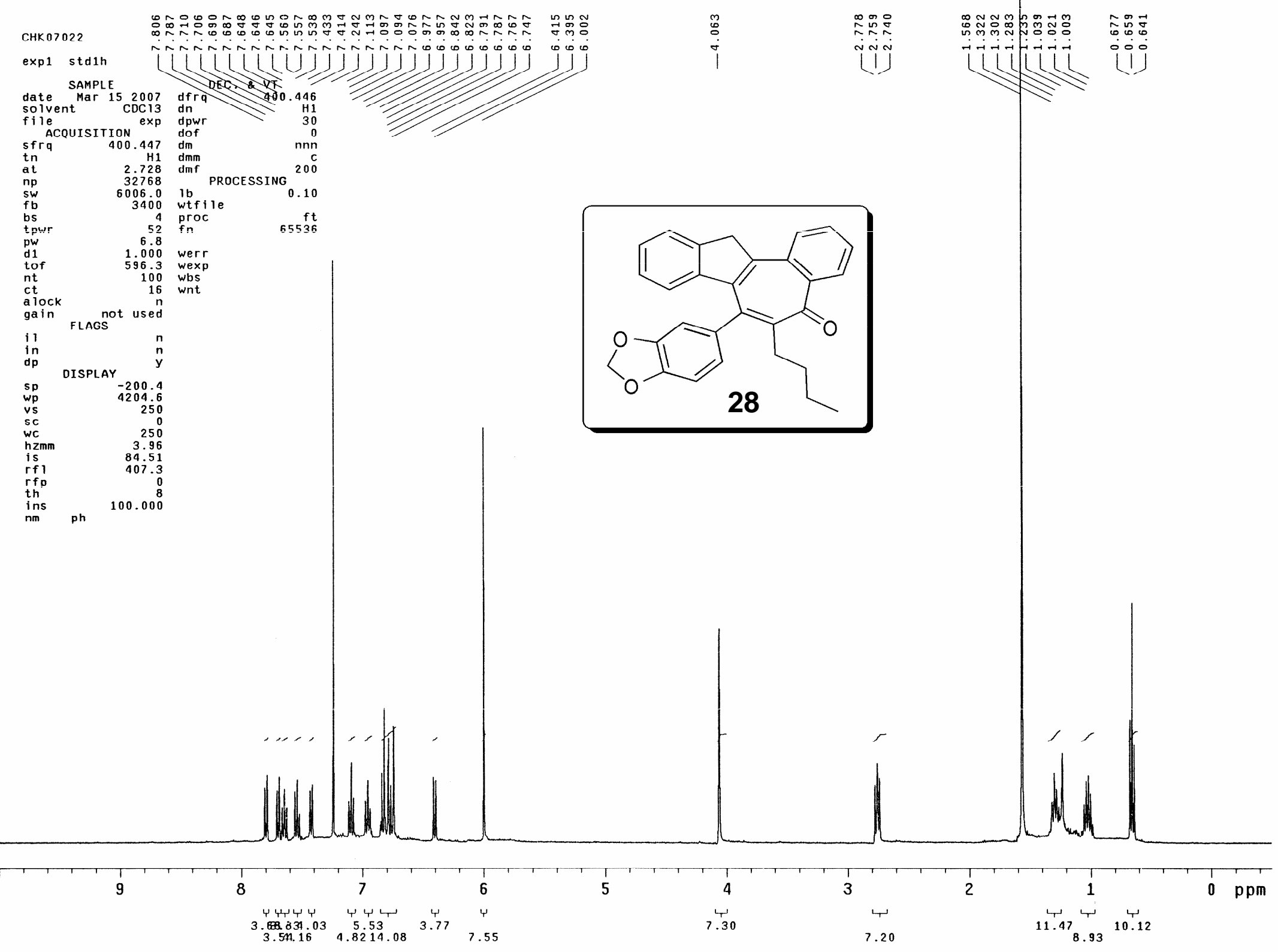




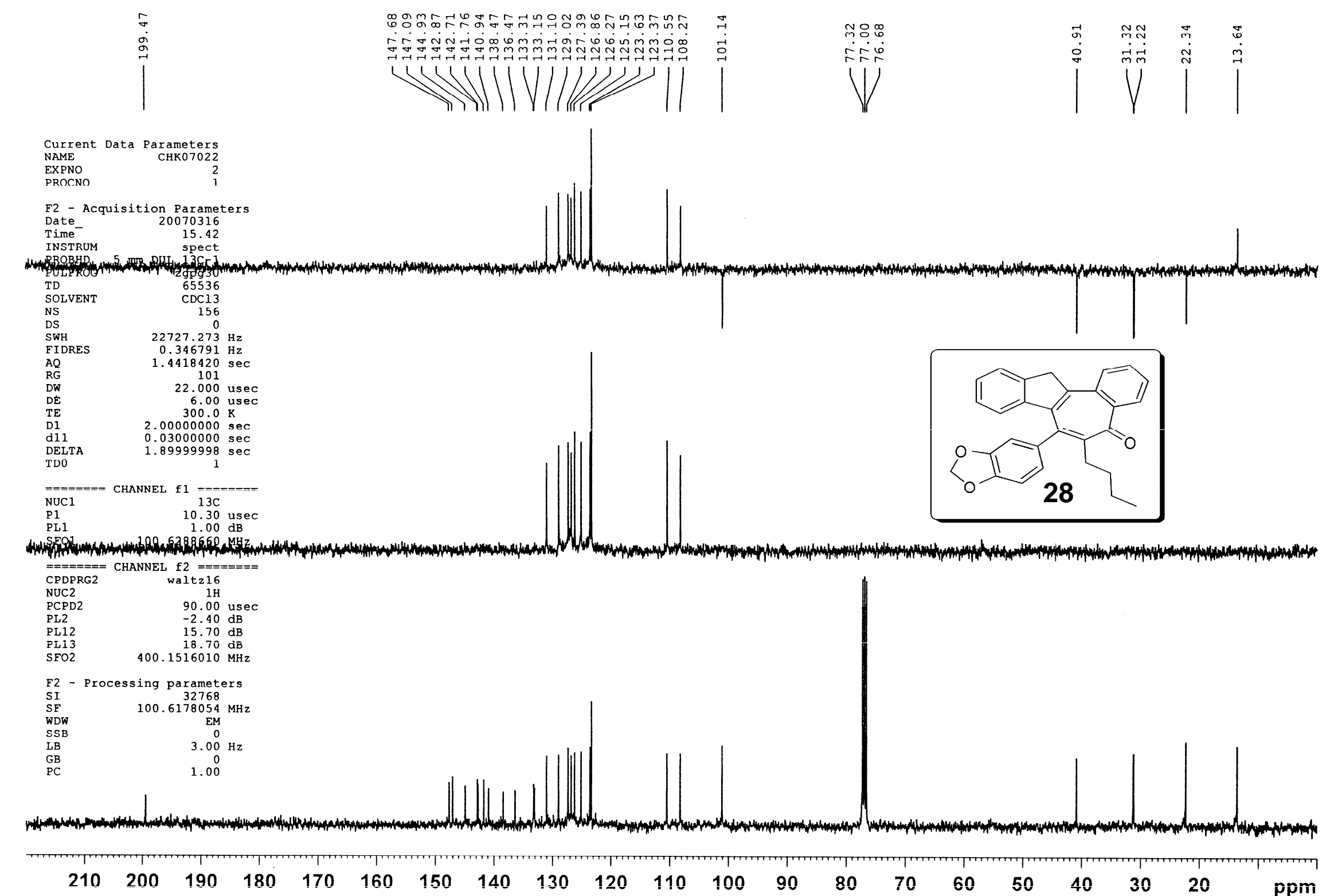




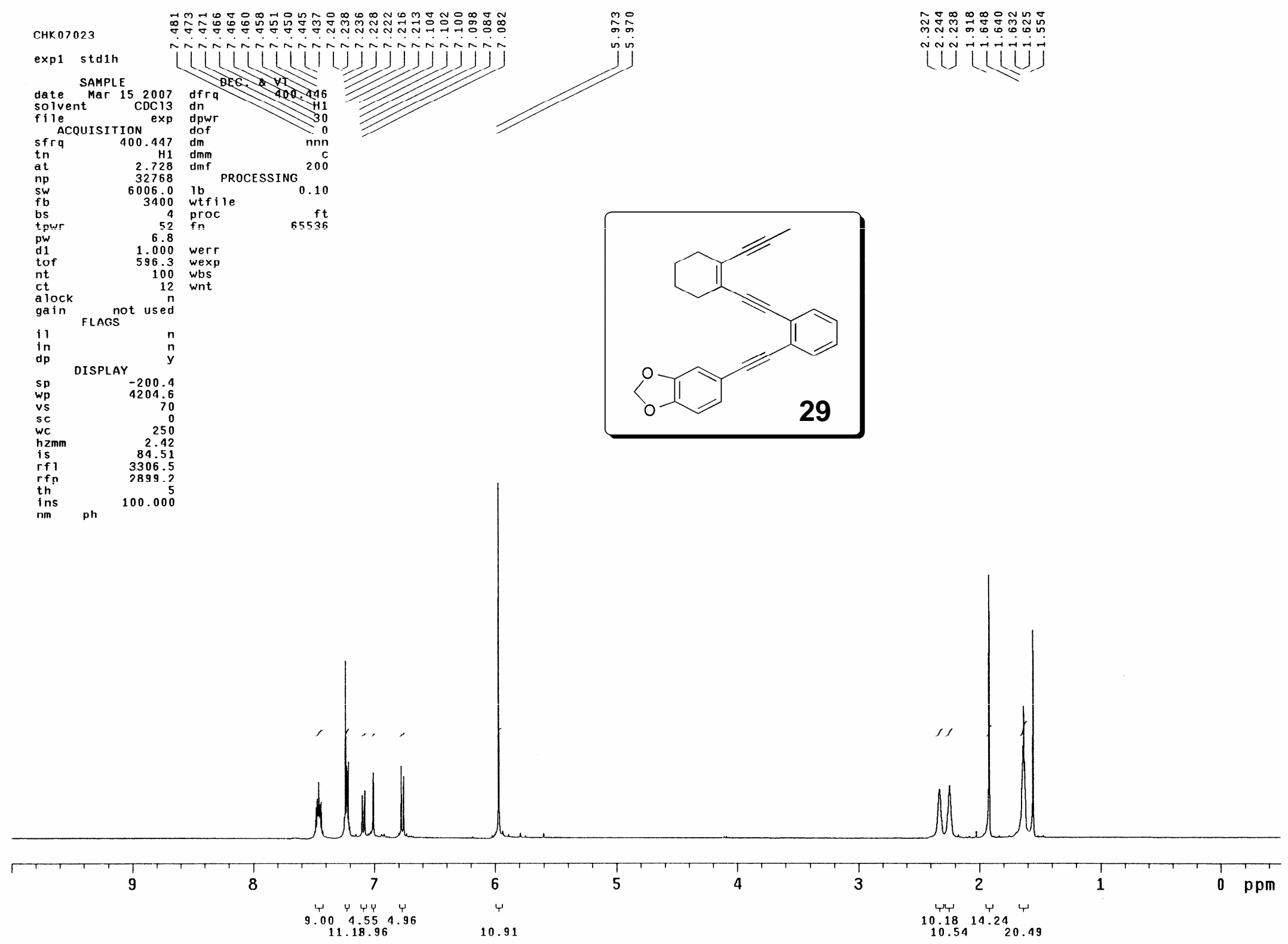



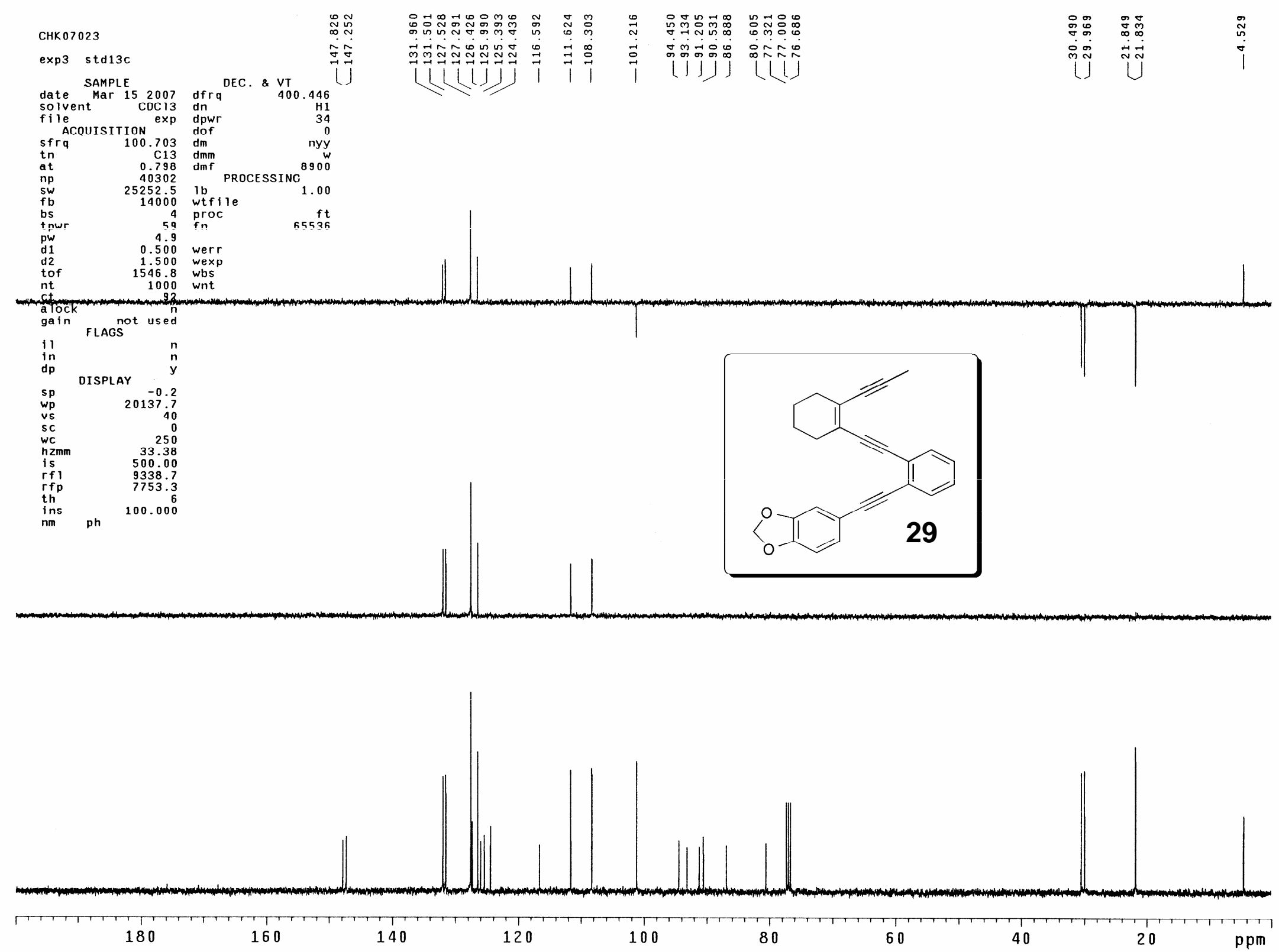


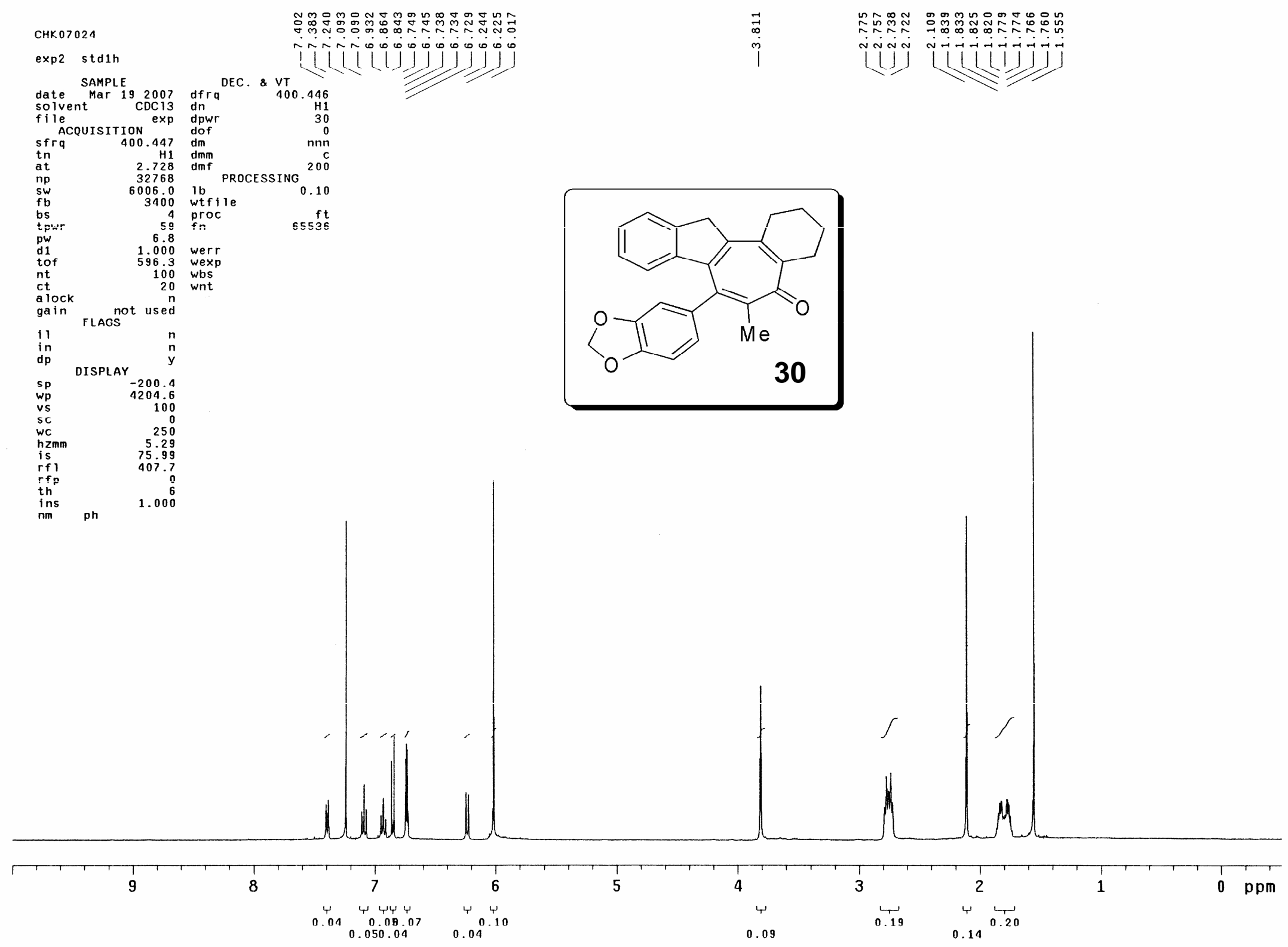



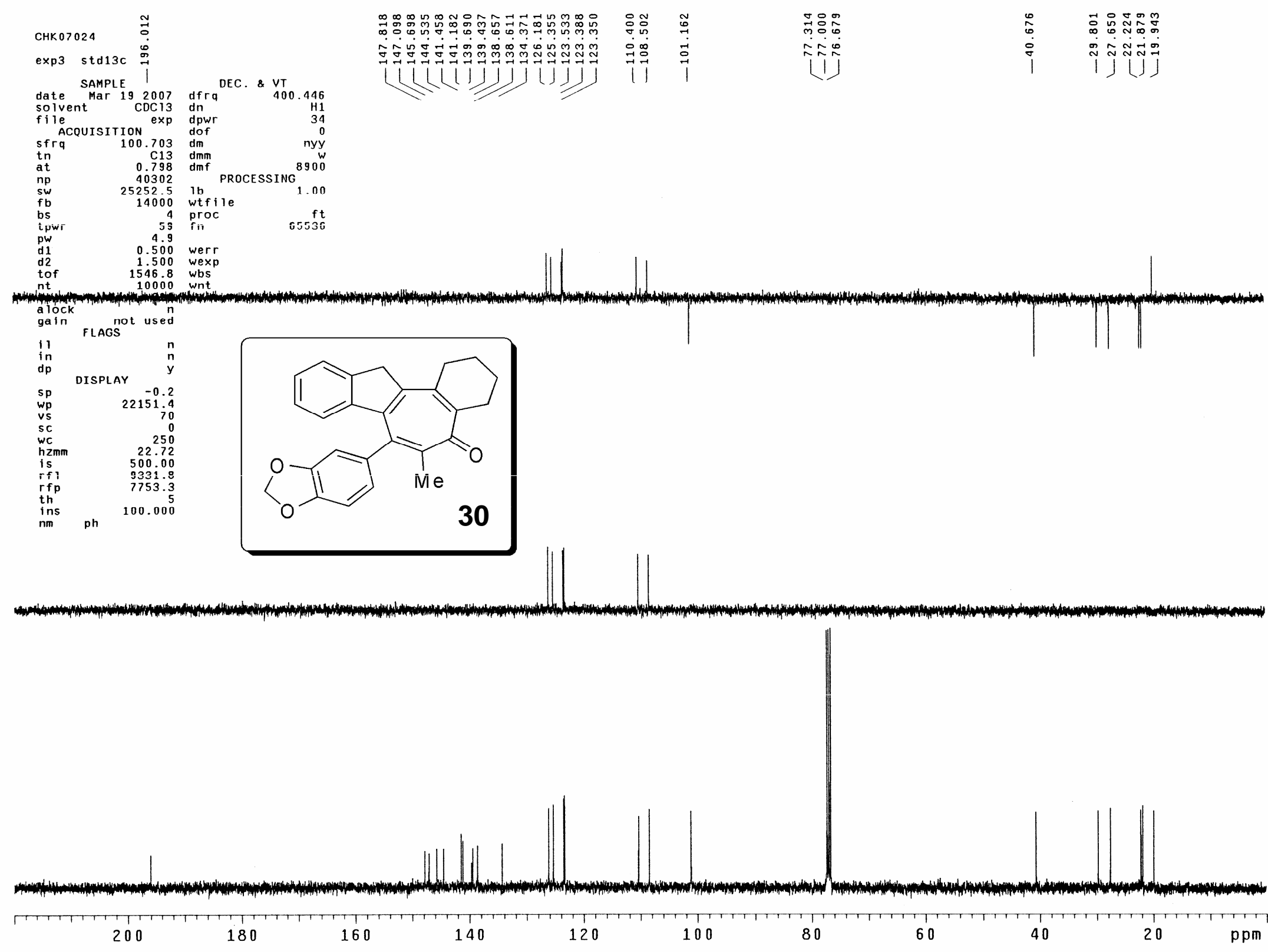


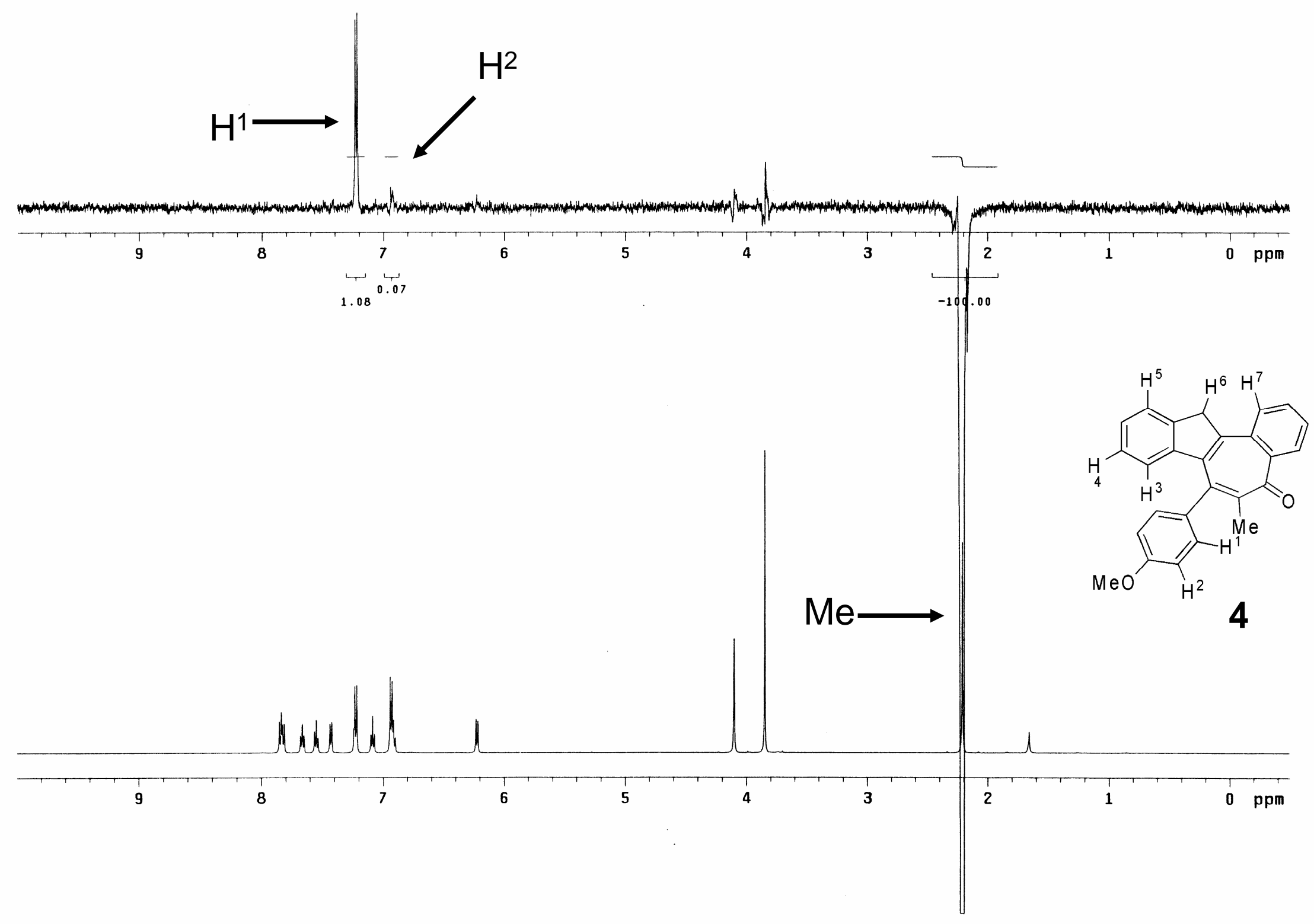




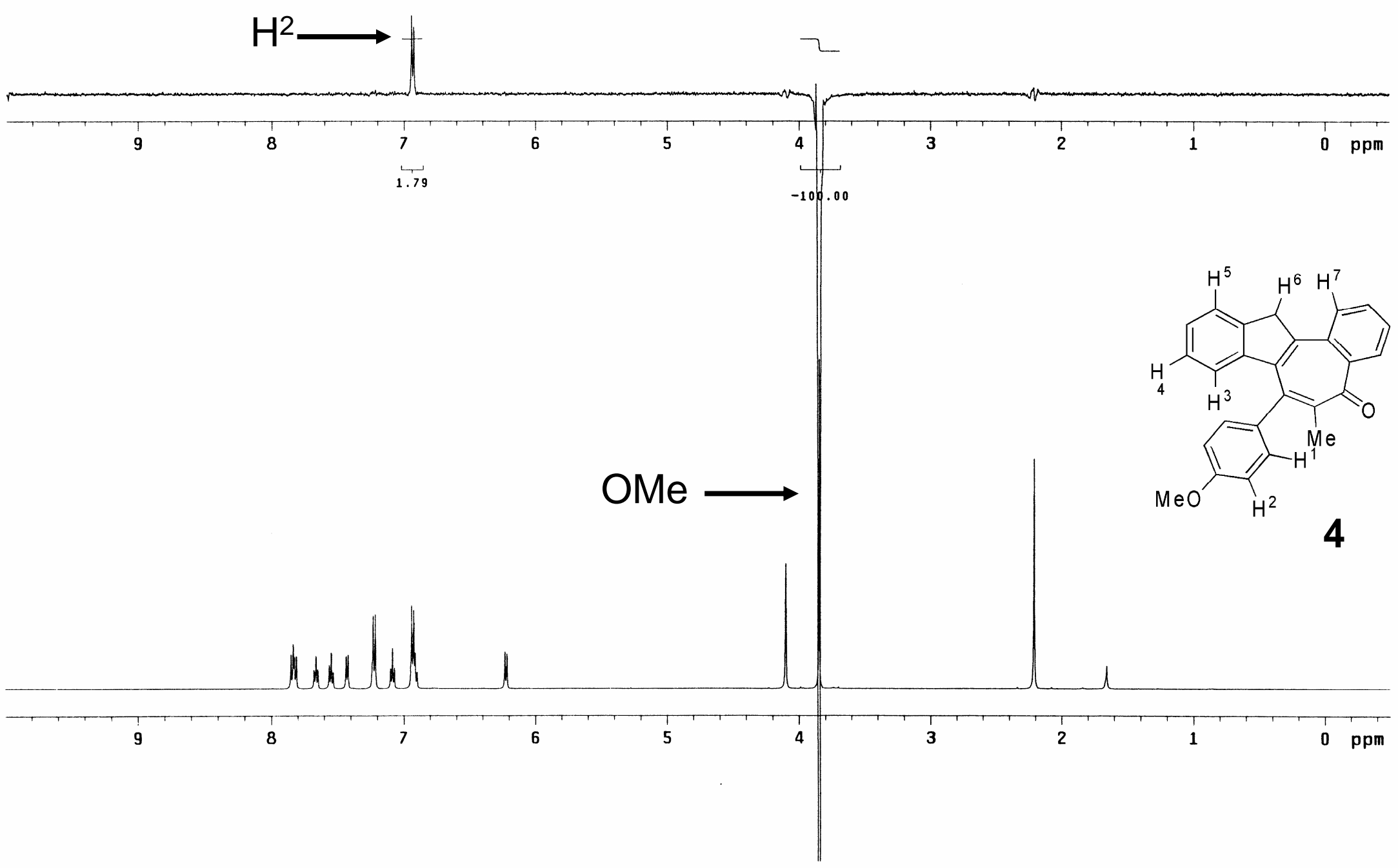




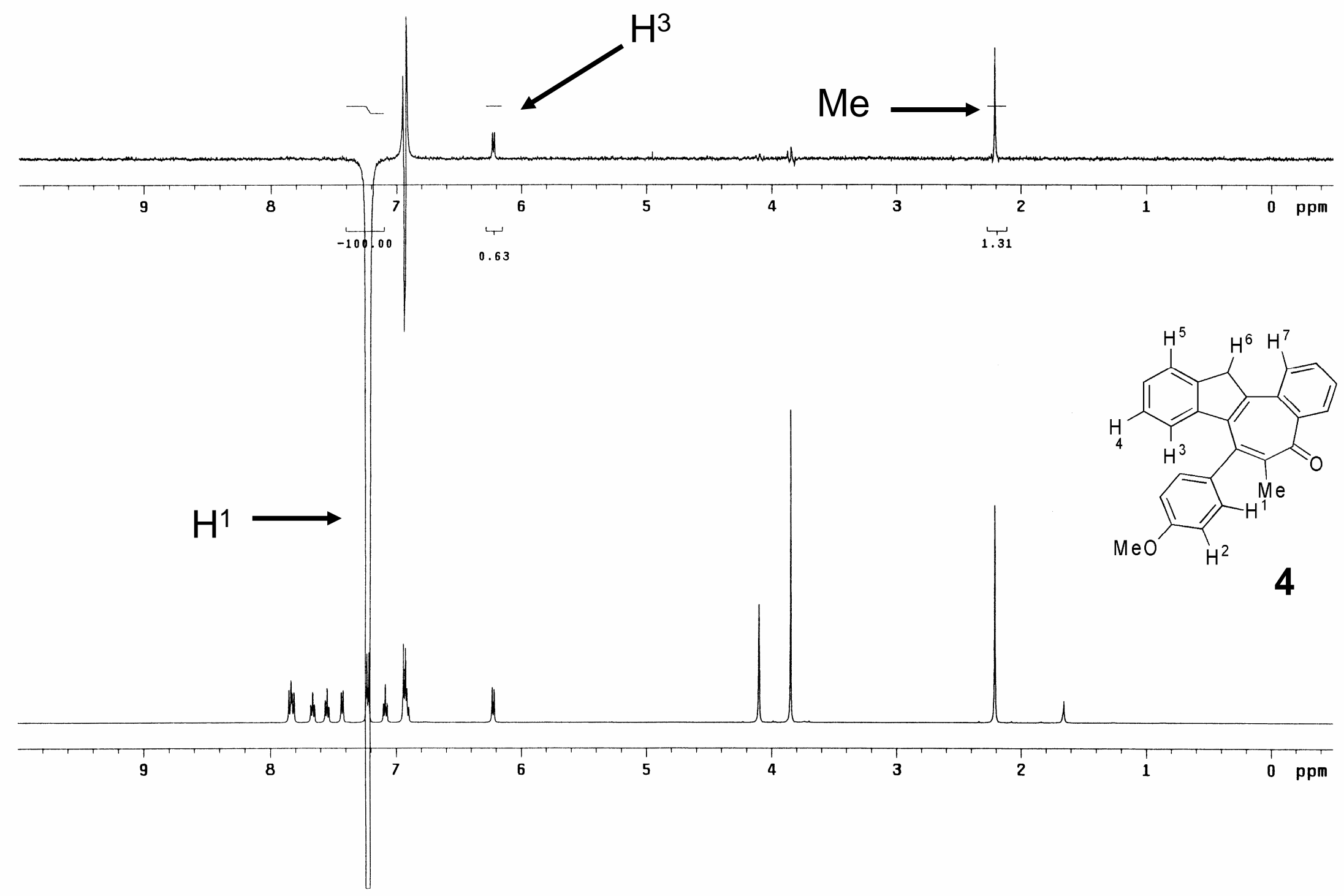




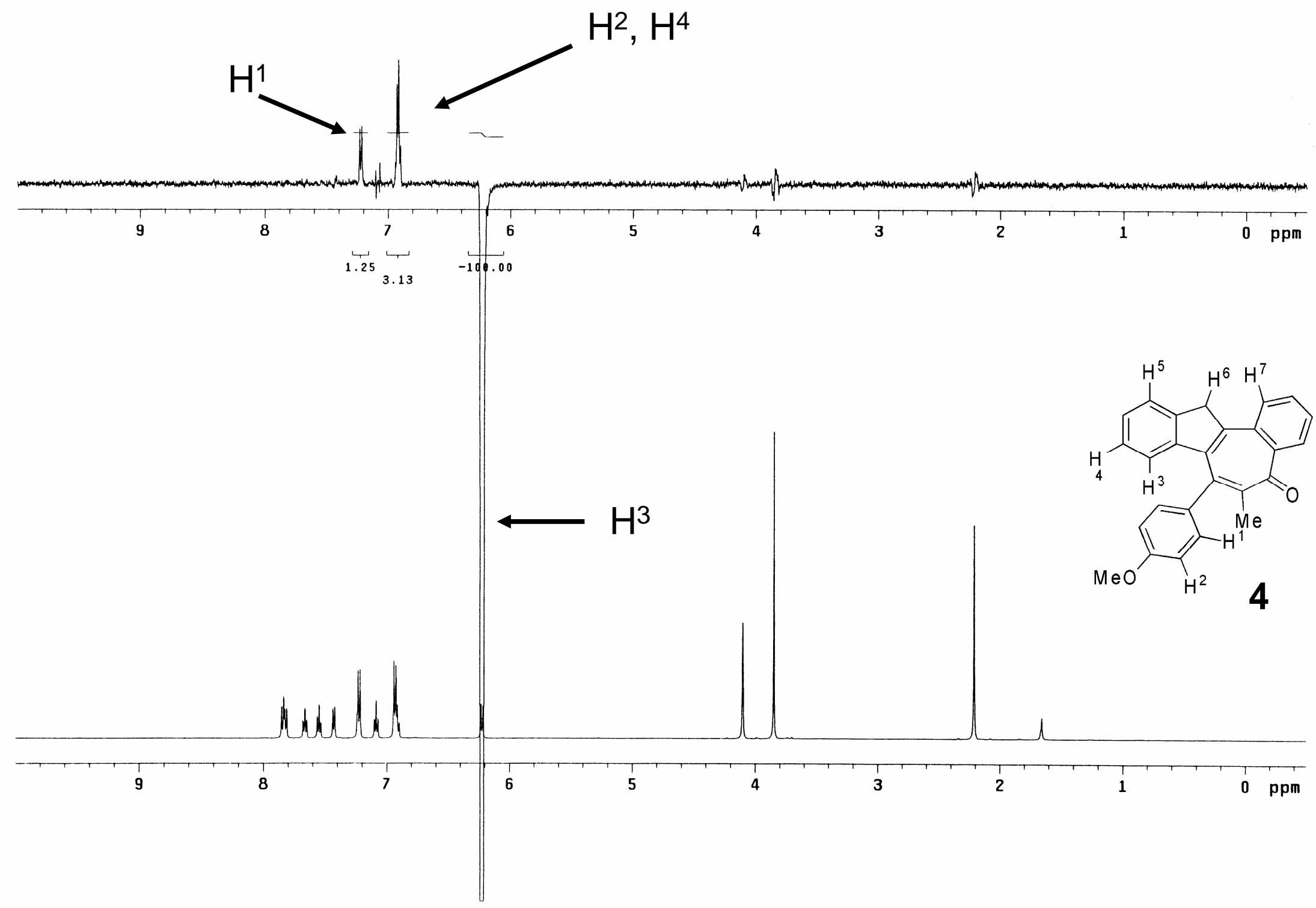




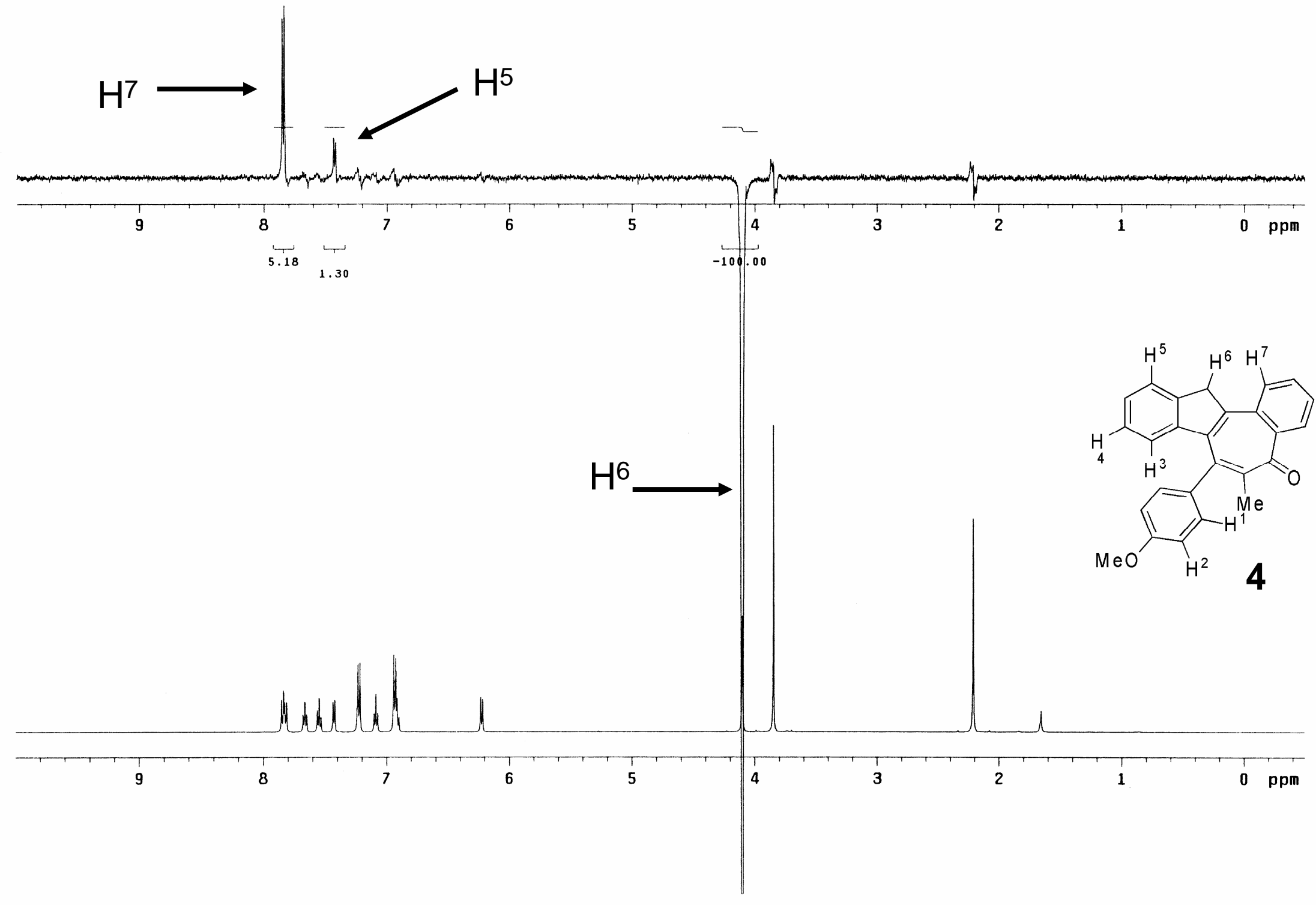




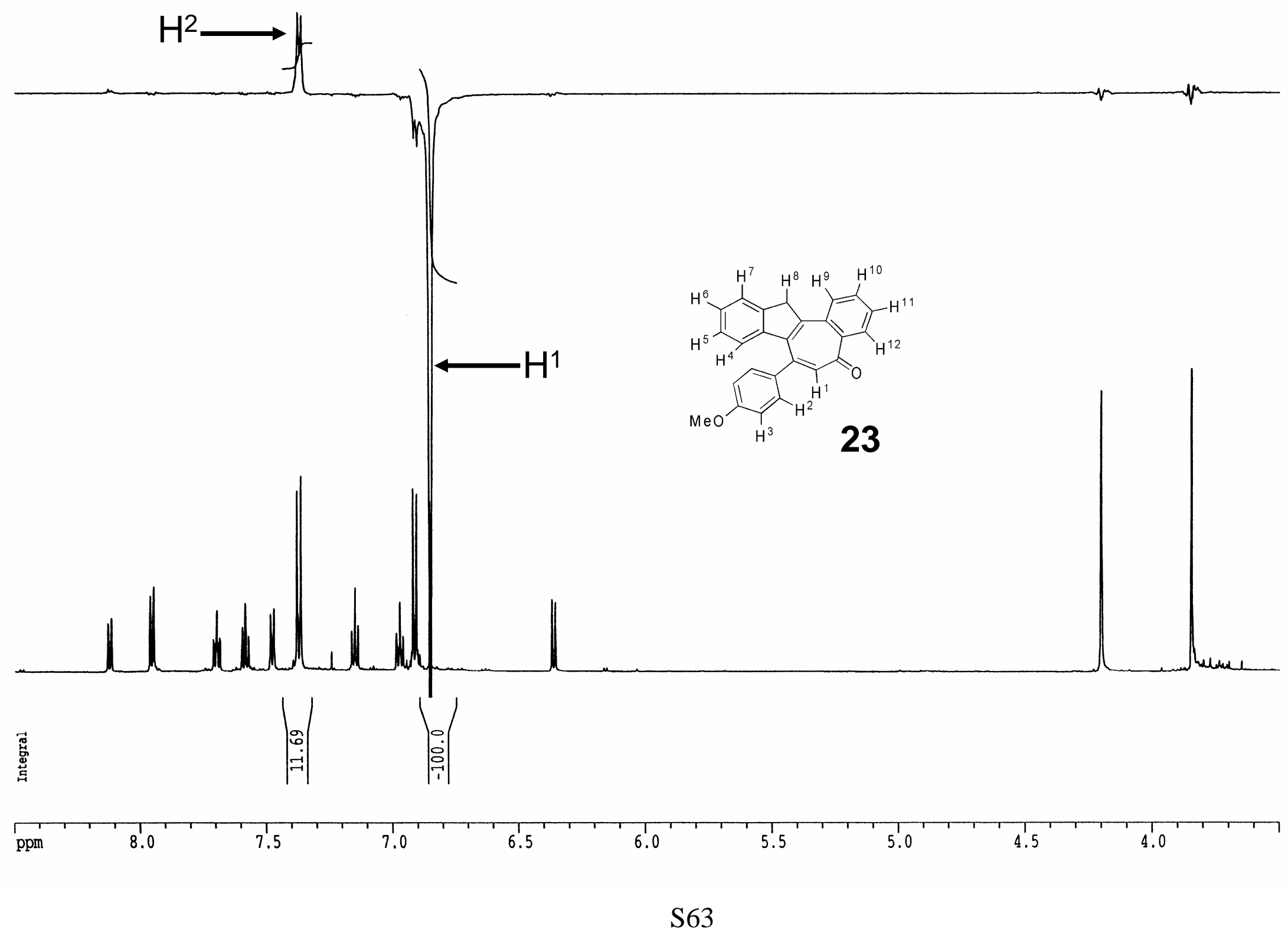




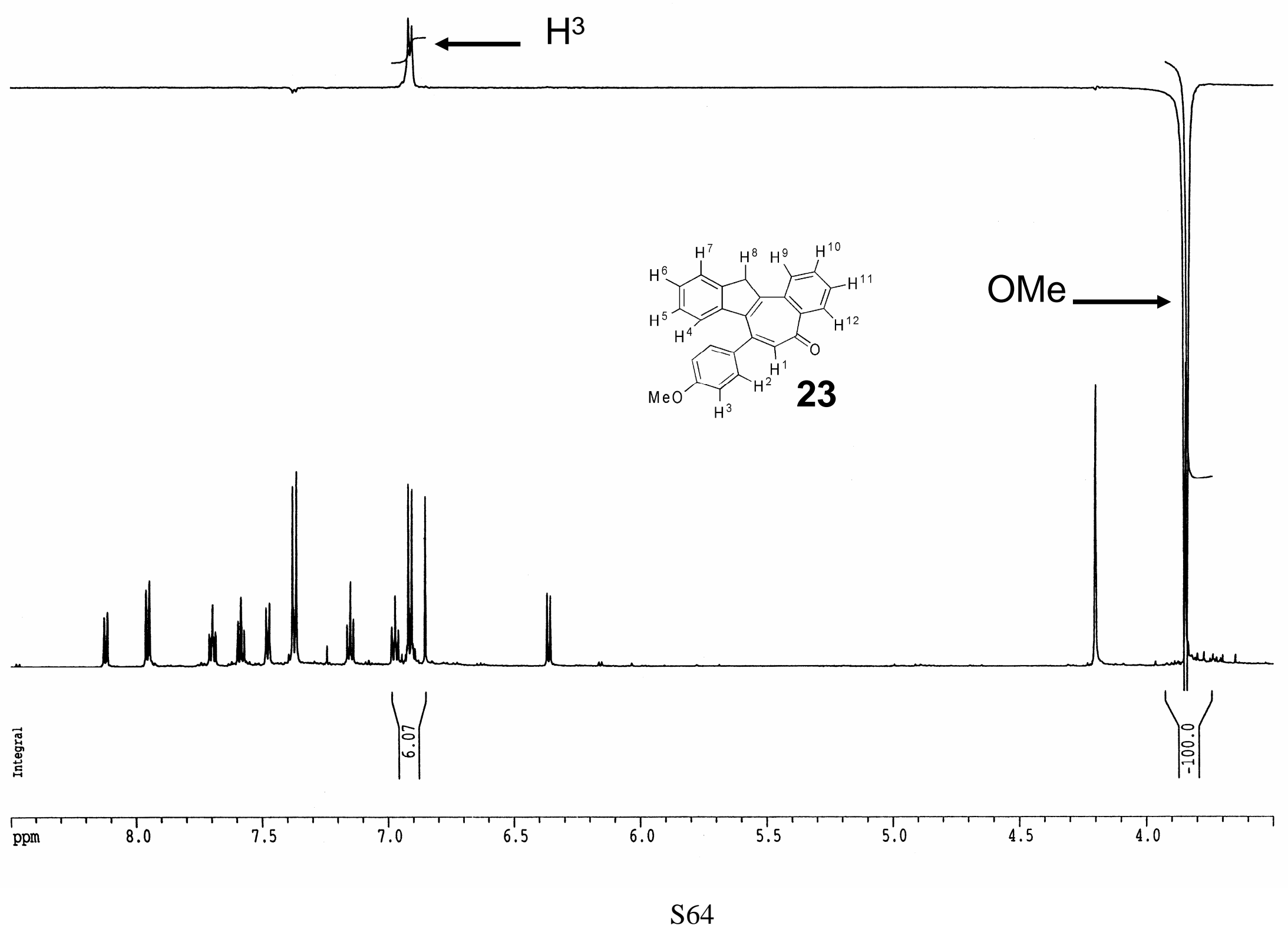




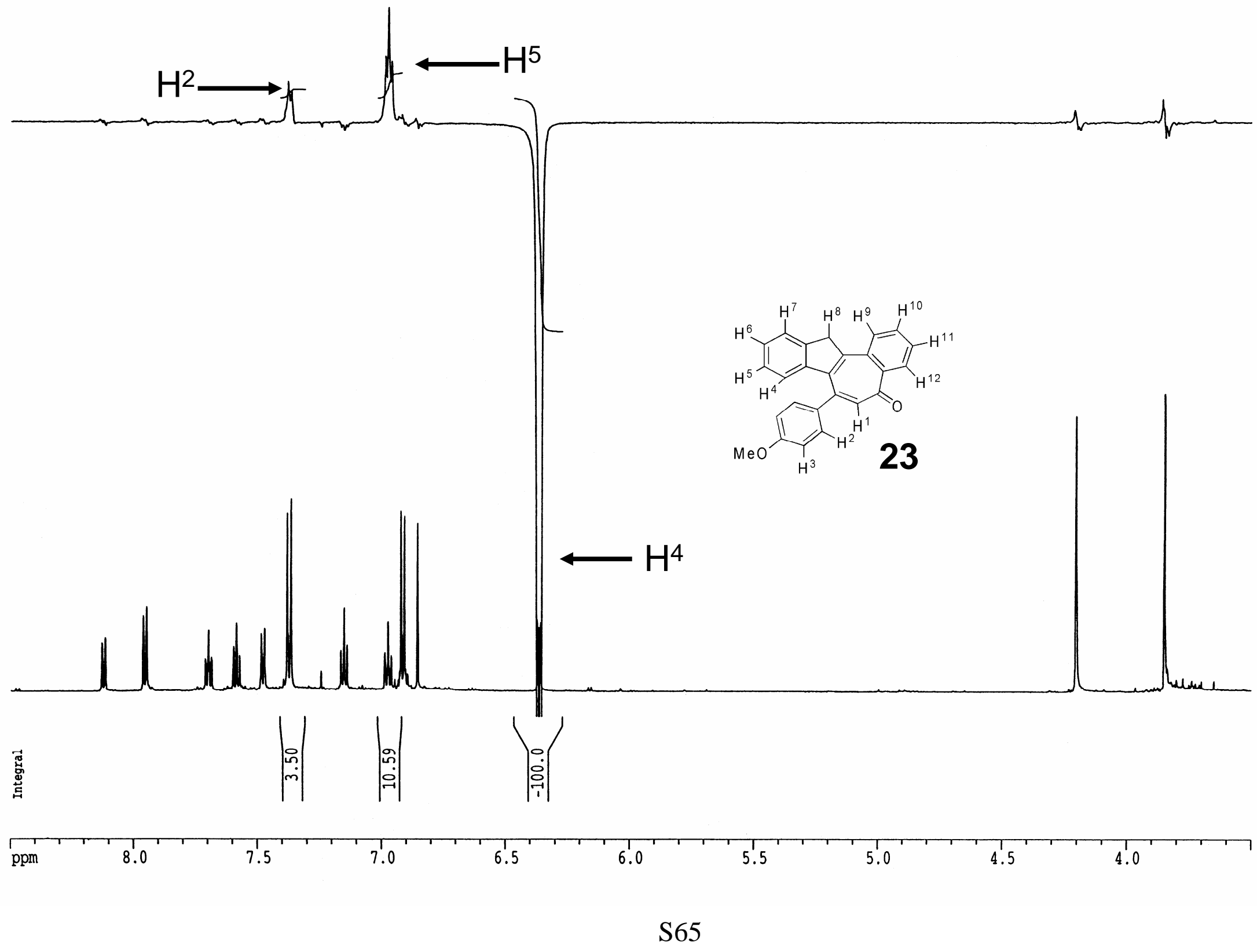




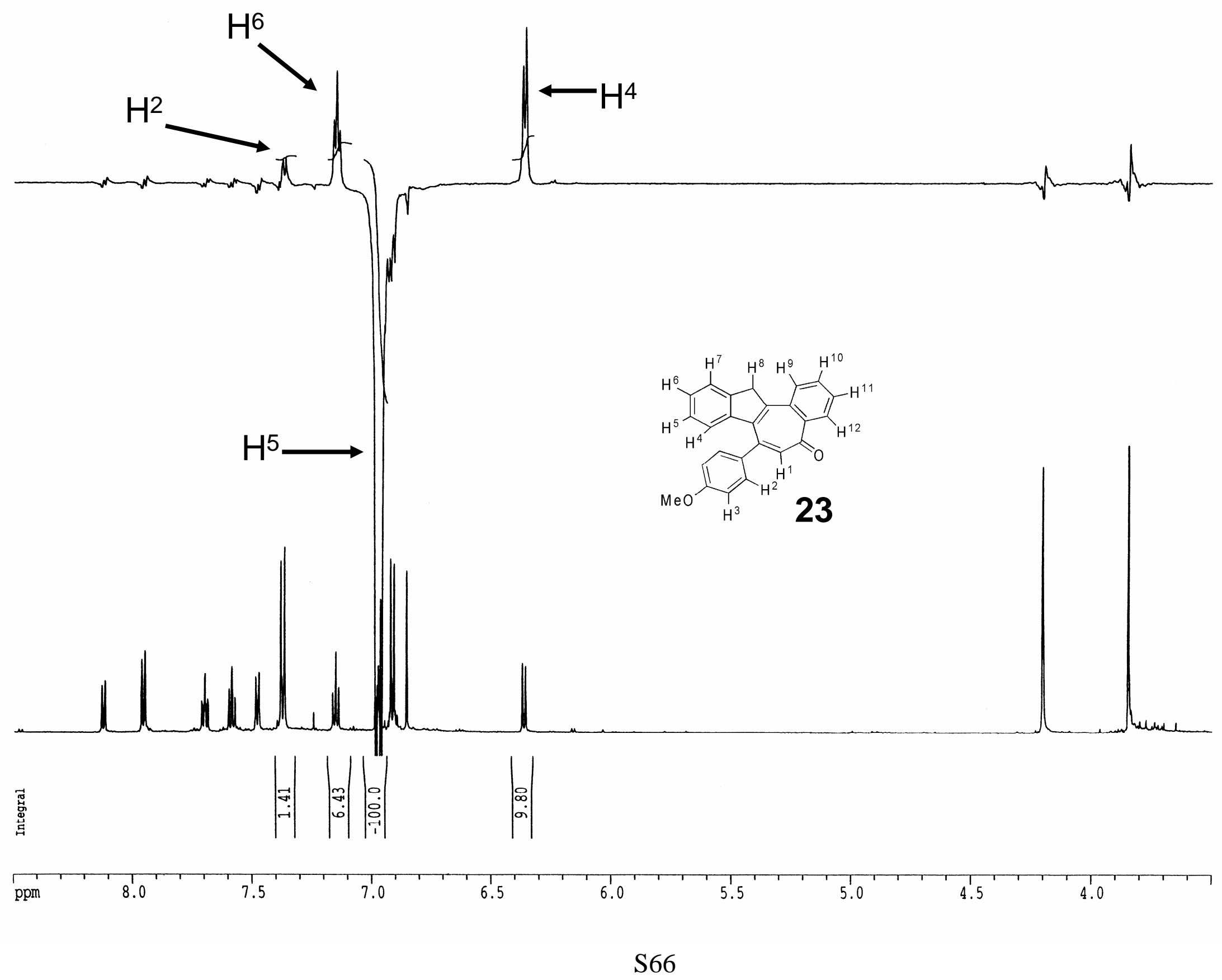




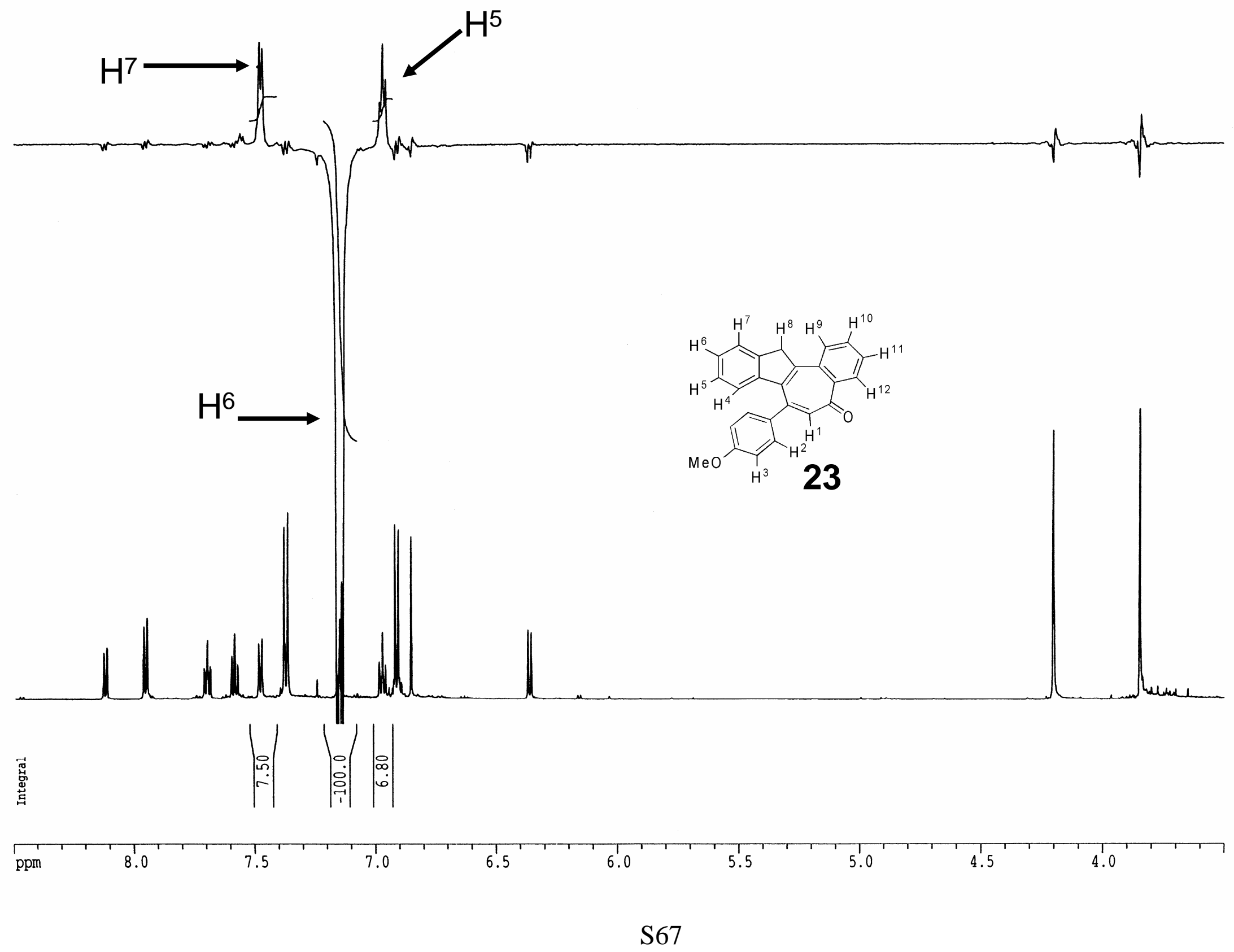




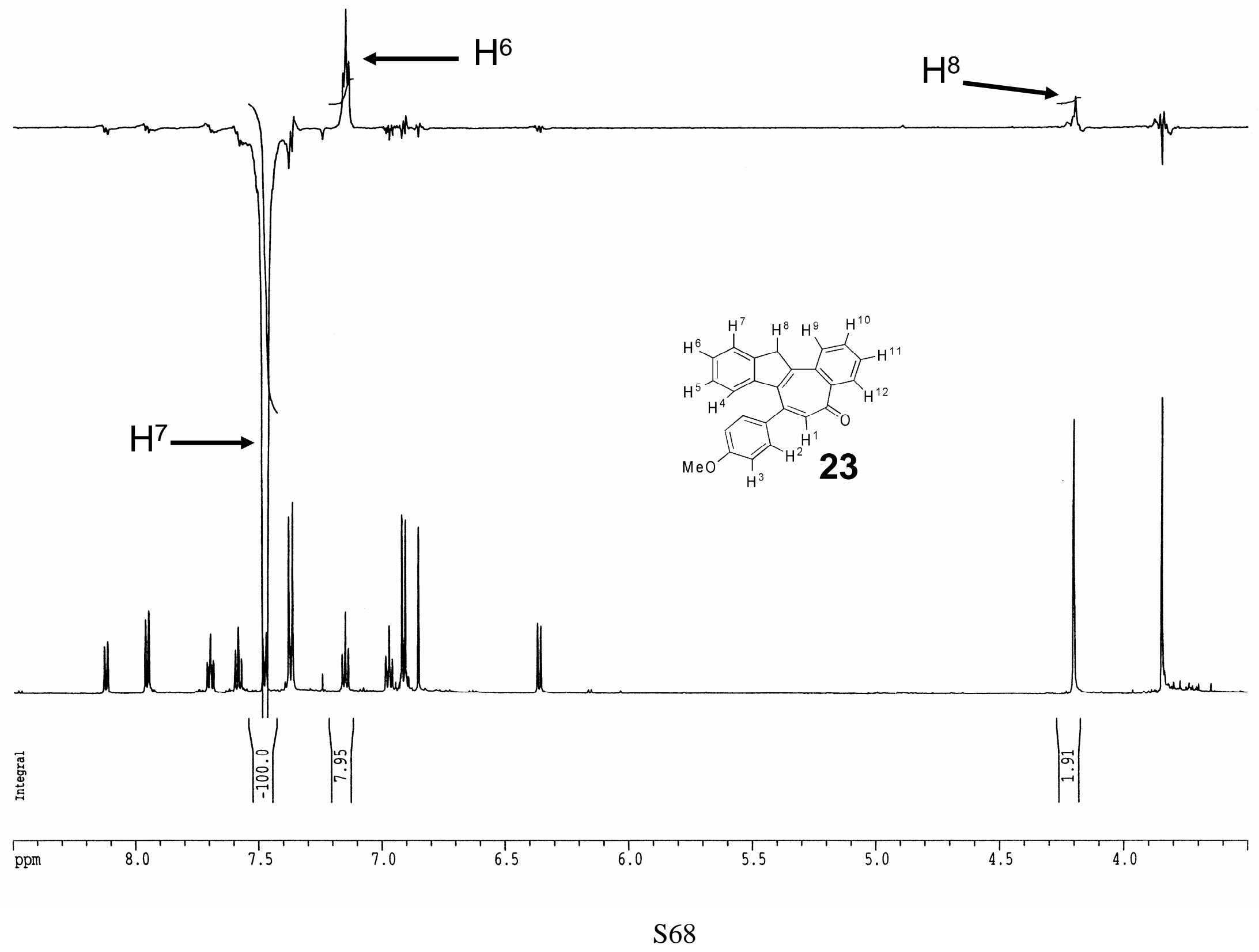



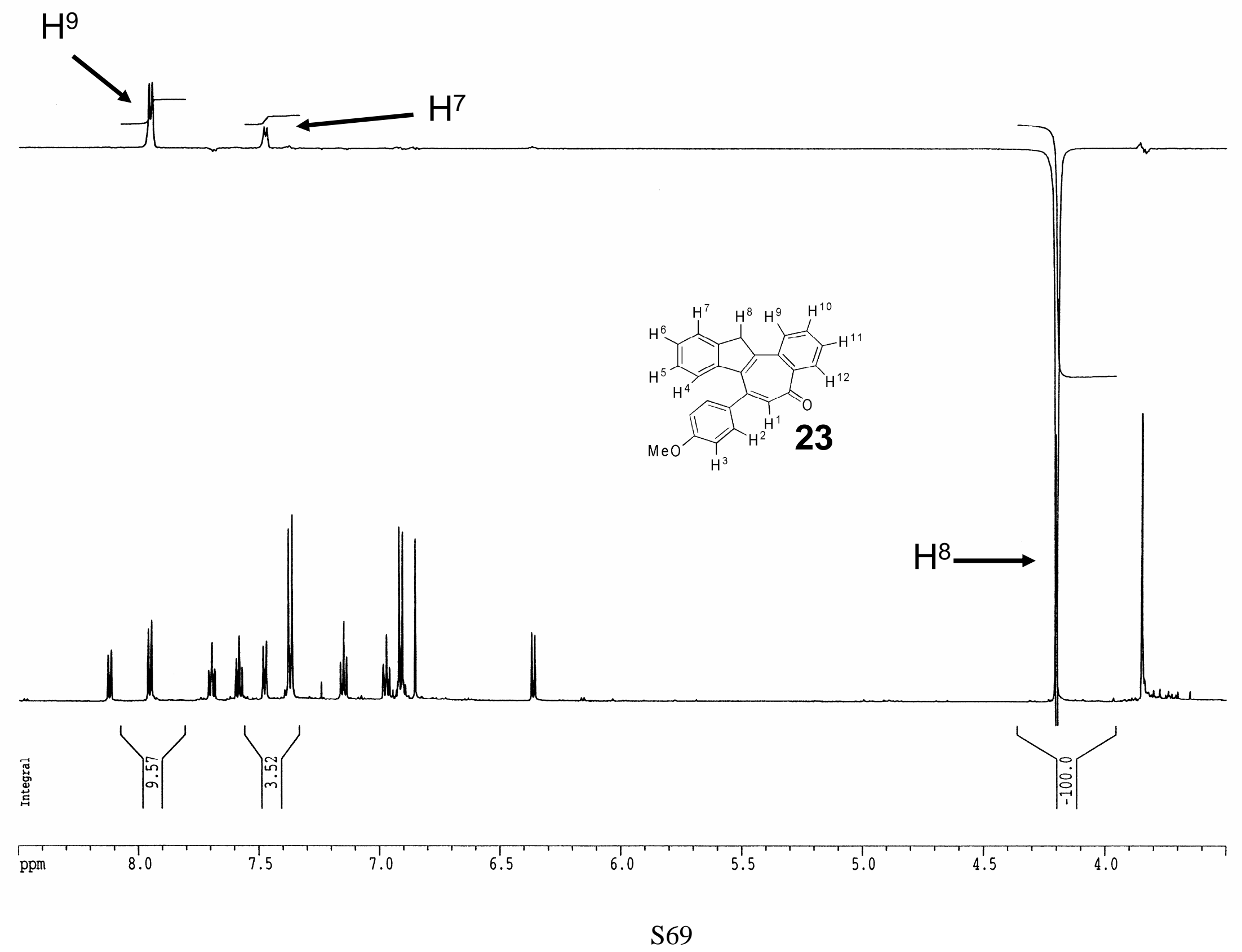


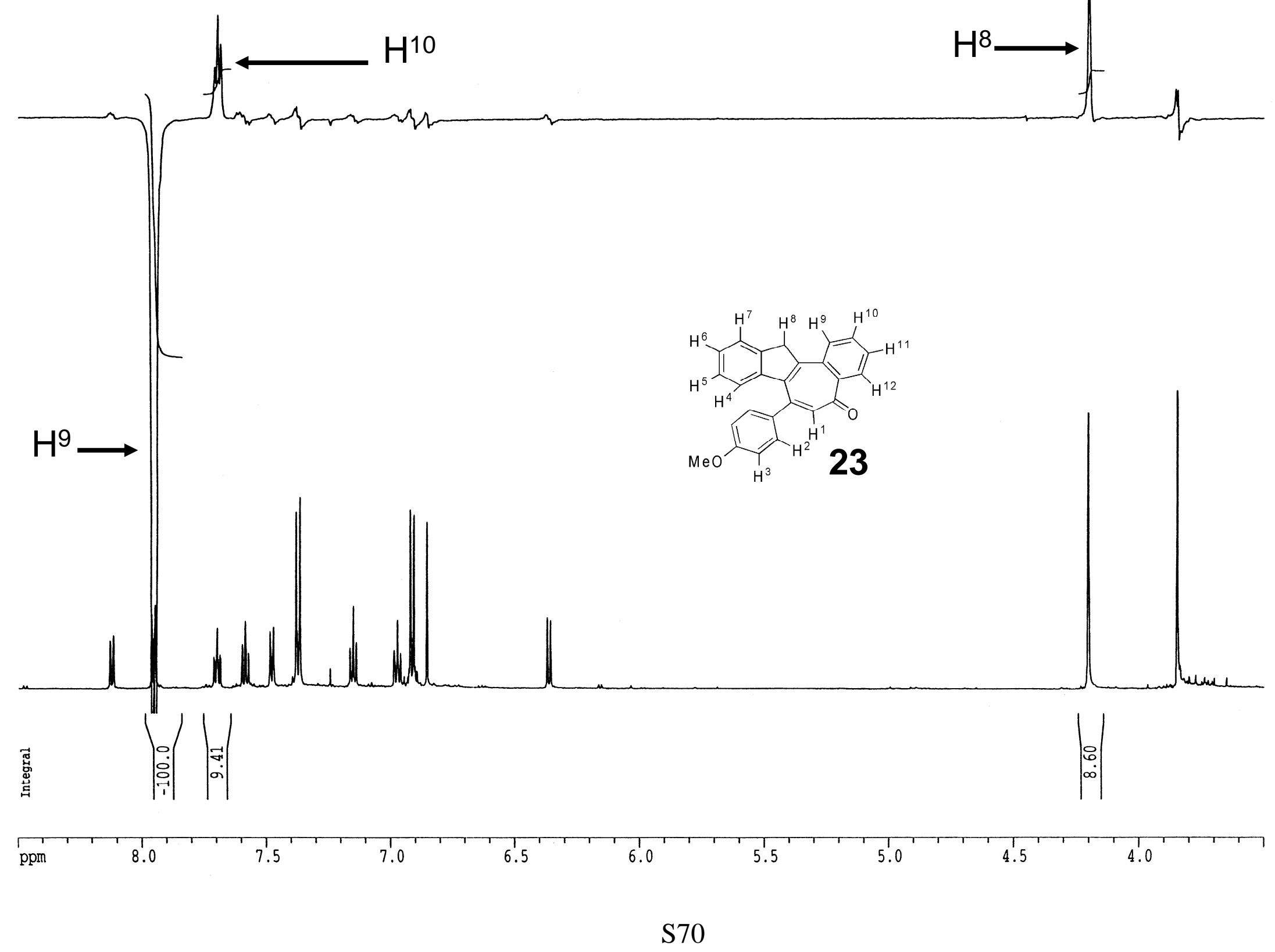




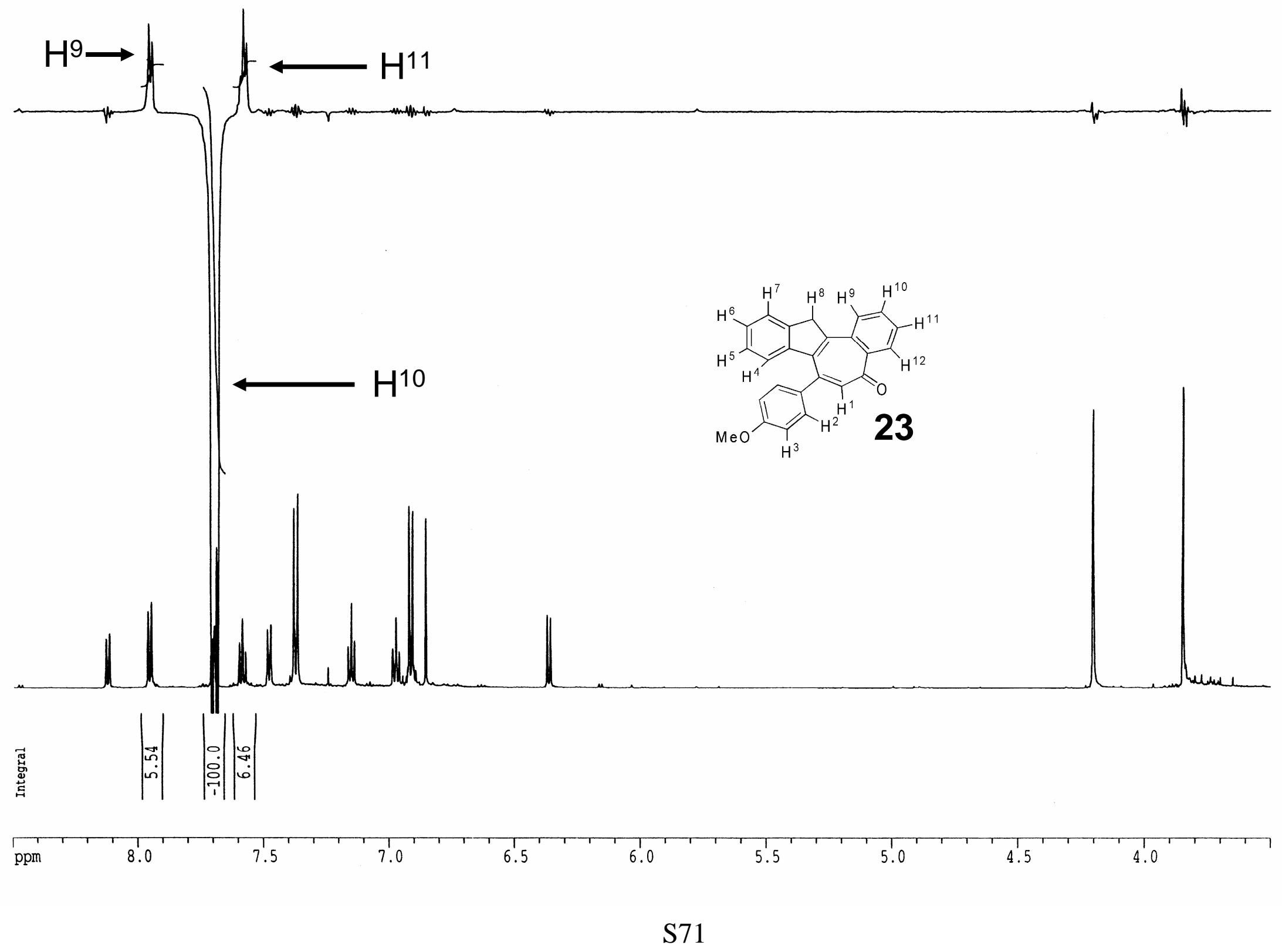




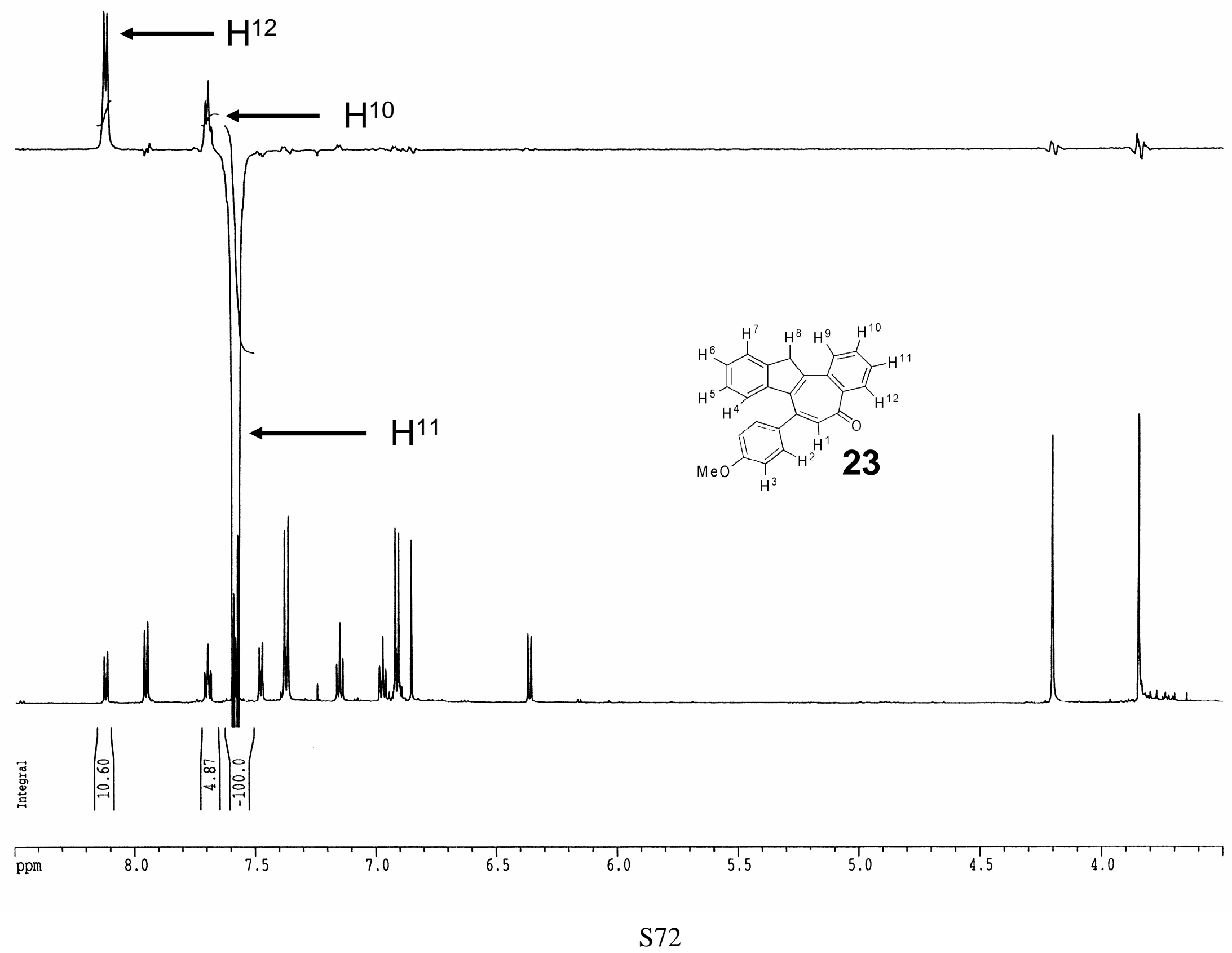




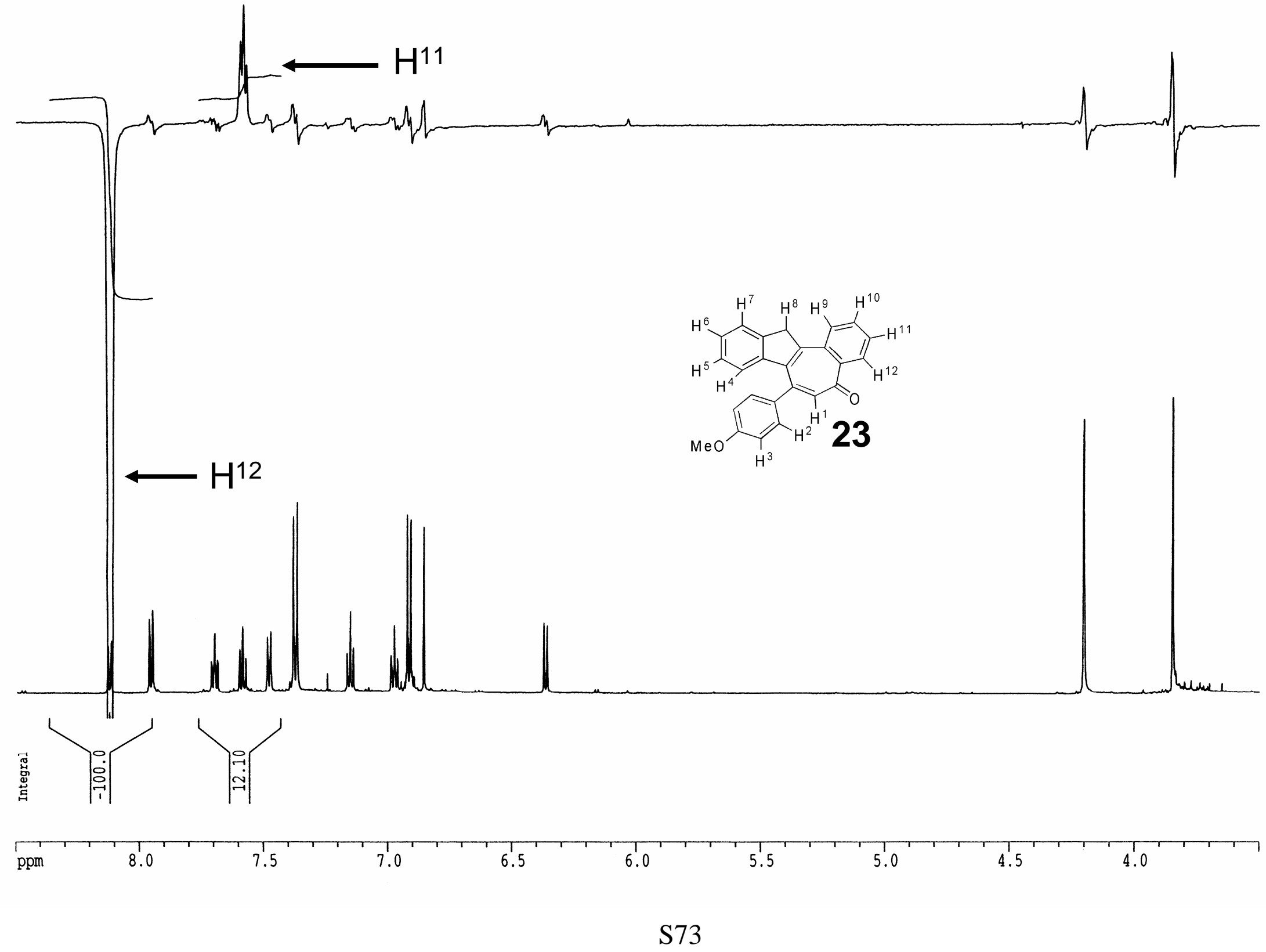




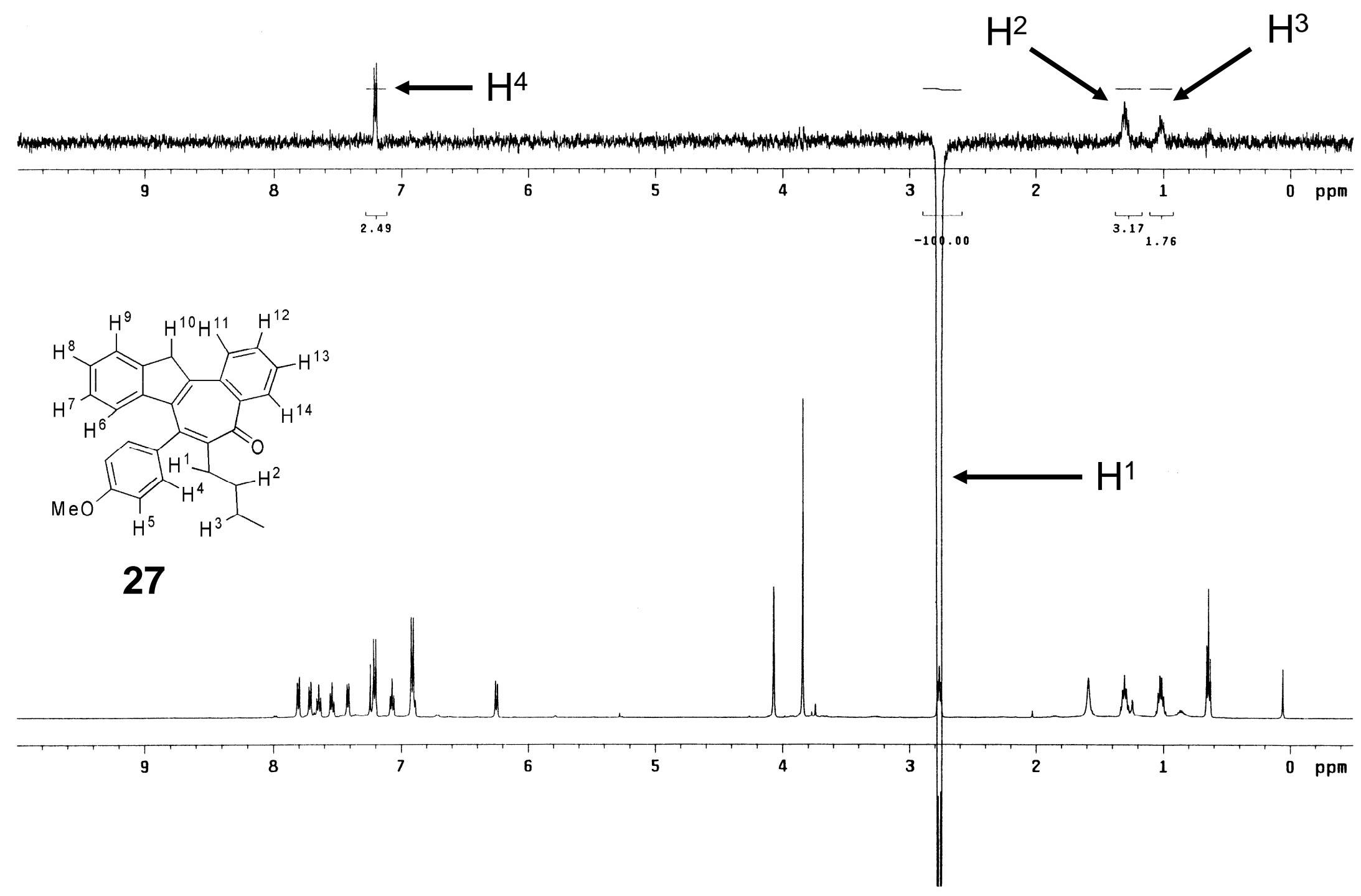




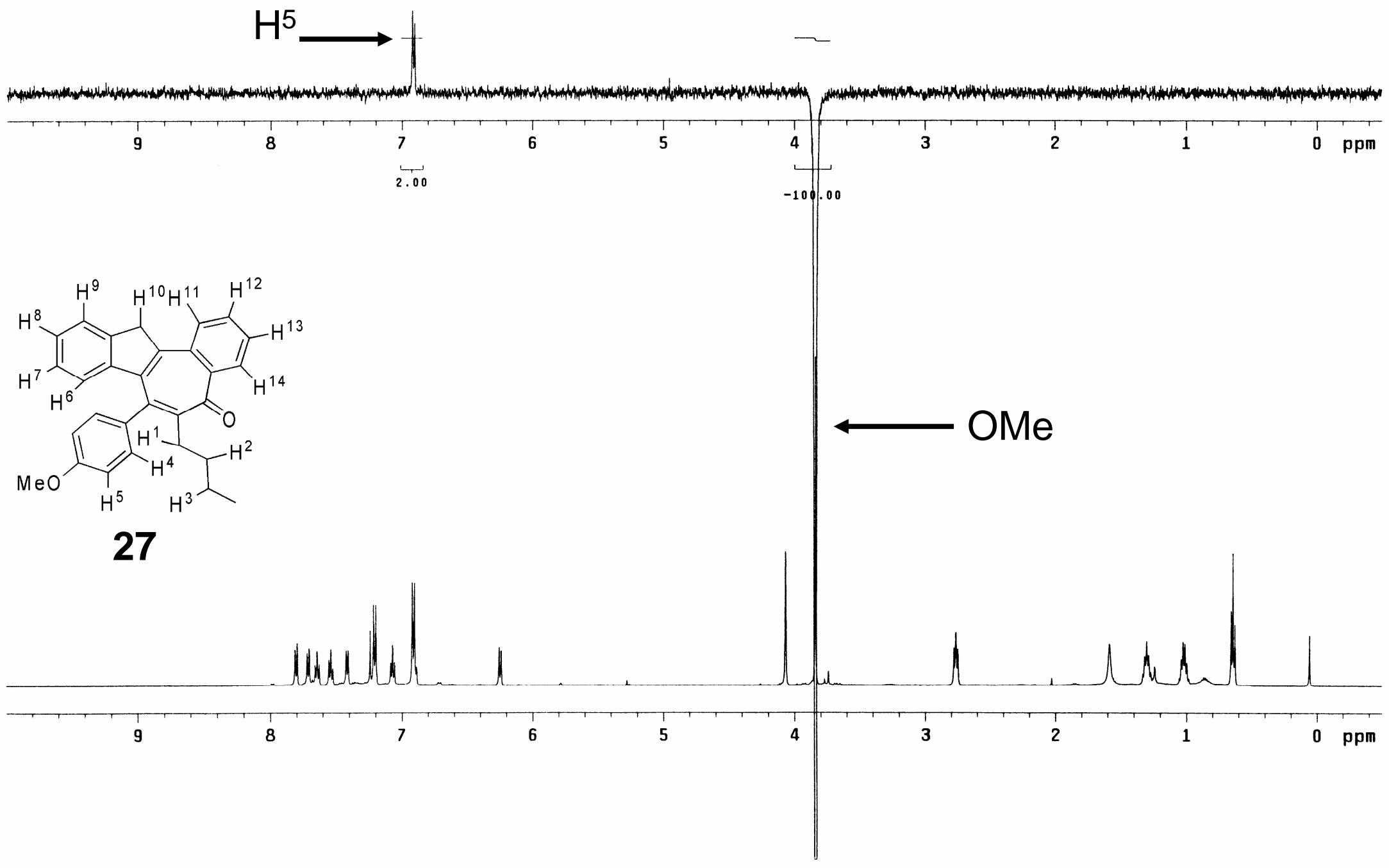




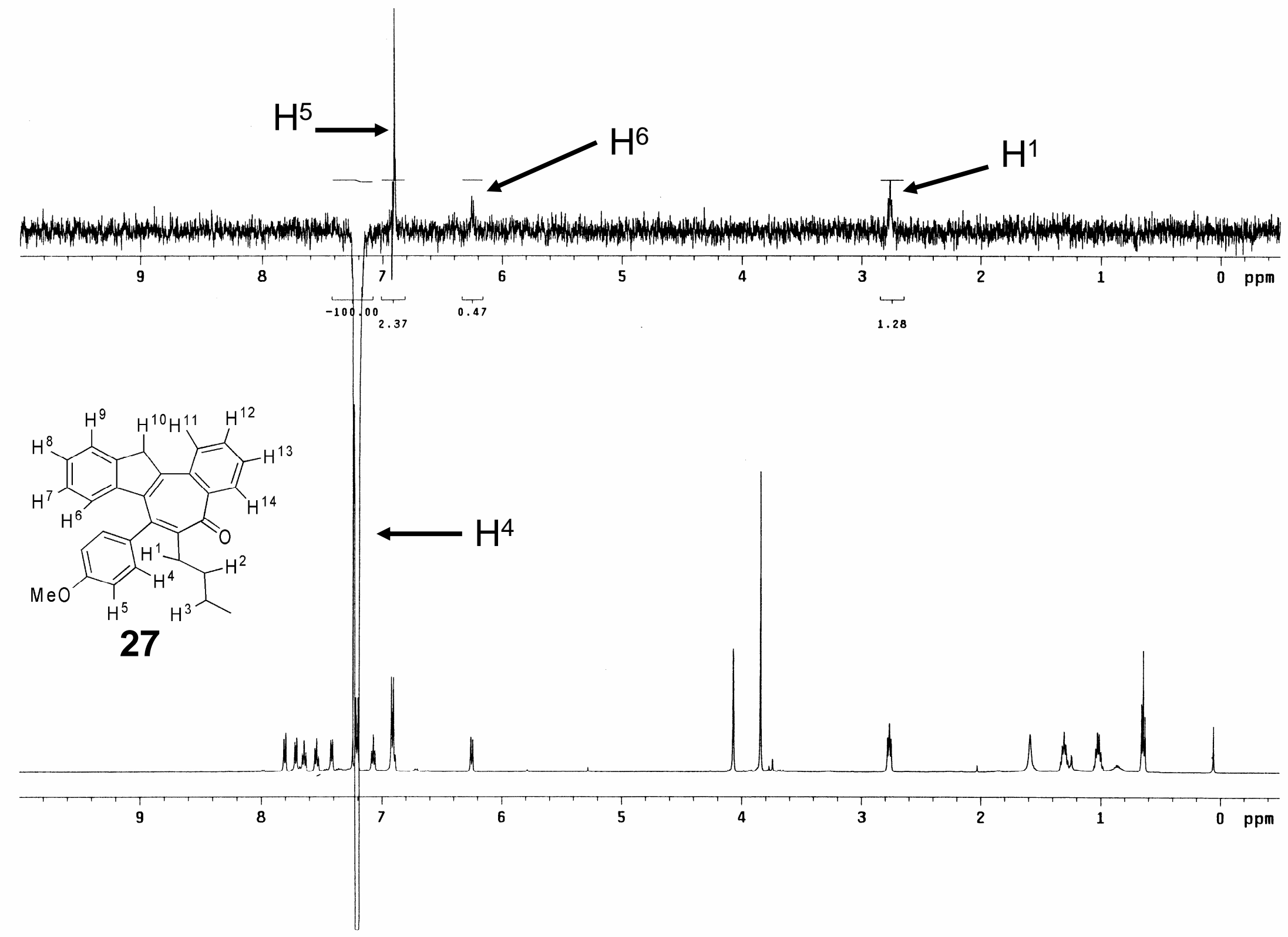




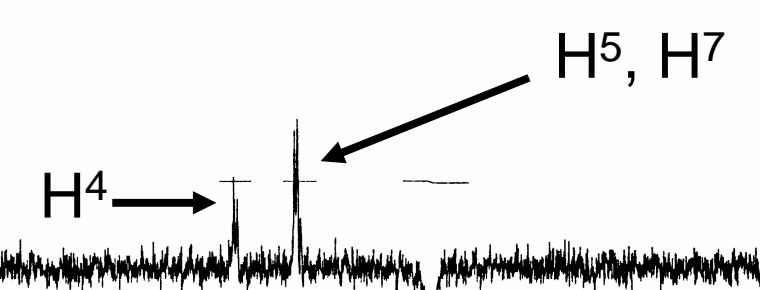

W
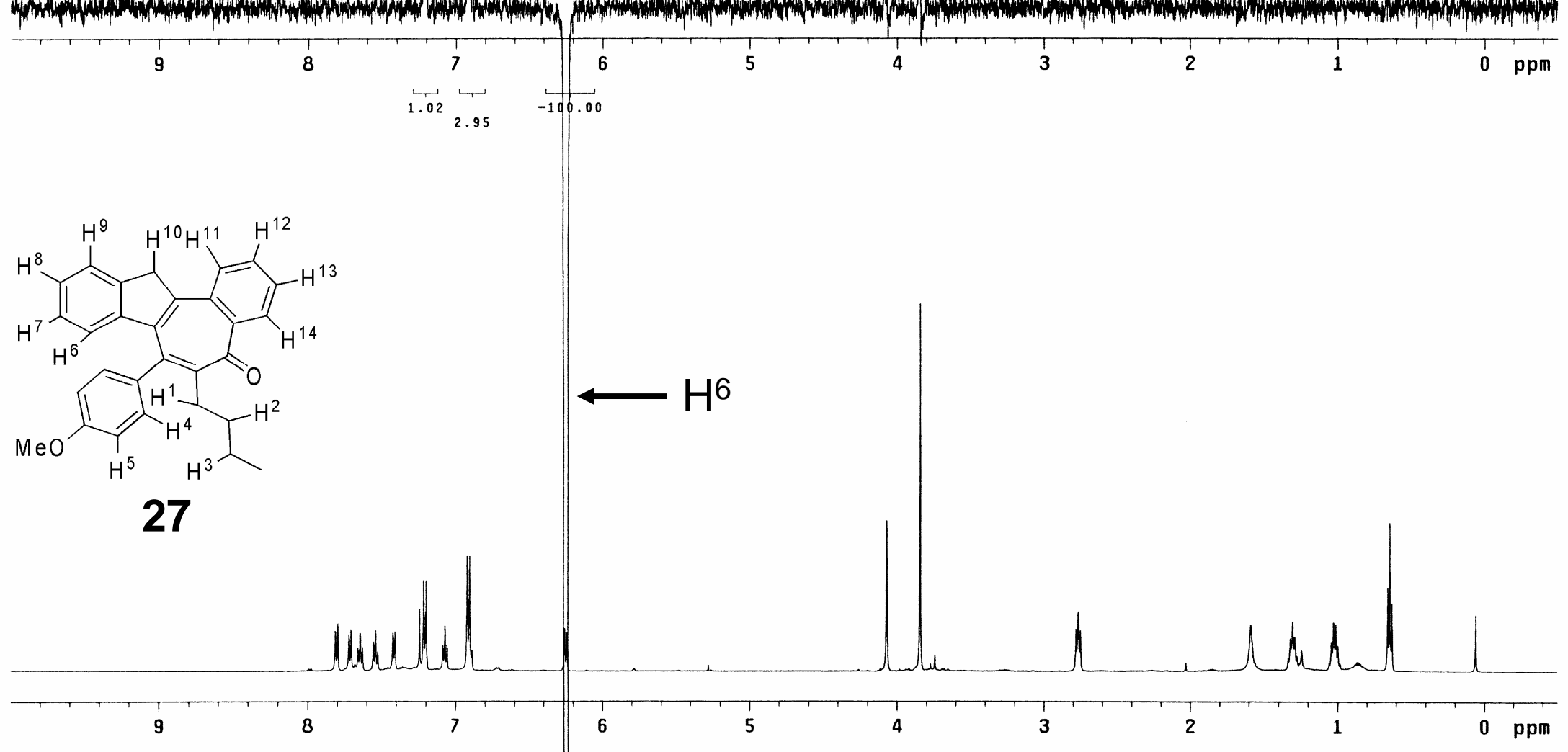


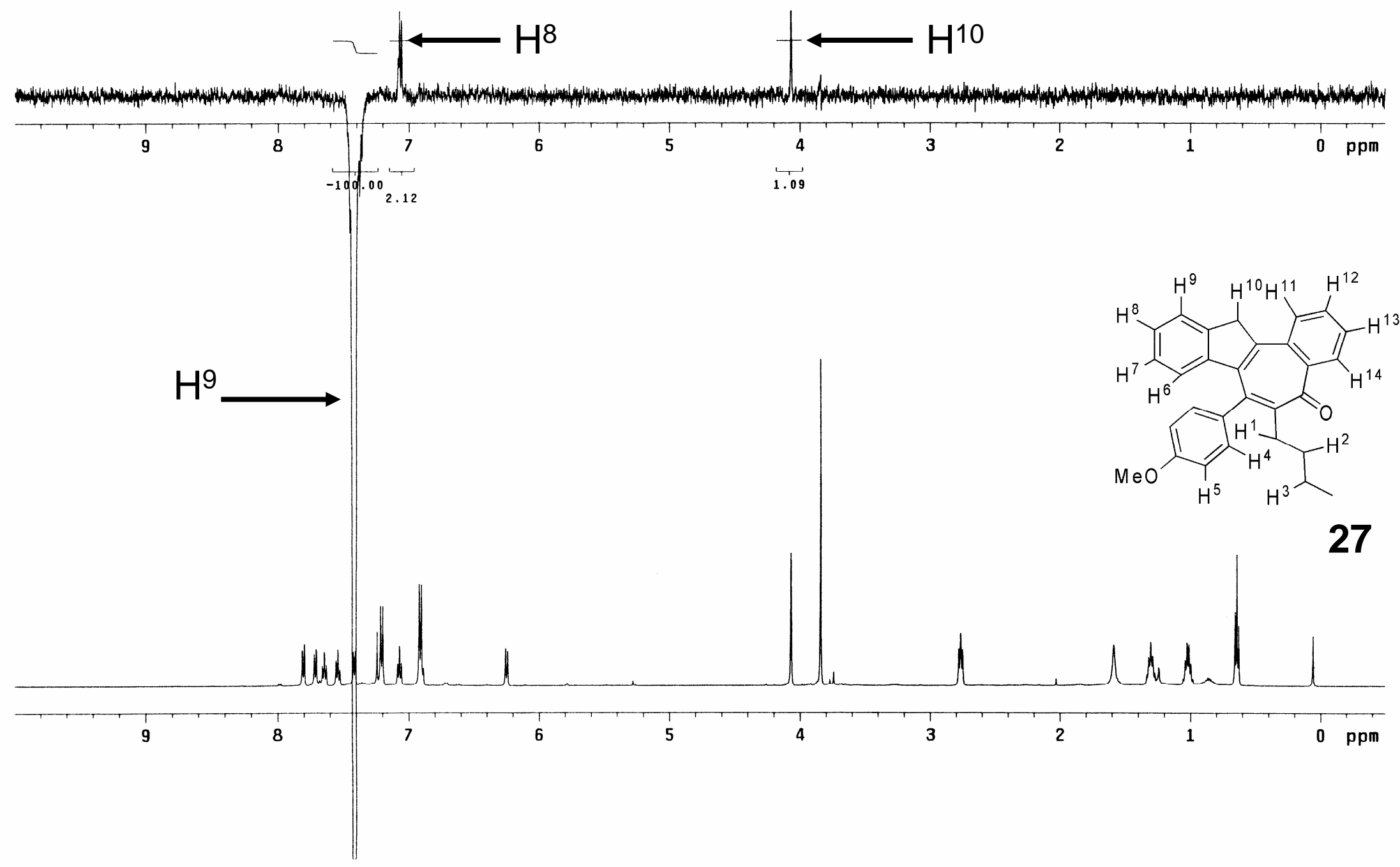




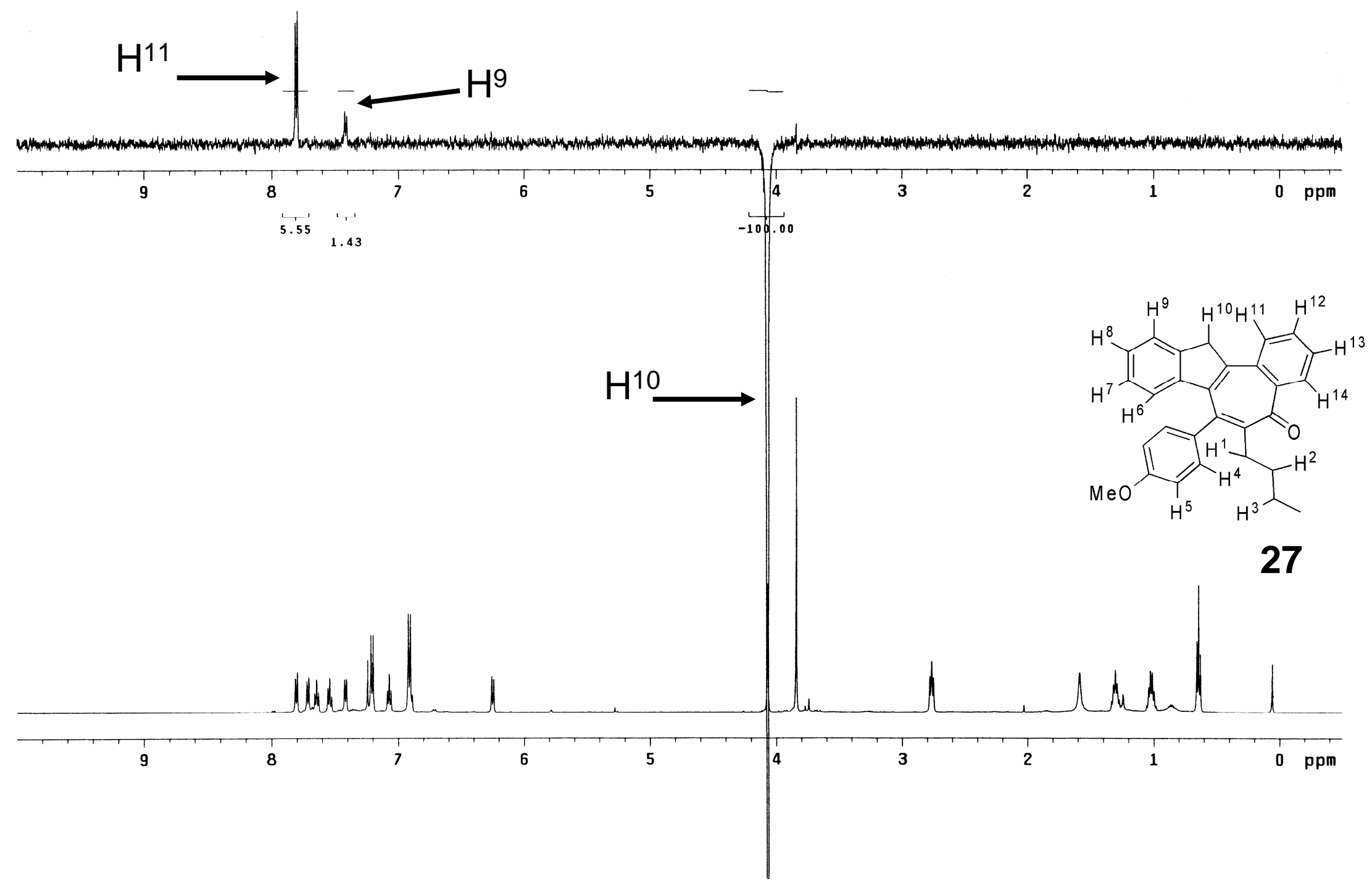




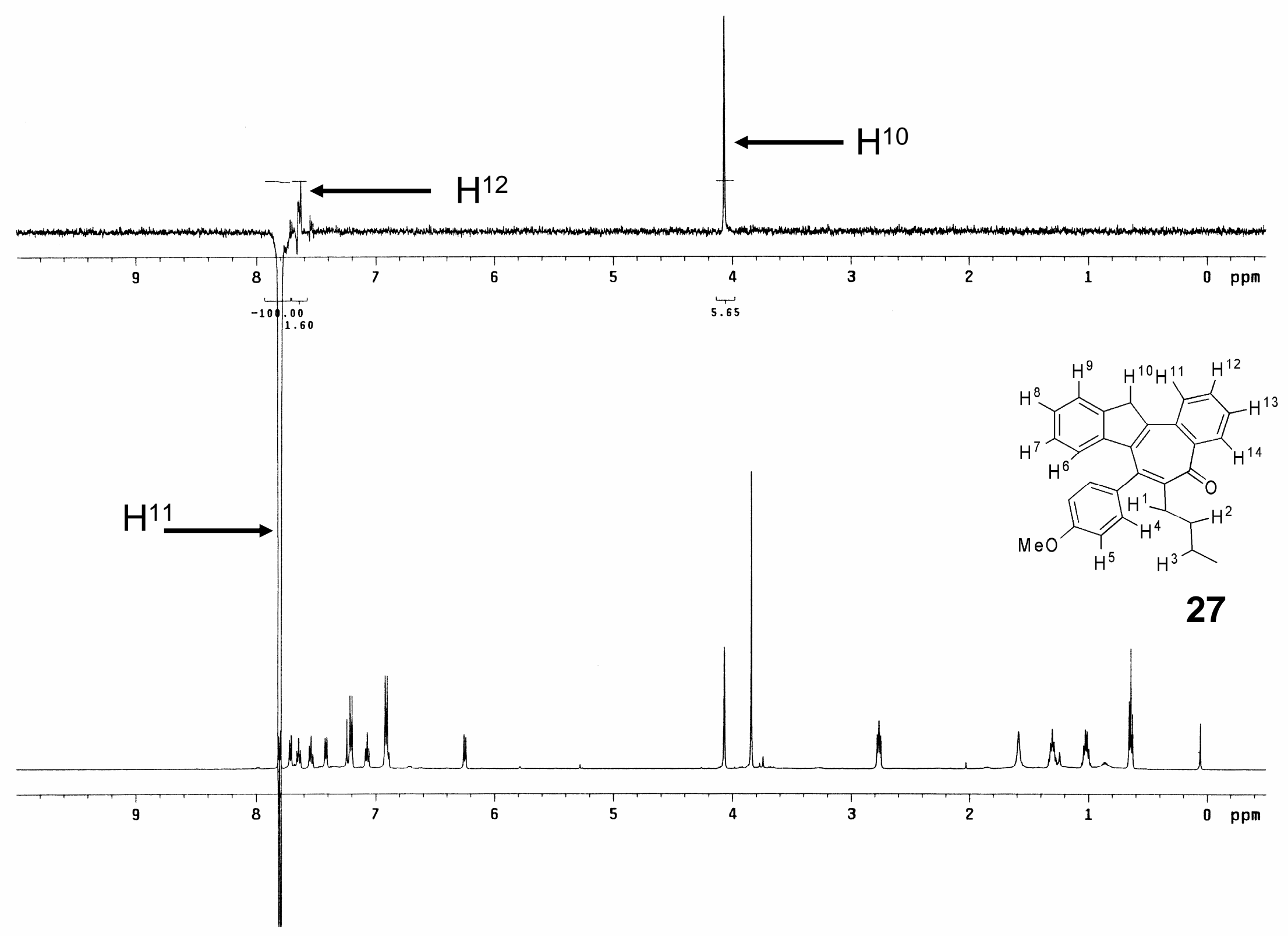




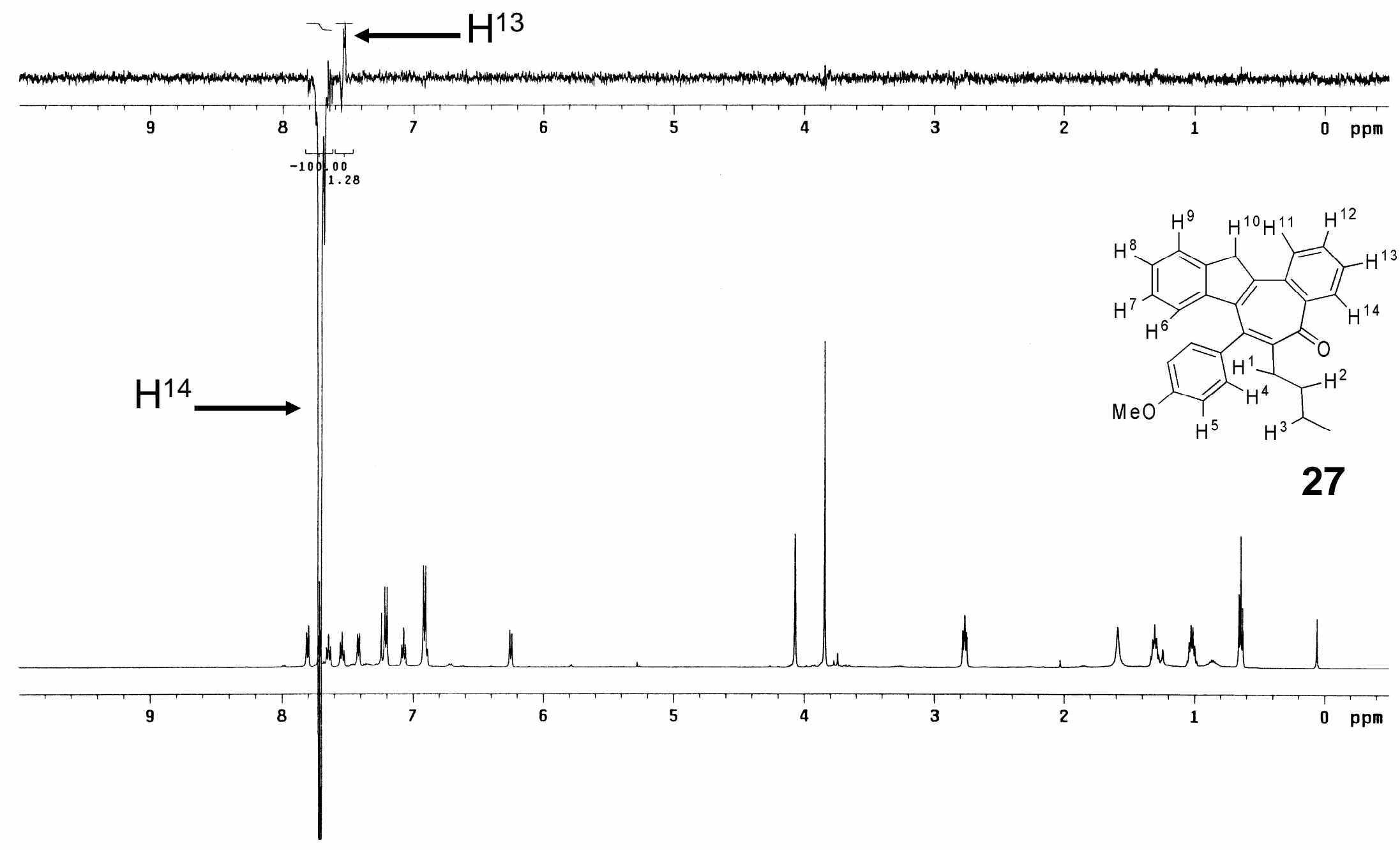



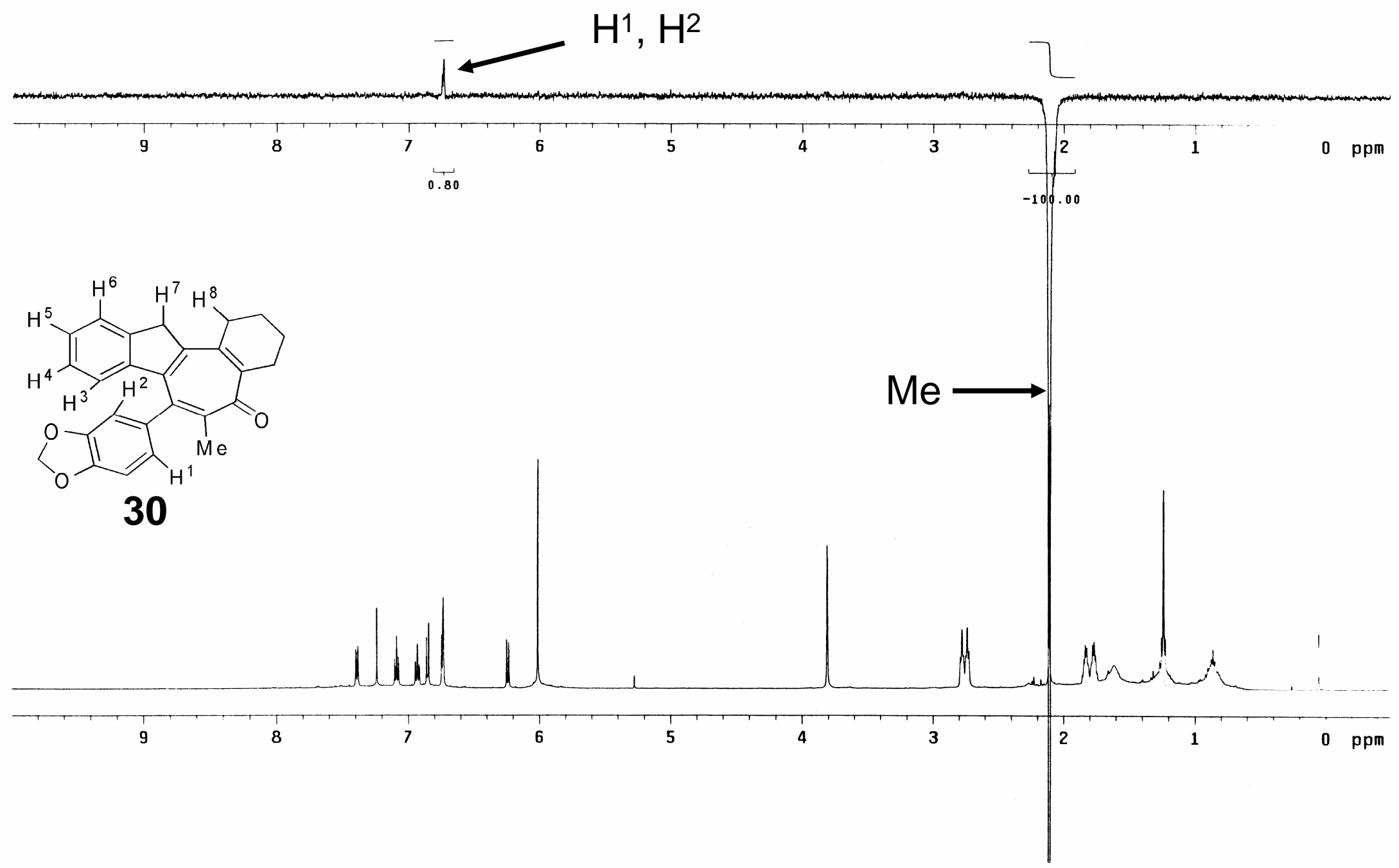


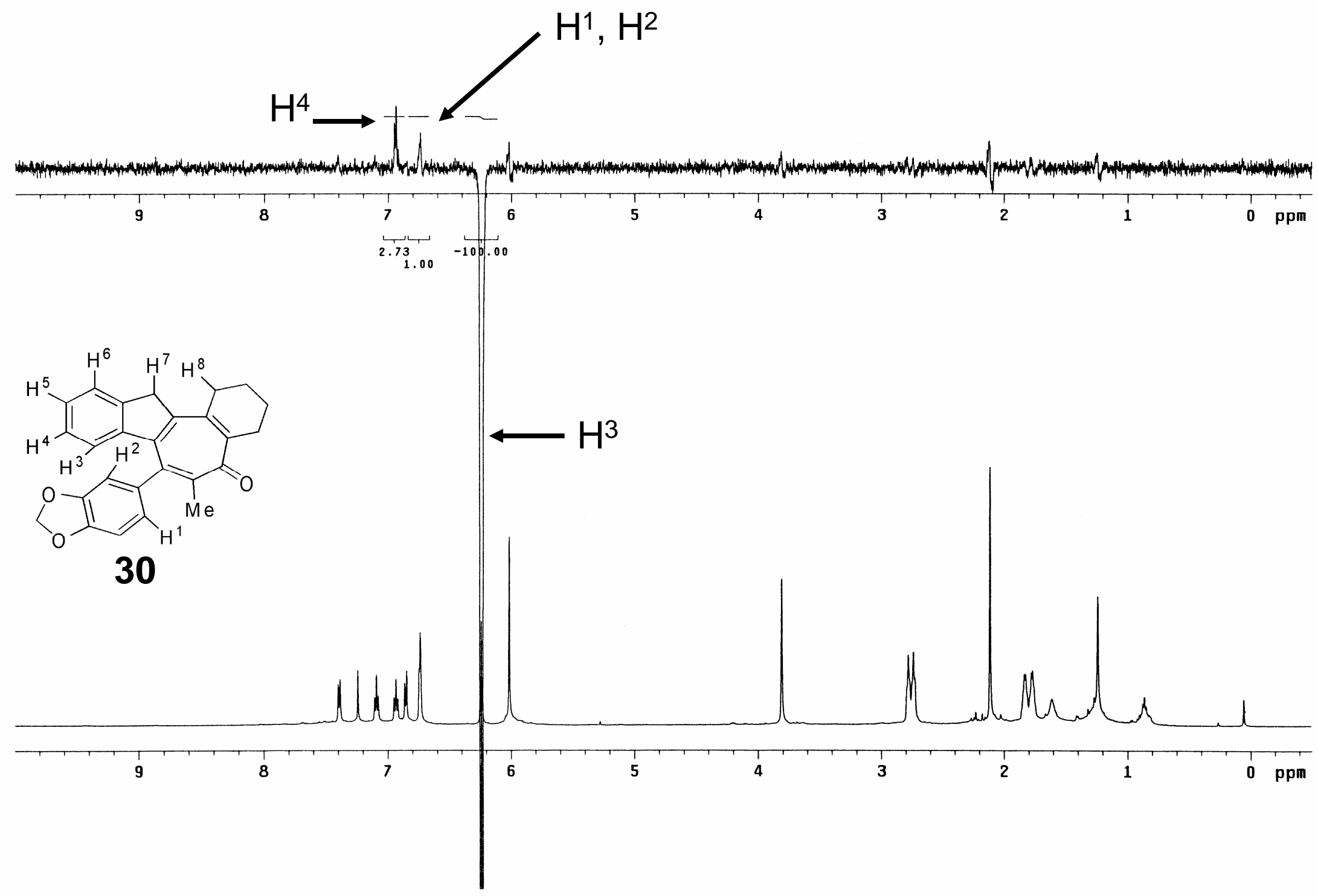




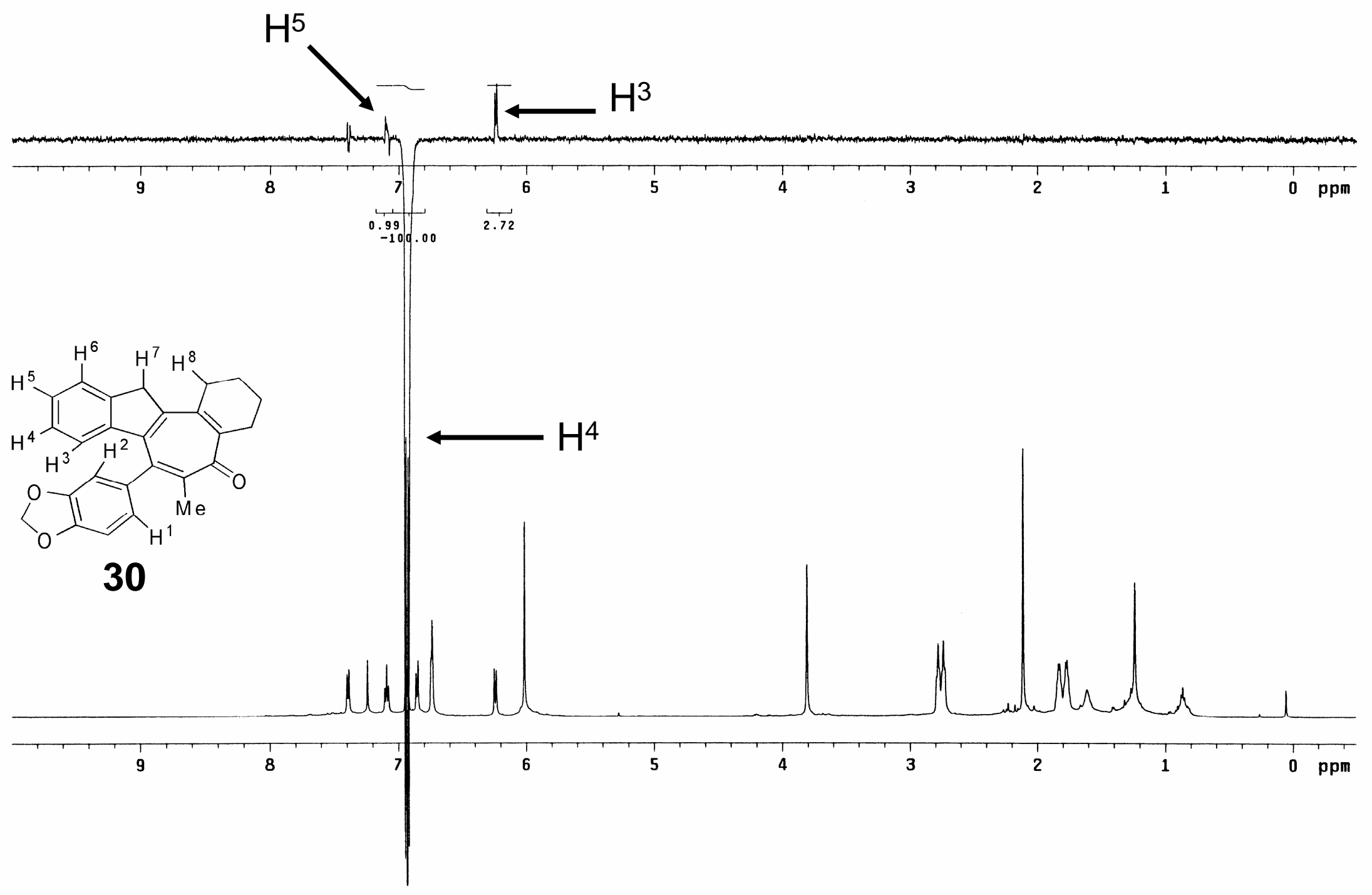




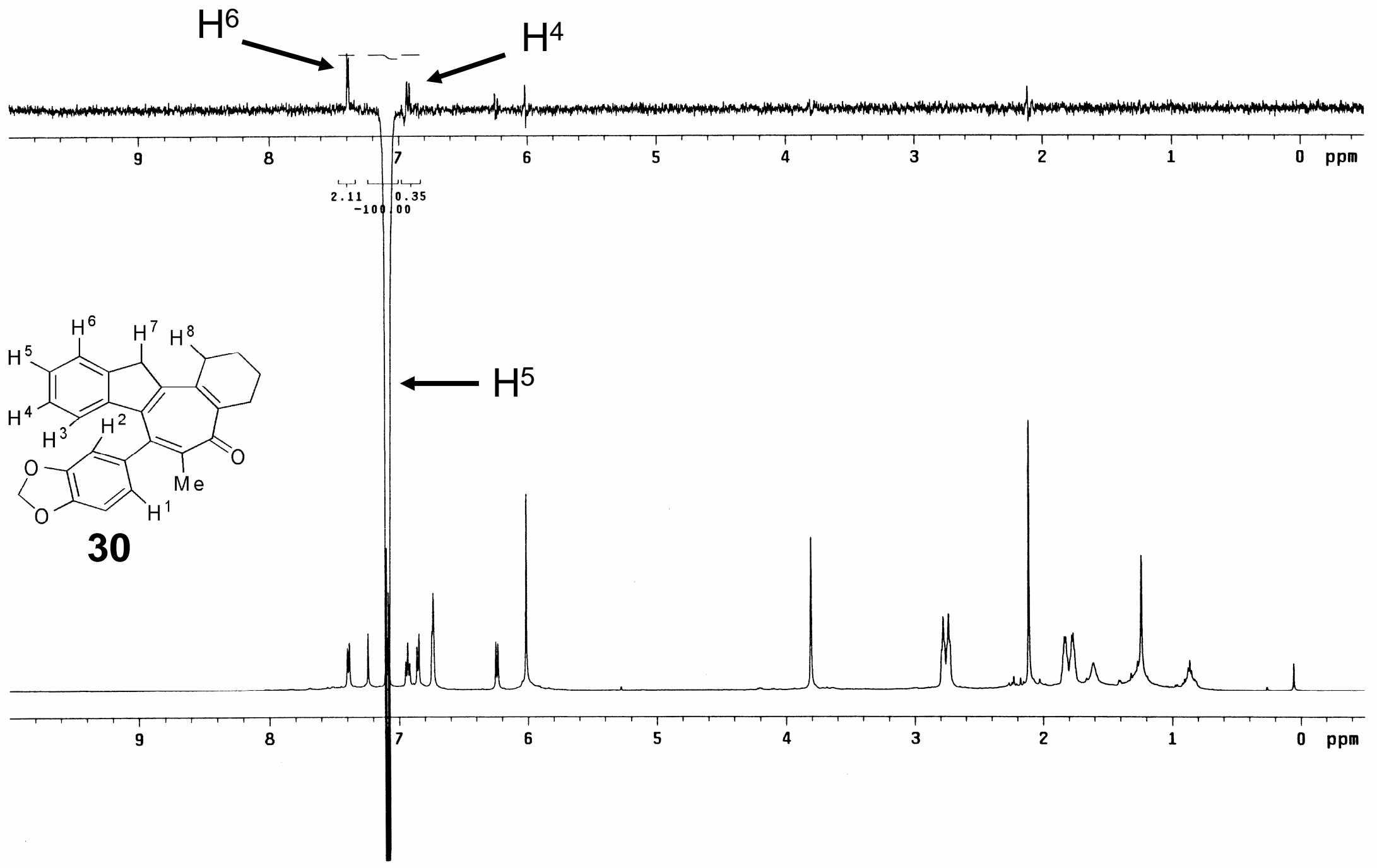




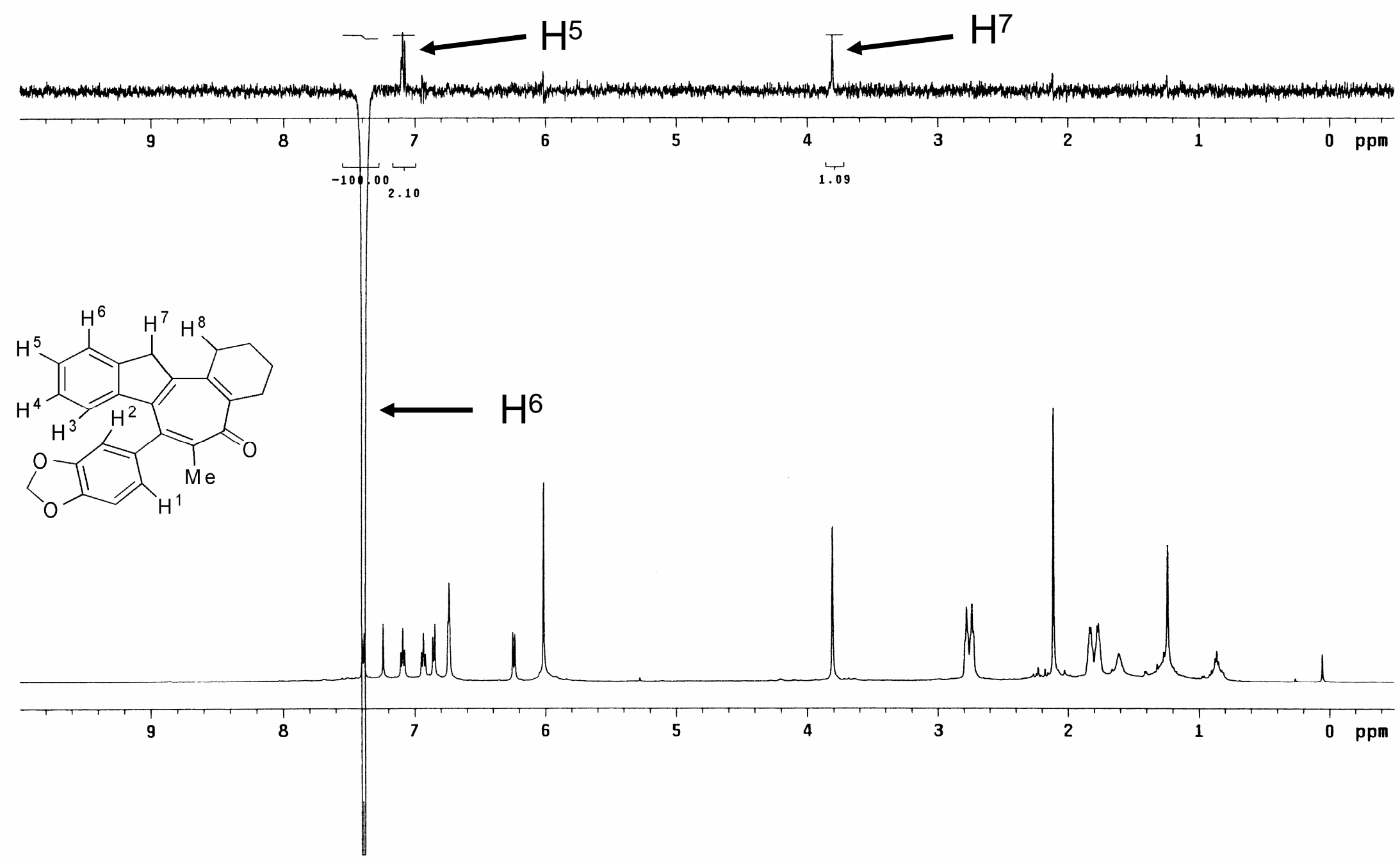




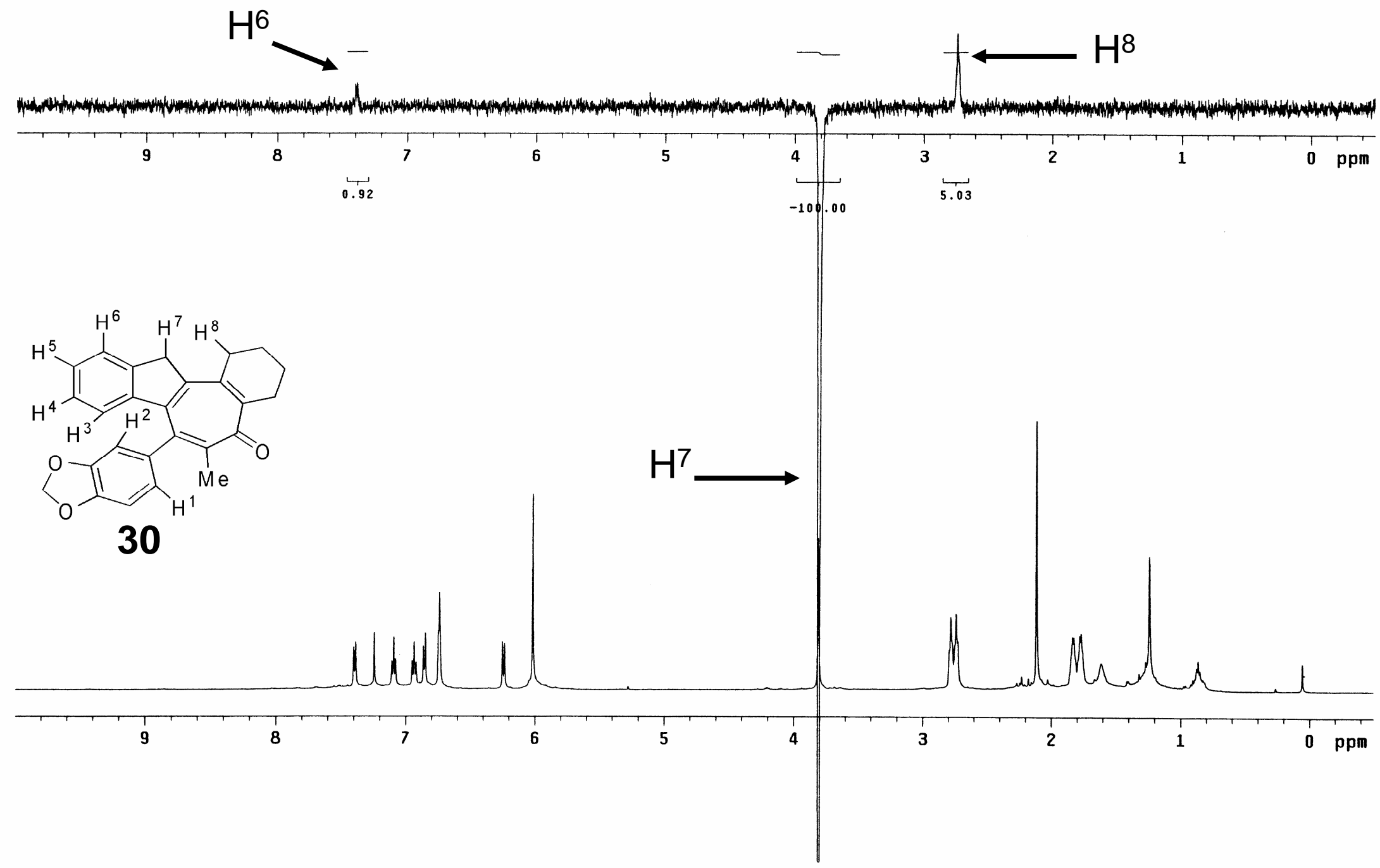

